\author{
UNIVERSIDADE DE SÃO PAULO \\ ESCOLA DE ENGENHARIA DE SÃO CARLOS \\ DEPARTAMENTO DE ENGENHARIA ELÉTRICA
}

\title{
ANÁLISE DE ESTRUTURAS DE MADEIRA, COM E SEM IMPREGNAÇÃO DE RESINA POLIURETANA DERIVADA DO ÓLEO DE MAMONA, APLICADAS EM LINHAS DE DISTRIBUIÇÃO DE ENERGIA ELÉTRICA
}

João Paulo Motta de Godoy

- São Carlos -

AGOSTO/2006 

UNIVERSIDADE DE SÃO PAULO

ESCOLA DE ENGENHARIA DE SÃO CARLOS

DEPARTAMENTO DE ENGENHARIA ELÉTRICA

\title{
ANÁLISE DE ESTRUTURAS DE MADEIRA, COM E SEM IMPREGNAÇÃO DE RESINA POLIURETANA DERIVADA DO ÓLEO DE MAMONA, APLICADAS EM LINHAS DE DISTRIBUIÇÃO DE ENERGIA ELÉTRICA
}

\author{
João Paulo Motta de Godoy \\ Dissertação apresentada à Escola de Engenharia de \\ São Carlos, da Universidade de São Paulo, como parte \\ dos requisitos para obtenção do título de Mestre em \\ Engenharia Elétrica.
}

ORIENTADOR: Prof. Dr. Diógenes Pereira Gonzaga

- São Carlos -

AGOSTO/2006 

A Décio e Darci, meus pais, Juliana, minha irmã, que souberam compreender minha ausência, dando sempre o seu fundamental apoio e compreensão, me ajudando a fazer com que fosse possível chegar até este momento. 


\section{Agradecimentos}

À Universidade Federal de Mato Grosso do Sul - UFMS, especialmente meus professores do Departamento de Engenharia Elétrica que me deram a formação de engenharia elétrica capaz de me ajudar a iniciar este mestrado.

Ao Professor Dr. Diógenes Pereira Gonzaga, pela amizade, apoio e dedicação durante a orientação para o desenvolvimento deste trabalho.

Aos meus pais, Décio e Darci, à minha irmã, Juliana, à minha namorada Inaiara e ao meu primo José Manoel, todos os meu tios e primos, por todo apoio e confiança.

Ao Professor Dr. Ruy Alberto Correa Altafim, a Dra. Cassilda Ribeiro Murakami, ao Me. Andersom Marques de Santana, ao Dr. Mariano Eduardo Moreno ao Me. Leandro Lima e todo o Grupo de Alta Tensão do Departamento de Engenharia Elétrica pelo convívio, amizade e ensinamentos fundamentais para a minha formação pessoal e acadêmica.

À Coordenação de Aperfeiçoamento de Pessoal de Nível Superior - CAPES pela concessão da bolsa de mestrado e pelo apoio financeiro para a realização dessa pesquisa.

Ao Departamento de Geotecnia da Universidade de São Paulo, ao Departamento de Engenharia de Materiais da Universidade Federal de São Carlos, que gentilmente permitiram que os ensaios pudessem ser realizados em seus laboratório, e ao corpo técnico do Laboratório de Geosintéticos.

Ao Departamento de Engenharia Mecânica da Universidade de São Paulo por ter permitido o uso de seus recursos computacionais na simulação em elementos finitos.

À todos os colegas, amigos, professores e funcionários do Departamento de Engenharia Elétrica da EESC/USP, pela amizade verdadeira, convívio intenso trabalho, momentos ímpares e colaboração.

À todos os amigos e amigas de Limeira, São Carlos, Campo Grande, Cuiabá, e Santos pelo apoio e incentivo que me ajudaram a acreditar que seria capaz de chegar até aqui. 


\section{Resumo}

As empresas concessionárias de energia elétrica convivem com elevados custos de manutenção em suas redes de distribuição de energia elétrica; em particular um dos motivos está ligado a preço e durabilidade de cruzetas de madeira, seja na sua instalação inicial, seja na sua troca que pode ocorrer freqüentemente, havendo a necessidade de utilização de madeiras nobres em princípios as quais, além do preço, sofrem restrições ambientais em seus usos. Este trabalho visa à análise destas vigas de madeira, do ponto de vista de ensaios mecânicos e suas simulações computacionais, com base em madeiras com menores restrições ambientais, submetidas ou não a impregnação com resina poliuretana derivada do óleo de mamona. É apresentado, também, um texto para o auxílio de futuros leitores e usuários na aplicação do software ANSYS®.

Palavras-chaves: redes de distribuição de energia elétrica; cruzetas; impregnação; resina poliuretana derivada do óleo de mamona; simulação computacional. 


\section{Abstract}

The power supply dealership companies live together with high maintenance costs on electrical systems, in private one of reasons is linked to the cost and durability of wood crossarms, either in its initial installation, either in its exchange that can occur frequently, having the necessity of noble wood use in principles which, beyond the price, suffer enviromental restrictions in its uses. This work aims at to the analysis of these beams wooden, of the point of view of mechanical tests and its computational simulation, on the basis of wood with lesser enviromental restrictions, submitted or not to the impregnation with castor-oil polyurethane resin. It is presented, also, a text for the aid of reading and using futures in the application of software ANSYS $\AA$.

Key words: electrical systems, timber crossarms, computer simulation, castoroil polyurethane resin. 


\section{Lista de llustrações}

Figura 3.1 - Sistema de eixos ortogonais e seus simétricos 28

Figura 3.2 - Simetria elástica em um plano 30

Figura 3.3 - Rotação de $180^{\circ}$ em torno do eixo $x_{3}$

Figura 3.4 - Rotação de $180^{\circ}$ em torno do eixo $x_{1} 33$

Figura 3.5 - Plana de isotropia - material transversalmente isotrópico 36

Figura 3.6 - Eixos de simetria da madeira 42

Figura 3.7 - Porção de uma molécula de celulose $\quad 44$

Figura 3.8 - Modelo das camadas da parede celular da conífera traqueídeos $\quad 45$

$\begin{array}{ll}\text { Figura } 3.9 \text { - As camadas constituintes da madeira } & 47\end{array}$

Figura 3.10 - Usina Hidrelétrica de Marmelos com destaque para a cruzeta 51

Figura 3.11 - (a) Rede aérea nua, (b) Estrutura padronizada para redes de distribuição de energia elétrica aérea $\quad 52$

Figura 3.12 - Dimensões em mm da cruzeta de madeira 53

Figura 3.13 - Conjunto de misturador em câmara de vácuo MARCONI® 59

Figura 3.14 - Corpo de prova da resina RI3 sofrendo o ensaio de tração 60

Figura 3.15 - Curvas dos resultados dos ensaios de tração SEO 63

Figura 4.1 - Áreas de carga das cruzetas $\quad 65$

Figura 4.2 - Diagrama do processo de análise por Elementos Finitos 66

$\begin{array}{ll}\text { Figura 4.3 - Malhas de elementos geradas de maneira livre } & 78\end{array}$

Figura 4.4 - Malhas de elementos geradas de maneira Mapeada 79 
Figura 4.5 - Malha refinada com 256.996 elementos gerada por extrusão de áreas

Figura 5.1 - Malha representando a madeira recoberta com resina, face $B$ e Malha representando apenas a camada de resina, face $A$

Figura 5.2 - Resposta para a $2^{a} H$ considerando $E=318,35 \mathrm{MPa}$, face A 86

Figura 5.3 - Comparação entre deformação de corpos-de-prova de madeira tratada e não tratada no teste de flexão

Figura 5.4 - Distribuição de forças na flexão das fibras da madeira 


\section{Lista de Tabelas}

Tabela 1 - Módulos de elasticidade paralelo às fibras $\quad 49$

Tabela 2 - Valores dos coeficientes ortotrópicos das madeiras 50

Tabela 3 - Grupos dos corpos de prova separados por tempo de cura 57

Tabela 4 - Média dos resultados dos ensaios de tração PE16 60

Tabela 5 - Resultados dos ensaios de tração SEO 62

Tabela 6 - Forças aplicadas nos ensaios de resistência à flexão 64

Tabela 7 - Valores dos coeficientes ortotrópicos das madeiras 72

Tabela 8 - Comparação dos resultados reais e simulados para

$\begin{array}{ll}\text { Eucalyptus citriodora } & 73\end{array}$

Tabela 9 - Comparação dos resultados reais e simulados para

$\begin{array}{ll}\text { Pinus elliotti } & 73\end{array}$

Tabela 10 - Valores dos deslocamentos para Pinus elliotti 76

Tabela 11 - Valores dos deslocamentos para Eucalyptus citriodora $\quad 77$

Tabela 12 - Módulo de elasticidade $E$ ensaiado $\quad 85$

Tabela 13 - Comparação entre os resultados simulados e os resultados reais para

Pinus eliiotti impregnada com R/3 $\quad 85$

Tabela 14 - Deslocamentos para a simulação da cruzeta de Pinus elliotti-3,92 kN 88

Tabela 15 - Deslocamentos para a simulação da cruzeta de Eucalyptus citriodora-3,92 kN $\quad 89$

Tabela 16 - Deslocamentos para a simulação da cruzeta de Pinus elliotti-5,49 kN 89

Tabela 17 - Deslocamentos para a simulação da cruzeta de Eucalyptus citriodora - 5,49 kN 90

Tabela 18 - Módulos de elasticidade efetivos para Pinus elliotti e Eucalyptus citriodora 92

Tabela 19 - Módulos de elasticidade efetivos para a camada de compósito 92 


\section{Sumário}

Dedicatória 3

Agradecimentos $\quad 4$

Resumo 5

Abstract $\quad 6$

$\begin{array}{ll}\text { Lista de llustrações } & 7\end{array}$

Lista de Tabelas $\quad 9$

Sumário 10

Capítulo 1

1. Introdução 13

1.1. Simulações Computacionais 13

1.2. Justificativa da Dissertação 14

1.3. Objetivos do Trabalho 17

Capítulo 2

2. Revisão Bibliográfica 20

$\begin{array}{ll}2.1 \text { Cruzetas de Madeira } & 20\end{array}$

2.2 Resina Poliuretana à Base de Óleo de Mamona 22

2.3 Compósitos 23

Capítulo 3

3. Materiais 26

3.1. Tipos de Mateiais 26

3.1.1. Classificação dos Materiais Segundo o Número de Planos de Simetria Elástica $\quad 29$

3.1.1.1. Material com Simetria Elástica em um Plano 30

3.1.1.2. Material com Simetria Elástica em três Planos 32

3.1.1.3. Material Transversalmente Isotrópico 35

$\begin{array}{lll}\text { 3.1.1.4. } & \text { Material Isotrópico } & 37\end{array}$

3.2. Madeiras 39

3.2.1. A Ortotropia Aplicada à Madeira 41

3.2.2. Constituição da Madeira 44

3.2.3. Características Mecânicas da Madeira 48 
3.3. Cruzetas de Madeira 50

3.4. Polímeros 53

3.4.1. Resinas Poliuretanas $\quad 55$

3.4.2. Característica Mecânica da Resina poliuretana Derivada do Óleo de Mamona RI3 56

Capítulo 4

4. Método Proposto 64

4.1. Método dos Elementos Finitos 66

4.2. Entrada de Dados 72

4.3. Abordagem Numérica $\quad 74$

4.3.1. Número dos Elementos de Malha $\quad 76$

4.3.2. Enriquecendo o Modelo $\quad 77$

4.3.3. Modelo com Alto Grau de Refinamento 80

Capítulo 5

5. Simulações 82

5.1. Resultados 85

5.2. Discussões 90

Capítulo 6

6. Conclusões e Sugestões Futuras 93

$\begin{array}{ll}\text { Bibliografia } & 95\end{array}$

APÊNDICE A

Timber Cross-Arms Coated With Polyurethane Resin - Test And Numerical Solutions 102 APÊNDICE B

Como Usar o ANSYS 114 


\section{Capítulo 1}

\section{Introdução}

\subsection{Simulações Computacionais}

A simulação é parte integrante das ações do ser humano, pois este tem a capacidade de raciocinar, pensar a respeito de problemas que se apresentem, criando em sua mente situações e analisando suas possíveis conseqüências o que o tornou diferente dos outros animais, colocando-o em vantagem na linha da evolução.

O raciocínio diante de situações de dificuldade gerou aos seus ancestrais o pensamento, que durante sua evolução acelerou o desenvolvimento tornando-o capaz de se comunicar com seus semelhantes de maneira verbal e complexa. Posteriormente vieram a forma escrita, a criação e o uso de ferramentas para ajudar em operações de seu cotidiano até atingir a capacidade de desenvolver sempre novas tecnologias que promovam a sua evolução contínua. 
Durante todo esse processo a simulação sempre esteve presente, com a descoberta de maneiras de utilizar a eletricidade e suas componentes. O salto evolutivo foi de proporções gigantescas, pois possibilitou a transmissão e a utilização da energia de trabalho das mais diversas maneiras buscando sempre a melhoria da qualidade de vida do ser humano.

Segundo (CARLGREN,1964), a antroposofia, do grego "conhecimento do ser humano", introduzida no início do século XX pelo austríaco Rudolf Steiner, pode ser caracterizada como um método de conhecimento da natureza do ser humano e do universo, que amplia o conhecimento obtido pelo método científico convencional, bem como a sua aplicação em praticamente todas as áreas da vida humana.

O conceito de modelagem, no qual a simulação é baseada, tem sido usado por vários anos. Alguns exemplos históricos de modelos são a segunda lei de Newton e teoria da relatividade de Einstein, mostrado por (GRAYBEAL; POOCH, 1980). O conceito de modelagem sempre foi antigo, mas com o advento do computador, a simulação tem sido aplicada para aproximar todos os campos do empenho humano. Problemas em diversos campos como negócios, política, leis e engenharia têm sido resolvidos com sucesso por meio do uso da simulação.

\subsection{Justificativas da Dissertação}

O desenvolvimento das pessoas que vivem em centros urbanos provém da necessidade de buscar melhorias para promover o aumento da sua qualidade de 
vida. Atualmente, esse desenvolvimento é baseado essencialmente em tecnologias que utilizam, de alguma forma, a energia elétrica.

Dessa forma, o fornecimento ininterrupto da energia elétrica, oferecido pelas concessionárias passa a ser um fator econômico de altíssima prioridade, já que qualquer interrupção desse fornecimento traz prejuízos a todos seus usuários. Assim, as concessionárias são rigorosamente monitoradas por órgãos reguladores como a Agência Nacional de Energia Elétrica (ANEEL), que quando necessário, aplicam multas a essas concessionárias, para garantir o fornecimento deste insumo que vem se tornando mais caro a cada dia.

A distribuição urbana dessa energia elétrica feita pelas concessionárias é alvo de falhas causadas por degradação, depredação de componentes dos sistemas de transmissão e principalmente desarme do sistema devido à ocorrência de curtocircuito.

Para a construção ou manutenção das linhas de distribuição de energia elétrica no Brasil, em tensão primária de 13,8 kV, são usualmente utilizadas várias peças e componentes de fixação como presilhas, parafusos, elementos de sustentação mecânica, as chamadas mãos francesas, isoladores e destacando-se em especial neste trabalho as cruzetas de madeira.

As cruzetas de madeira fazem parte do sistema de distribuição de energia elétrica mais utilizado no Brasil. Devem ser construídas com madeiras nobres, de puro cerne ou cerne-alburno seca, recomendadas por norma da concessionária de energia elétrica, como pode ser visto em (ELEKTRO,1995), devido à sua grande resistência mecânica.

Essa recomendação visa a utilização de cruzetas de madeira que suportem o maior tempo possível de uso, tempo este que hoje só chega até cinco anos (SILVA, 
2003). Essa estratégia ajuda garantir a manutenção do sistema prevenindo falhas no fornecimento de energia elétrica a seus consumidores. A substituição dessas cruzetas é feita com base na sua vida útil.

O custo elevado de cruzetas de madeira de puro cerne como Ipê, Jatobá, Sucupira, Faveiro, Cabreúva, Aroeira, Roxinho, Angico Preto e outras madeiras duras, segundo (ELEKTRO,1995) ocorre porque tais árvores demoram cerca de 30 anos para se desenvolver, conforme (SALES,1991).

Levando em consideração que se duas das concessionárias de energia elétrica do estado de São Paulo possuem juntas mais de 1,8 Milhões de postes instalados (SILVA, 2003), dos quais aproximadamente $40 \%$ destes possuem cruzetas, o número de cruzetas existentes está em torno de 720 mil. Dessa maneira estima-se que sejam trocadas 140 mil cruzetas por ano. Assim, o gasto com troca de cruzetas torna-se alto, sendo desta forma, interessante a busca de técnicas de redução destes custos.

As concessionárias brasileiras de energia elétrica preocupadas com a preservação das espécies de madeiras, juntamente com centros de pesquisa, estão buscando alternativas mais econômicas e duráveis para a construção de linhas de distribuição. Um exemplo da busca de redução de custo no uso das cruzetas, é a utilização de cruzetas à base de polipropileno (SILVA,2003).

Antes de serem colocadas em uso, as cruzetas devem ser aprovadas nos ensaios mecânicos previstos pela Associação Brasileira de Normas Técnicas (ABNT), em (NBR8458, 1984). Esses ensaios, quando positivos, comprovam a capacidade mecânica das cruzetas para suportar as tensões que sofrerão nas linhas de transmissão, sob as devidas condições reais de trabalho. 
Em (ALTAFIM et al., 2004) é demonstrado experimentalmente que, a impregnação das cruzetas de madeira com resina poliuretana derivada do óleo de mamona, aumenta a capacidade mecânica do conjunto, já que a penetração da resina na superfície da madeira, configurando-se essa região um compósito, que é composto por dois tipos de materiais diferentes: madeira e resina.

Isso traz a necessidade de estudar como o compósito de madeira/resina pode se comportar nas situações previstas em (NBR8458, 1984).

A resina poliuretana de óleo de mamona, desenvolvida no Instituto de Química da Universidade de São Paulo - IQSC-USP, além de ser comercialmente reconhecida e utilizada, provou ser muito útil nas mais diversas aplicações, desde

próteses ósseas (SILVESTRE, 2001) a isoladores de alta tensão (MURAKAMI, 2002) e (BONOMO, 2003).

\subsection{Objetivos do Trabalho}

Dois aspectos a serem considerados:

- a necessidade da realização das simulações espaciais envolvendo o uso de vigas de madeira, e de madeira com revestimento de resina poliuretana derivada do óleo de mamona, como as cruzetas;

- a necessidade de ter-se à mão um texto, no qual o procedimento do uso do software ANSYS® seja bem detalhado, para que novos usuários não tenham a necessidade de começar do zero.

Com o mesmo intuito de reduzir custos de equipamentos de distribuição da rede elétrica de alta tensão, este trabalho vem propor um modelo numérico de 
simulação computacional capaz de demonstrar a capacidade mecânica das cruzetas utilizadas nas redes de alta tensão, podendo estas possuir uma interface com uma casca ou camada de outro tipo de material através do Método dos Elementos Finitos, utilizando o software ANSYS®, que já possui representatividade comprovada, pois este é extremamente utilizado na indústria mundial nas mais diversas áreas de transmissão térmica, estruturas mecânicas, aerodinâmica e eletromagnetismo.

O modelo proposto pode ser configurado para materiais como, madeira, aço, polímero, concreto, e outros desde que tenham as características físicas do material utilizado devidamente representada no modelo, onde a correta inserção das características dos materiais, baseados em valores definidos em normas ou obtidos através de ensaios normalizados, garantem o melhor ajuste de resultados obtidos na simulação.

O trabalho apresentado por (ALTAFIM et al.,2004) tem a colaboração do autor deste trabalho na busca da representação numérica de ensaios de flexão de cruzetas de madeiras de reflorestamento, Eucalyptus citriodora e Pinus elliotti, em estado natural. (ALTAFIM et al.,2004) ainda traz ensaios dessas cruzetas impregnadas com resina poliuretana a base de óleo de mamona. Assim mais uma vez, o autor deste trabalho veio a contribuir com as simulações numéricas destes ensaios.

O trabalho envolve fases de simulação das cruzetas de madeira em estado natural e também, impregnadas com a resina poliuretana derivada do óleo de mamona.

As características mecânicas dos materiais envolvidos no trabalho foram obtidas através das publicações que são base de dados deste estudo. As madeiras 
já possuem dados suficientes caracterizados (NBR7190, 1997) necessários para a simulação, e a resina conta com o levantamento dessas grandezas realizado por (BONOMO, 2002).

Este trabalho desenvolveu um modelo de simulação computacional, que por meio do método dos elementos finitos capaz de representar os resultados dos ensaios mecânicos normativos de cruzetas de madeira de 2,4 metros de comprimento utilizadas em redes de distribuição urbana de tensão primária 13,8 kV, com interface de uma casca ou cobertura de resina poliuretana derivada do óleo de mamona. 


\section{Capítulo 2}

\section{Revisão Bibliográfica}

Neste capítulo apresentam-se algumas bases de dados que foram necessárias para o levantamento das informações sobre cruzetas de madeira, para redes de distribuição de energia elétrica e algumas informações sobre resina poliuretana à base de óleo de mamona e de cruzetas de madeira impregnadas com a mesma resina encontradas na literatura. Esta revisão bibliográfica também proverá a base teórica para o desenvolvimento deste trabalho.

\subsection{Cruzetas de Madeira}

Segundo (CPFL, 2003) define-se cruzeta como uma peça de madeira de eixo reto, contínua, destinada a suportar condutores e equipamentos de redes aéreas de distribuição de energia elétrica. Para poder realizar sua construção são necessários 
alguns cuidados especiais como, por exemplo, estar de acordo com as espécies autorizadas para corte pelo INSTITUTO BRASILEIRO DO MEIO AMBIENTE E DOS RECURSOS NATURAIS RENOVÁVEIS - IBAMA, atender às dimensões especificadas pela (NBR8459, 1984). Podendo destacar neste trabalho que outras espécies podem ser aceitas desde que previamente aprovadas pela concessionária dos serviços de energia elétrica, atendendo às características mecânicas, densidade igual ou superior a $0,81 \mathrm{~g} / \mathrm{cm}^{3}$, e alta resistência aos agentes apodrecedores quando submetidas aos ensaios previstos pela mesma norma. Os ensaios deverão ser realizados em órgãos competentes para tal.

Para saber se as cruzetas estão em condições de operação, pode-se realizar inspeção preditiva através de vibrometria, que prevê o acidente ou falha antes que aconteça. Essa medição pode ser realizada com o auxílio de helicóptero, segundo (STACK et al., 2003), que sobrevoa as linhas de transmissão com um sensor ligado a um computador que com o auxílio de uma rede neural, e através da correlação entre a tensão de ruptura e o espectro de freqüência, consegue fazer um bom diagnóstico da situação da cruzeta de madeira.

Em geral, as vibrações às quais a estrutura é submetida, levam-na à fadiga, podendo causar o desligamento do sistema, e fatores naturais como, o vento, podem ser causadores de tal fadiga (HARVARD; PERRY, 2000). 


\subsection{Resina Poliuretana à Base de Óleo de Mamona}

(PLEPIS, 1991), traz estudos sobre o comportamento térmico e dinâmicomecânico de resinas preparadas a partir dos derivados do óleo de mamona e outros componentes químicos, o tolueno diisocianato (TDI) e o difenilmetano diisocianato (MDI), demonstrando que o uso de MDI leva à obtenção de poliuretanas com menor relaxação de tensão, maiores durezas e sutil melhora na estabilidade térmica. Também, mostra que as poliuretanas têm comportamento elastomérico a altas temperaturas, seu módulo de elasticidade varia entre 6,0 MPa e 1,4 GPa.

Este trabalho espera possibilitar melhor compreensão dos fenômenos e efeitos que podem ocorrer nestes polímeros, quando aplicados sobre a madeira.

Já em (ARAÚJO, 1992) constam quatro tipos de materiais poliuretanas preparadas com dois tipos de polióis ( $\mathrm{A}$ e $\mathrm{B}$ ), e um tipo de pré-polímero, ambos à base de óleo de mamona, e quimicamente caracterizados. Estes materiais elastômeros receberam os nomes de resinas $\mathrm{RI}$ 1, 2, 3 e 4 e foram investigados através de ensaios mecânicos normalizados. A pesquisa mostra um aspecto interessante a respeito das potencialidades do óleo de mamona como matéria prima de polióis e prepolímeros empregando-se diferentes espécies de reagentes. As características deste material mostraram ser controláveis através de processos químicos adequados, tornando a manipulação das proporções dos polióis e prepolímeros confiável e segura, na busca de propriedades específicas dentro das muitas possibilidades de mistura de ambos.

Para exemplificar a diversidade de aplicações da resina poliuretana à base de óleo de mamona cita-se (MURAKAMI et al., 1999), que mostra a utilização da resina na construção de isoladores de alta tensão, onde além do uso de resina pura foram 
adicionadas cargas mecânicas na resina, o que caracteriza um compósito, para a redução no seu custo. Também foi observado que as resinas não são higroscópicas, ou seja, não absorvem umidade.

Após vários ensaios mecânicos e de envelhecimento artificial, que simula as condições da intempérie, chegou-se à conclusão que das resinas testadas apenas a resina RI 1 tem grande potencial para ser usada neste tipo de aplicação.

\subsection{Compósitos}

Buscando um exemplo na natureza onde o pássaro conhecido popularmente como João-de-barro (nome científico Furnarius rufus), encontrado desde o estado do Mato Grosso, passando por Minas Gerais, São Paulo, até no território argentino, constrói seu ninho com barro, musgo e penas que leva em seu bico até o local escolhido, geralmente postes e galhos de árvores. Logo, a casa do João-de-barro é composta por vários materiais, caracterizando assim um compósito.

Novamente é necessário citar (MURAKAMI et al., 1999) onde foram acrescentadas cargas ou reforços ao material constituinte dos isoladores para uso em redes de alta tensão. Em (BONOMO, 2003) empregou-se o método de prototipagem rápida com a construção de moldes à base de silicone, utilizou-se a resina poliuretana à base de óleo de mamona pura e formando compósitos na confecção de isoladores de alta tensão para uso em ambientes externos.

Como é visto em (SILVESTRE et al., 2001) o compósito é uma combinação macroscópica de dois ou mais materiais diferentes, onde cada um mantém a sua característica sem se dissolver ou se descaracterizar completamente, atuando de 
forma conjugada, para que as propriedades do compósito sejam superiores às de cada material separadamente.

Os compósitos são normalmente aplicados em situações que necessitem de boas propriedades estruturais. Logo esta definição pode ser a incluir somente aqueles materiais que contemplem um reforço e um material aglomerante, pois o aglomerante mantém os reforços unidos e os reforços suportam as cargas transmitidas pelo aglomerante.

(SILVESTRE, 2001) e (SILVESTRE et al., 2001) tratam de estudos que envolvem a formação de uma metodologia para a construção de hastes de implante de quadril feitas de um compósito de resina poliuretana à base de óleo de mamona com fibra de carbono, onde a técnica utilizada para a construção mais uma vez foi à prototipagem rápida com molde de silicone. Convém ressaltar que nestes dois trabalhos utilizou-se o desenvolvimento de protótipos virtuais através de sistema de simulação computacional fundamentados no método dos elementos finitos.

Como já era esperado, o reforço da estrutura com as fibras de carbono em diferentes frações volumétricas, apresentou aumento no desempenho mecânico do compósito, se comparado aos resultados obtidos para a resina poliuretana sem reforço. Mostrando então que o compósito de resina poliuretana reforçado por fibra de carbono apresenta ótimo desempenho mecânico com baixo peso específico.

(SILVA et al., 2004) explica a importância da utilização de madeiras de reflorestamento na construção de cruzetas de madeira devido necessidades ecológicas e econômicas onde se propõe a impregnação de cruzetas de madeiras de reflorestamento Pinus elliotti e Eucalyptus citriodora com a resina poliuretana derivada do óleo de mamona formando então um novo compósito. 
Estes, por sua vez, também foram submetidos a ensaios normalizados para comprovar a resposta das cruzetas impregnadas e não impregnadas com a resina. Posteriormente, na comparação dos resultados ficou claro que as cruzetas impregnadas tiveram melhor resposta aos testes de flexão e principalmente a espécie Eucalyptus citriodora possui melhores propriedades, o que a classifica apta para o uso nas redes urbanas de distribuição de tensão primária 13,8 kV.

Finalmente, em (ALTAFIM et al., 2004a), complementando o que foi mostrado em (ALTAFIM et al., 2004b), traz as simulações computacionais das cruzetas de madeiras de reflorestamento através do método dos elementos finitos, para as cruzetas de madeira não impregnadas com resina, uma representação da espécie Pinus elliotti muito próxima do resultado experimental e para a espécie Eucalyptus citriodora com alguma diferença.

Isso mostra a necessidade de um maior aprofundamento neste campo em busca de um modelo computacional que possa representar satisfatoriamente o comportamento das cruzetas impregnadas com resina poliuretana. Assim parte de (ALTAFIM et al., 2004a) pode ser considerado fruto deste trabalho e base desenvolvimento para o mesmo. 


\section{Capítulo 3}

\section{Materiais}

Neste capítulo os materiais envolvidos neste trabalho de pesquisa são classificados e definidas suas características mecânicas capazes de representá-los no modelo de simulação utilizado.

\subsection{Tipos de Materiais}

De um modo geral, de acordo com (LEKHNITSKII, 1981), todos os materiais podem ser divididos em homogêneos e não-homogêneos e, também, em isotrópicos e anisotrópicos.

Pode-se considerar como fato que as propriedades físicas de um material homogêneo são iguais para todos os pontos de um sistema de coordenadas $\boldsymbol{x}_{\boldsymbol{i}}$ referentes a esse material. Por outro lado, em um material não-homogêneo estas 
propriedades não se mantêm constantes para diferentes pontos de $\boldsymbol{x}_{\boldsymbol{i}}$ do mesmo material.

Já num material isotrópico as suas propriedades de elasticidade não variam em nenhuma direção estabelecida que passa por um ponto. Por outro lado um material anisotrópico exibe diferentes propriedades de elasticidade para diferentes direções estabelecidas passando por um ponto.

Além disto, se a estrutura de um sólido apresenta algum tipo de simetria, as suas propriedades de elasticidade também a exibem.

Nestes termos, em (LOVE, 1994) é estabelecido um princípio que diz que a simetria elástica de um material tem a mesma espécie de simetria que a organização de seus cristais possui.

Assim se um sólido anisotrópico apresentar algum tipo de simetria, as suas propriedades de elasticidade também a exibirão (LEKHNITSKII, 1981). Neste contexto, podem ocorrer simplificações nos tensores compliância $\left(S_{i l}\right)$ e constantes de elasticidade $\left(\boldsymbol{C}_{\boldsymbol{i j}}\right)$

A abordagem destas possíveis simplificações pode ser realizada por diferentes artifícios, como o usado por (LOVE,1994) que se baseia na variação da energia de deformação através da mudança de sistemas simétricos de coordenadas $\left(\boldsymbol{x}_{\boldsymbol{i}}\right.$ e $\left.\boldsymbol{x}_{\boldsymbol{i}}{ }^{\prime}\right)$. Já em (LEKHNITSKII, 1981) tais simplificações acontecem analiticamente, desenvolvendo as leis constitutivas em relação aos dois sistemas de coordenadas e compara as expressões obtidas, identificando assim, as simetrias existentes. Este trabalho faz uso do último tratamento para os tensores $S_{i j}$ e $C_{i j}$.

Como exemplo, adotamos um sólido sob a ação de forças externas e, conseqüentemente, com deformações $\boldsymbol{\varepsilon}_{i j}$. Lembrando que o sólido está vinculado a 
um sistema de coordenadas cartesiana $\boldsymbol{x}_{\boldsymbol{i}}$ (e $\boldsymbol{x}_{\boldsymbol{1}}, \boldsymbol{x}_{\mathbf{2}}$ e $\boldsymbol{x}_{3}$ ), levando em conta um sistema simétrico a este, ou $\boldsymbol{x}_{\boldsymbol{i}}{ }^{\prime}=-\boldsymbol{x}_{\boldsymbol{i}}$.

Como as deformações são tensores de segunda ordem, estes estão sujeitos a seguinte lei de transformação:

$$
\mathcal{\varepsilon}_{i j}^{\prime}=l_{i m} l_{j n} \varepsilon_{m n}
$$

onde: $\mathcal{E}_{i j}^{\prime}$ é a componente no novo sistema de coordenadas,

$$
\mathcal{E}_{m n} \text { é a componente no antigo sistema de coordenadas e } l_{i j} \text { são os }
$$

\section{cossenos diretores}

De acordo com a figura 3.1, os cossenos diretores serão:

$$
l_{i j}=\left[\begin{array}{ccc}
-1 & 0 & 0 \\
0 & -1 & 0 \\
0 & 0 & -1
\end{array}\right]
$$

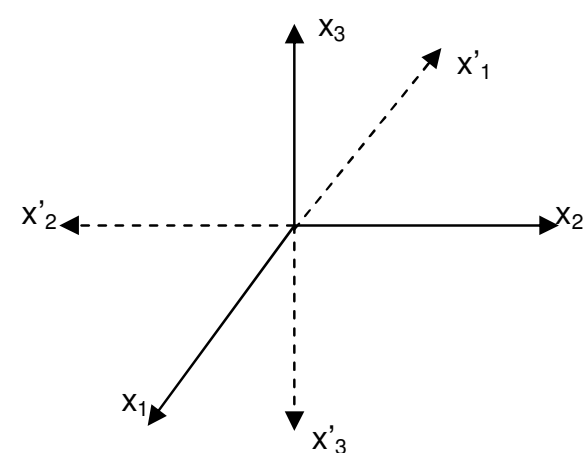

Figura 3.1 - Sistema de eixos ortogonais e seus simétricos Baseado em (MASCIA, 1991) 
Aplicando agora a lei de transformação (equação 3.1) com $i=1$ e $j=1$, $\varepsilon^{\prime}{ }_{11}$ torna - se:

$$
\begin{aligned}
\varepsilon_{11}^{\prime}= & l_{11} l_{11} \varepsilon_{11}+l_{11} l_{12} \varepsilon_{12}+l_{11} l_{13} \varepsilon_{13}+l_{12} l_{11} \varepsilon_{21}+l_{12} l_{12} \varepsilon_{22}+l_{12} l_{13} \varepsilon_{23}+ \\
& l_{13} l_{11} \varepsilon_{31}+l_{13} l_{12} \varepsilon_{32}+l_{13} l_{13} \varepsilon_{33}
\end{aligned}
$$

e com algumas simplificações:

$$
\varepsilon_{11}^{\prime}=l_{11}^{2} \varepsilon_{11}+l_{12}^{2} \varepsilon_{22}+l_{13}^{2} \varepsilon_{33}+l_{11} l_{12} 2 \varepsilon_{12}+l_{12} l_{13} 2 \varepsilon_{23}+l_{13} l_{11} \varepsilon_{31}
$$

Substituindo os valores dos cossenos diretores $l_{i j}$, encontra-se:

$$
\mathcal{E}^{\prime}{ }_{11}=\varepsilon_{11}
$$

e em uma forma generalizada:

$$
\mathcal{E}^{\prime}{ }_{i j}=\varepsilon_{i j}
$$

Usando esta teoria é possível fazer simplificações nos tensores $S_{i j}$ e $C_{i j}$, desde que, se estabeleçam direções determinadas por $x_{i}$ nas quais as propriedades de estabilidade não variem. Estas direções são chamadas direções principais de elasticidade. Como conseqüência, deixa-se de enfocar um material anisotrópico, pelo fato deste não possuir tais direções.

\subsubsection{Classificação dos Materiais Segundo o Número de Planos de Simetria Elástica}


Como é visto em (COWIN, 1987), são sintetizados os estudos desenvolvidos, os quais apresentaram nove quantidades distintas de coeficientes do tensor $C_{i j k l}$ para trinta e duas classes de cristais, enquanto que para os não cristais, ele mencionou a existência de somente três tipos tradicionais conhecidos como isotrópico, monotrópico e ortotrópico, este último é um dos que nos interessará mais adiante.

A seguir, será mostrado um estudo mais aprofundado da simetria elástica para os 3 três tradicionais tipos de cristais.

\subsubsection{Material com Simetria Elástica em Um Plano}

Considerando um sólido referido a um sistema de coordenadas $x_{i}$ conforme mostra a figura 3.2.

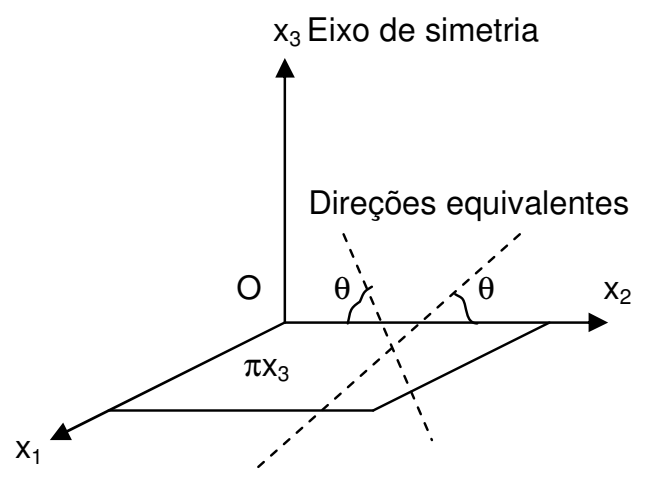

Figura 3.2 - Simetria elástica em um plano Baseado em (MASCIA, 1991)

O plano $x_{1}-x_{2}$ é de simetria elástica, ou seja, duas direções quaisquer passando por um ponto neste plano são equivalentes no que concerne às 
propriedades de elasticidade. Além disto, a direção normal a este plano é chamada de direção principal de elasticidade.

Promovendo rotações de $180^{\circ}$ em torno do eixo $x_{3}$, conforme esquema da figura 3.3.

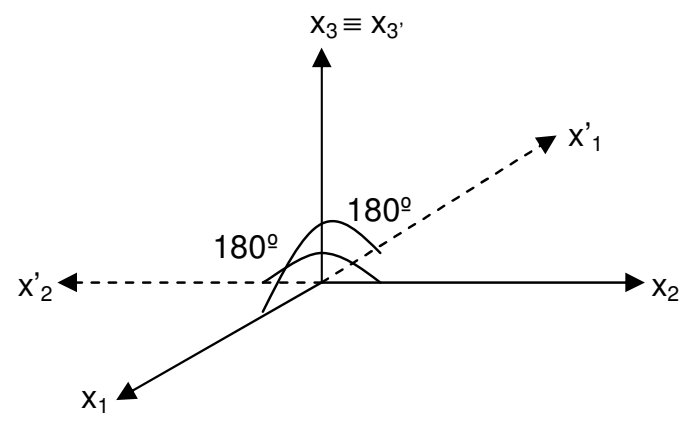

Figura 3.3 - Rotação de $180^{\circ}$ em torno do eixo $x_{3}$ Baseado em (MASCIA, 1991)

têm-se os seguintes cossenos diretores:

$$
l_{i j}=\left[\begin{array}{ccc}
-1 & 0 & 0 \\
0 & -1 & 0 \\
0 & 0 & -1
\end{array}\right]
$$

Com o uso da transformação tensorial de $S_{11}$ tem-se:

$$
S_{11}^{\prime}=q_{l m} q_{\mathrm{ln}} S_{m n}
$$

resultando:

$$
S_{11}^{\prime}=l_{11}^{4} S_{11}
$$

Devido às demais parcelas que contribuem para $S_{11}^{\prime}$ serem nulas, então 


$$
S_{11}{ }^{\prime}=S_{11}
$$

De semelhante análise para os outros termos do tensor, conclui-se que:

$$
S_{15}=S_{16}=S_{25}=S_{26}=S_{35}=S_{36}=S_{45}=S_{46}=0
$$

Então, o tensor $S_{i j}$ terá a seguinte configuração:

$$
S_{i j}=\left[\begin{array}{cccccc}
S_{11} & S_{12} & S_{13} & S_{14} & 0 & 0 \\
S_{21} & S_{22} & S_{23} & S_{24} & 0 & 0 \\
S_{31} & S_{32} & S_{33} & S_{34} & 0 & 0 \\
S_{41} & S_{42} & S_{43} & S_{44} & 0 & 0 \\
0 & 0 & 0 & 0 & S_{55} & S_{56} \\
0 & 0 & 0 & 0 & S_{65} & S_{66}
\end{array}\right]
$$

Com isto o tensor $S_{i j}$ passa a ter 13 (treze) elementos diferentes, sendo que apenas 11 (onze) são independentes, devido à dependência linear entre os termos $S_{55}, S_{56}$ e $S_{66}$.

\subsubsection{Material com Simetria Elástica em Três Planos}

Normalmente admitindo um sólido referido a um sistema de eixos coordenados $x_{i}$ e agora procedendo a uma rotação de $180^{\circ}$ em torno do eixo $x_{1}$ (um dos eixos de simetria) conforme figura 3.4. 


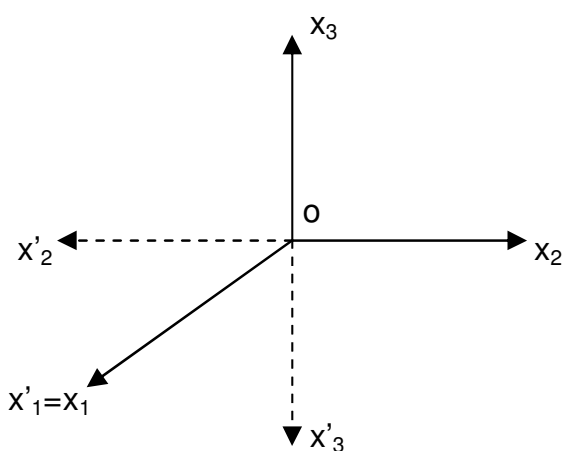

Figura 3.4 - Rotação de $180^{\circ}$ em torno do eixo $x_{1}$ Baseado em (MASCIA, 1991)

tem-se, analogamente ao item anterior:

$$
S_{14}=S_{24}=S_{34}=S_{56}=0
$$

Efetuando semelhante rotação nos eixos $x_{2}$ e $x_{3}$, um de cada vez, tem-

se:

$$
\begin{aligned}
& S_{16}=S_{26}=S_{36}=S_{54}=0 \\
& S_{15}=S_{25}=S_{35}=S_{56}=0,
\end{aligned}
$$

sendo assim, $S_{i j}$ fica com a seguinte forma:

$$
S_{i j}=\left[\begin{array}{cccccc}
S_{11} & S_{12} & S_{13} & 0 & 0 & 0 \\
S_{21} & S_{22} & S_{23} & 0 & 0 & 0 \\
S_{31} & S_{32} & S_{33} & 0 & 0 & 0 \\
0 & 0 & 0 & S_{44} & 0 & 0 \\
0 & 0 & 0 & 0 & S_{55} & 0 \\
0 & 0 & 0 & 0 & 0 & S_{66}
\end{array}\right]
$$


Neste ponto pode-se expressar os coeficientes do tensor compliance, em termos dos coeficientes elásticos usuais de engenharia (CAUWELAERT, 1977), ou seja, através do módulo de elasticidade longitudinal ou módulo de Young $E_{i}$, do coeficiente de Poisson $v_{i j}$ e do módulo de elasticidade transversal ou de rigidez $G_{i j}$

Assim $S_{i j}$ torna-se:

$$
S_{i j}=\left[\begin{array}{cccccc}
\frac{1}{E_{1}} & -\frac{v_{21}}{E_{2}} & -\frac{v_{31}}{E_{3}} & 0 & 0 & 0 \\
-\frac{v_{12}}{E_{1}} & \frac{1}{E_{2}} & -\frac{v_{31}}{E_{3}} & 0 & 0 & 0 \\
-\frac{v_{13}}{E_{1}} & -\frac{v_{23}}{E_{2}} & \frac{1}{E_{3}} & 0 & 0 & 0 \\
0 & 0 & 0 & \frac{1}{G_{12}} & 0 & 0 \\
0 & 0 & 0 & 0 & \frac{1}{G_{23}} & 0 \\
0 & 0 & 0 & 0 & 0 & \frac{1}{G_{31}}
\end{array}\right]=
$$

onde devido á simetria existente pode-se escrever:

$$
-\frac{v_{21}}{E_{2}}=-\frac{v_{12}}{E_{1}}
$$

ou genericamente:

$$
-\frac{v_{i j}}{E_{i}}=-\frac{v_{j i}}{E_{j}}
$$


Como observou-se anteriormente, é mais simples trabalhar com os coeficientes do tensor $S_{i j}$, ao invés dos coeficientes do tensor $C_{i j}$. A título de ilustração podem-se comparar os coeficientes a seguir:

$$
S_{11}=\frac{1}{E_{1}}
$$

e

$$
C_{11}=\frac{E_{1}\left(1-v_{32} v_{23}\right)}{1-2 v_{12} v_{23} v_{31}-v_{13} v_{31}-v_{12} v_{21}-v_{23 v 32}}
$$

\subsubsection{Material Transversalmente Isotrópico}

Considerando-se um sólido referido a um sistema de coordenadas, conforme a figura 3.5 , onde o plano $x_{1}-x_{2}$ é dito de isotropia, ou seja, todas as direções contidas neste plano são elasticamente equivalentes, o eixo $x_{3}$ é o eixo de simetria elástica. 


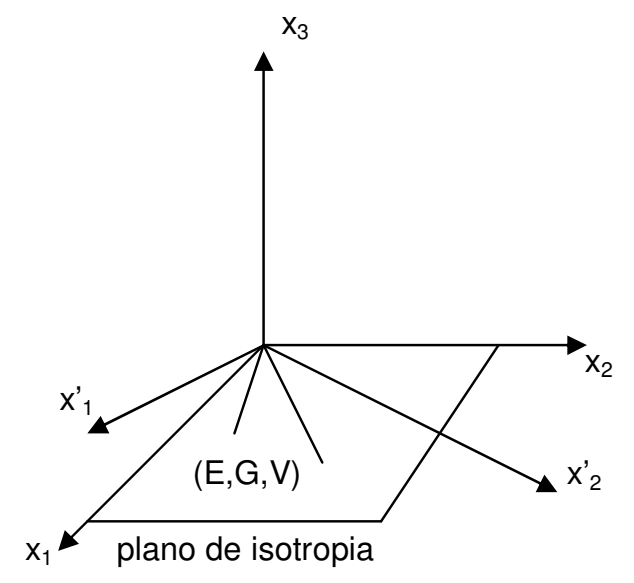

Figura 3.5 - Plano de isotropia - material transversalmente isotrópico Baseado em (MASCIA, 1991)

Baseando-se nas operações dos itens anteriores, de simetria elástica,

tem-se:

$$
S_{11}=S_{22} ; S_{13}=S_{23} ; S_{55}=S_{66} ; 2\left(S_{11}-S_{12}\right)=S_{44}
$$

Assim, com a utilização da notação usual de engenharia,ou notação técnica, em uma forma matricial, o tensor $S_{i j}$ torna-se:

$$
S_{i j}=\left[\begin{array}{cccccc}
\frac{1}{E} & -\frac{v}{E} & -\frac{v^{\prime}}{E} & 0 & 0 & 0 \\
-\frac{v}{E} & \frac{1}{E} & -\frac{v^{\prime}}{E^{\prime}} & 0 & 0 & 0 \\
-\frac{v^{\prime}}{E} & -\frac{v^{\prime}}{E^{\prime}} & \frac{1}{E^{\prime}} & 0 & 0 & 0 \\
0 & 0 & 0 & \frac{1}{G} & 0 & 0 \\
0 & 0 & 0 & 0 & \frac{1}{G^{\prime}} & 0 \\
0 & 0 & 0 & 0 & 0 & \frac{1}{G^{\prime}}
\end{array}\right]
$$


onde: $\quad E, E^{\prime}=$ módulo de elasticidade no plano de isotropia e na direção normal a ele;

$v, v^{\prime}=$ coeficiente de Poisson no plano de isotropia e na direção normal a ele e;

$G, G^{\prime}=$ módulo de elasticidade transversal no plano de isotropia e, também,

$$
2\left(S_{11}-S_{12}\right)=S_{44}
$$

ou

$$
G=\frac{E}{2(1+v)}
$$

Portanto, apenas 5 (cinco) coeficientes de $S_{i j}$ são independentes.

É importante salientar que a expressão do módulo de elasticidade transversal $G$ indica a isotropia no plano.

\subsubsection{Material Isotrópico}

Um material isotrópico é aquele em que todos os planos que passam por um ponto são isotrópicos (planos de simetria), ou seja, todas as direções são elasticamente equivalentes e principais. 
Assim:

$$
E^{\prime}=E, G^{\prime}=G \text { e } v^{\prime}=v
$$

tornando-se o tensor $S_{i j}$, em uma forma matricial, com o uso dos coeficientes de engenharia:

$$
S_{i j}=\left[\begin{array}{cccccc}
\frac{1}{E} & -\frac{v}{E} & -\frac{v}{E} & 0 & 0 & 0 \\
-\frac{v}{E} & \frac{1}{E} & -\frac{v}{E} & 0 & 0 & 0 \\
-\frac{v}{E} & -\frac{v}{E} & \frac{1}{E} & 0 & 0 & 0 \\
0 & 0 & 0 & \frac{1}{G} & 0 & 0 \\
0 & 0 & 0 & 0 & \frac{1}{G} & 0 \\
0 & 0 & 0 & 0 & 0 & \frac{1}{G}
\end{array}\right]
$$

Portanto, o tensor Sij passa a ter apenas 2 (dois) coeficientes independentes, ou seja, o módulo de elasticidade longitudinal $E$ e o Coeficiente de Poisson $v$, sendo que o módulo de elasticidade transversal $G$ é definido como na equação 3.24 .

O coeficiente de Poisson (v) é definido como a razão negativa entre as deformações laterais $\left(\varepsilon_{\mathrm{x}}, \varepsilon_{\mathrm{y}}\right)$ e longitudinal ou axial $\left(\varepsilon_{\mathrm{z}}\right)$ do material, teremos então $\varepsilon_{\mathrm{x}}=\varepsilon_{\mathrm{y}}$ quando o material é isotrópico e a tensão aplicada for uniaxial, apenas na direção $z$. 


$$
v=-\frac{\varepsilon_{X}}{\varepsilon_{Z}}=\frac{\varepsilon_{Y}}{\varepsilon_{Z}}
$$

Ainda sobre o coeficiente de Poisson (v) como é visto em (OSTROSABLIN, 1986), através de cálculos algébricos define o intervalo para estes materiais como:

$$
0<v<\frac{1}{2} \text { ou }-1<v<0,
$$

onde a primeira inequação representa o intervalo para um material isotrópico mais usual, enquanto a segunda inequação, apresenta o intervalo para um material dito menos usual, como por exemplo uma barra cujo material sob tração apresenta alongamento em direções arbitrárias.

Com relação ao valor negativo da inequação, pode-se citar (OSTROSABLIN, 1986), que mostra coeficientes de Poisson negativos para materiais isotrópicos em ensaios de laboratório.

\subsection{Madeiras}

Desde os primórdios da vida dos ancestrais, que originaram a raça humana, a madeira é utilizada para as mais diversas funções e, então, pode ser considerada um dos materiais mais utilizados pelo homem. Dentre estas funções podemos citar: 
matéria prima para a confecção de ferramentas, armas, instrumentos, estruturas, abrigos, móveis, carros, casas, etc.

Essa variedade de funções ocorre devido à sua abundância na natureza e ao simples manuseio, requerendo apenas a força de mãos humanas e ferramentas rudimentares. Além disso, possui ótimas propriedades específicas resistência mecânica/densidade. Com isso, torna-se fácil entender porque a madeira continua sendo utilizada atualmente.

Segundo (SALES, 1991), durante a revolução industrial ocorreu o incremento às formas de utilização da madeira como chapas particuladas e papel e, também, um elevado aumento de necessidade de produção de energia.

Conseqüentemente existiu uma grande exploração das reservas naturais, realizada geralmente de forma não racionalizada ocasionando sua devastação, principalmente nos países da Europa durante o século XIX e, recentemente, nos países sul-americanos em desenvolvimento como o Brasil.

Infelizmente, segundo (GUINNES, 2004), o Brasil atualmente é recordista em áreas desmatadas. O País perdeu no século passado uma área de florestas equivalente ao Estado de Sergipe. A média anual de devastação de matas entre 1900 e 2000 foi de 22.264 quilômetros quadrados.

A Amazônia perdeu 17\% de cobertura florestal, e o ritmo do desflorestamento acentuou-se nos últimos 50 anos. Juntos, Mata Atlântica, Amazônia, Cerrado e a formação florestal Araucária, perderam 3,6 milhões de quilômetros quadrados.

A maneira encontrada para recuperar as florestas segundo (AGÊNCIA BRASIL, 2003), foi o reflorestamento, feito inicialmente com as espécies nativas pertinentes a cada região. Ocorreu, porém, uma grande dificuldade de readaptação 
das espécies nativas e a baixa produtividade destas reservas tornaram a exploração comercial inviável.

O crescente aumento da população brasileira e mundial, assim como o desenvolvimento econômico que exige grandes volumes de madeira que só podem ser atendidos por plantações. O suprimento de madeira e outros produtos da floresta devem ser estruturados em base produtiva racional, que permita atender as demandas sem dilapidação do patrimônio biológico.

As florestas plantadas permitem a produção concentrada de grandes volumes de madeira em prazos relativamente curtos. Por exemplo, um hectare de floresta plantada, adequadamente manejada, permite produzir cerca de 30 vezes mais produtos do que a floresta nativa manejada.

É interessante citar que as variedades de madeira Eucalyptus citriodora e a Pinus elliotti demonstraram sua qualidades, tanto em relação a sua capacidade de adaptação edafoclimática, quanto à sua alta taxa de crescimento mesmo com pouco espaçamento entre as árvores plantadas. Cabe aqui citar que as árvores de Eucalyptus citriodora podem atingir de trinta a quarenta e cinco metros de altura.

\subsubsection{A Ortotropia Aplicada à Madeira}

Como já foi dito, a madeira tem sido um material estrutural de grande uso e é estudada por diversos pesquisadores a respeito de suas características tanto físicas em geral quanto mecânicas em particular.

As madeiras utilizadas comercialmente são classificadas em dois grupos: as coníferas e as dicotiledôneas. A distinção entre os dois grupos tem que ser feita 
através de suas características anatômicas, pois é possível encontrar madeiras do grupo das coníferas mais duras que as das dicotiledôneas.

As propriedades físicas da madeira freqüentemente exibem uma grande variabilidade resultante das condições de crescimento e de fatores ambientais como o clima, o solo, a água, quantidade e tipo de nutrientes disponíveis, etc. Além disso, deve-se levar em conta o aspecto hereditário, o qual pode resultar em diferenças nas propriedades físicas em madeiras da mesma espécie.

A complexidade da estrutura interna estabelece suas características (SALES, 1991), resultando em um modelo anisotrópico. Desta forma, pode-se afirmar que existem diferentes tipos de anisotropia nesta estrutura. Mas, em função de suas particularidades, foram feitos estudos que adequaram a madeira ao modelo ortotrópico, pelo motivo de existir três planos de simetria na estrutura da madeira, figura 3.6 e também através do conhecimento desta estrutura microscópica.
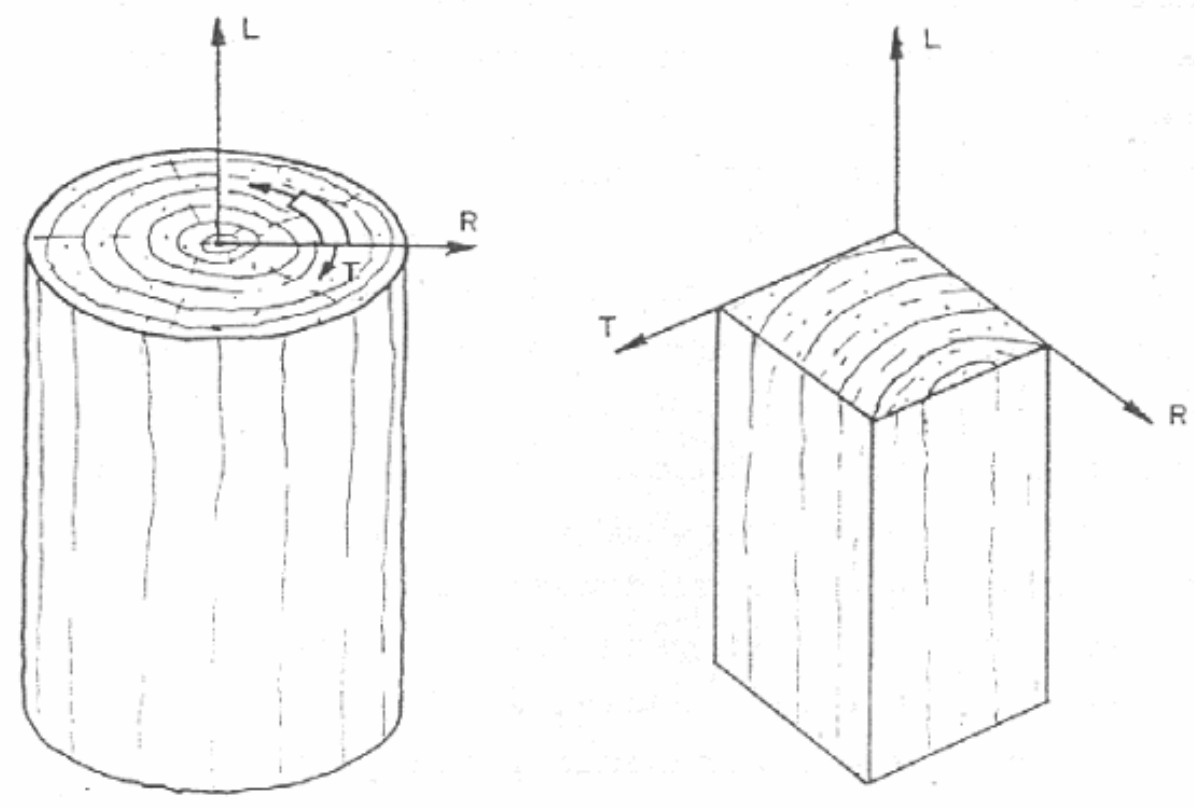

Figura 3.6 - Eixos de simetria da madeira (SALES, 1991) 
Logo a madeira é representada como um material do tipo Ortotrópico, ou seja, que há três eixos de simetria nesse material, sendo eles o sentido longitudinal $(L), 0$ sentido radial $(R)$ e o tangencial $(T)$. Essa representação ocorre devida à configuração natural de agrupamento das fibras da madeira, que são dispostas longitudinalmente ao seu comprimento e em anéis radiais.

Baseando-se nisso será necessário adotar um sistema de eixos ortogonais coincidentes representando as principais direções de elasticidade da madeira. Assim podemos admitir a coincidência dor eixos de referência $x=\left(x_{1}, x_{2}, x_{3}\right)$ com os eixos de simetria elástica $S=(L, R, T)$.

Substituindo esses valores subscritos na equação 3.16 temos a representação para a madeira:

$$
S_{i j}=\left[\begin{array}{cccccc}
\frac{1}{E_{L}} & -\frac{v_{R L}}{E_{R}} & -\frac{v_{T L}}{E_{T}} & 0 & 0 & 0 \\
-\frac{v_{L R}}{E_{L}} & \frac{1}{E_{R}} & -\frac{v_{T R}}{E_{T}} & 0 & 0 & 0 \\
-\frac{v_{L T}}{E_{L}} & -\frac{v_{R T}}{E_{R}} & \frac{1}{E_{T}} & 0 & 0 & 0 \\
0 & 0 & 0 & \frac{1}{G_{L R}} & 0 & 0 \\
0 & 0 & 0 & 0 & \frac{1}{G_{R T}} & 0 \\
0 & 0 & 0 & 0 & 0 & \frac{1}{G_{T L}}
\end{array}\right]
$$

Dessa forma é possível obter a representatividade numérica das características mecânicas da madeira, que são mostradas mais à frente. 


\subsubsection{Constituição da Madeira}

Para iniciar a explicação da constituição da madeira, como pode ser visto em (BODIG e JAYNE, 1982), é interessante visualizar uma representação da unidade de glucose dentro da porção de uma molécula de celulose e outros constituintes, o que aparece na figura 3.7 .

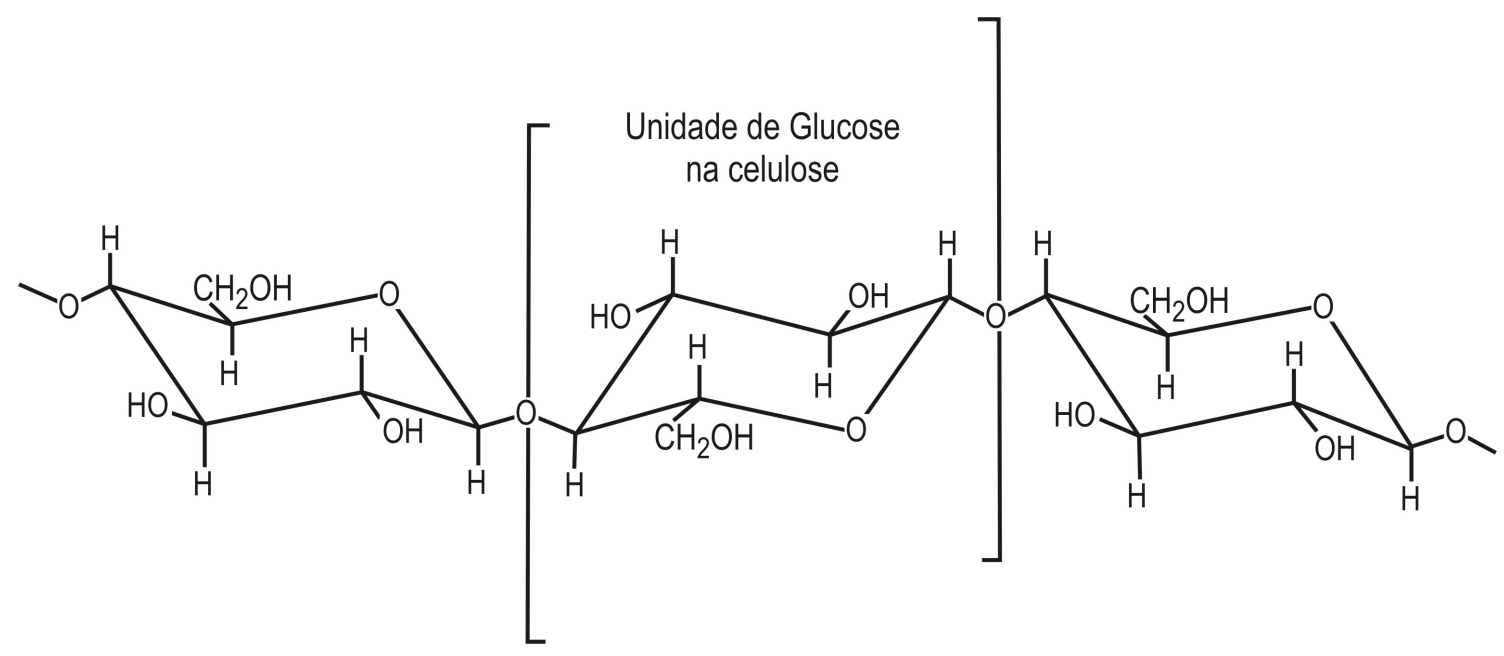

Figura 3.7- Porção de uma molécula de celulose (BODIG e JAYNE, 1982)

A madeira é constituída internamente por células alongadas com a presença de vazios. As células apresentam formas e tamanhos variados de acordo com a classificação da árvore. Deste modo, identificam-se os elementos básicos mencionados a seguir.

As coníferas são formadas por traquenídeos (que atingem até $90 \%$ de sua constituição, os quais são células alongadas), e por raios medulares que se dispõem radialmente em forma de fitas. Já as dicotiledôneas são compostas de vasos (que podem compor até $50 \%$ de sua constituição), de fibras e raios medulares. 
Sob esta ótica, conclui-se que o arranjo de células nas coníferas é mais homogêneo do que nas dicotiledôneas.

Baseando-se nisto, pode-se antever que os estudos das propriedades físicas ou mecânicas da madeira são relacionadas como arranjo e com a composição das paredes celulares que formam os elementos básicos da mesma, como os traqueídeos e os raios medulares. A figura 3.8 mostra um modelo das camadas da parede celular da conífera traqueídeos.

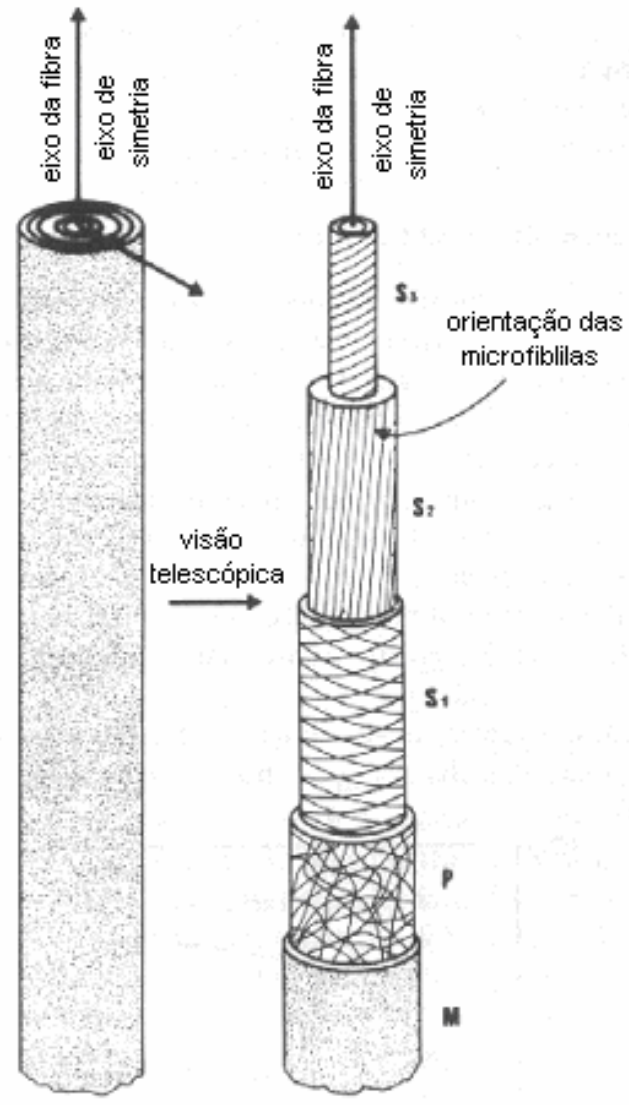

Figura 3.8 - Modelo das camadas da parede celular da conífera traqueídeos (BODIG e JAYNE, 1982)

A estrutura celular é formada por microfibrilas, ou fileiras paralelas de moléculas de celulose, que formam as lamelas (arranjos de várias centenas de 
microfibrilas, as chamadas camadas $S_{1}, S_{2}$ e $S_{3}$.) sendo que o arranjo das moléculas de celulose na parede celular, em ordem crescente de complexidade, vai das microfibrilas até a parede celular de dimensões macroscópicas.Deste modo, as características físicas da madeira estão relacionadas ao arranjo destas microfibrilas nas paredes celulares.

Por outro lado, a orientação da celulose nas fibras dos traqueídeos, a qual pode ser externada em um nível macroscópico pela disposição das camadas de crescimento da madeira, caracteriza a ortotropia da madeira.

Em um corte transversal de um tronco de árvore, podem ser identificadas as camadas que compõem a estrutura macroscópica da madeira. Estas camadas são formadas durante o crescimento da árvore. São formadas, neste crescimento, camadas sucessivas, sobrepostas e concêntricas, chamadas anéis de crescimento. Na figura 3.9 está esquematizado um corte transversal de um tronco: 


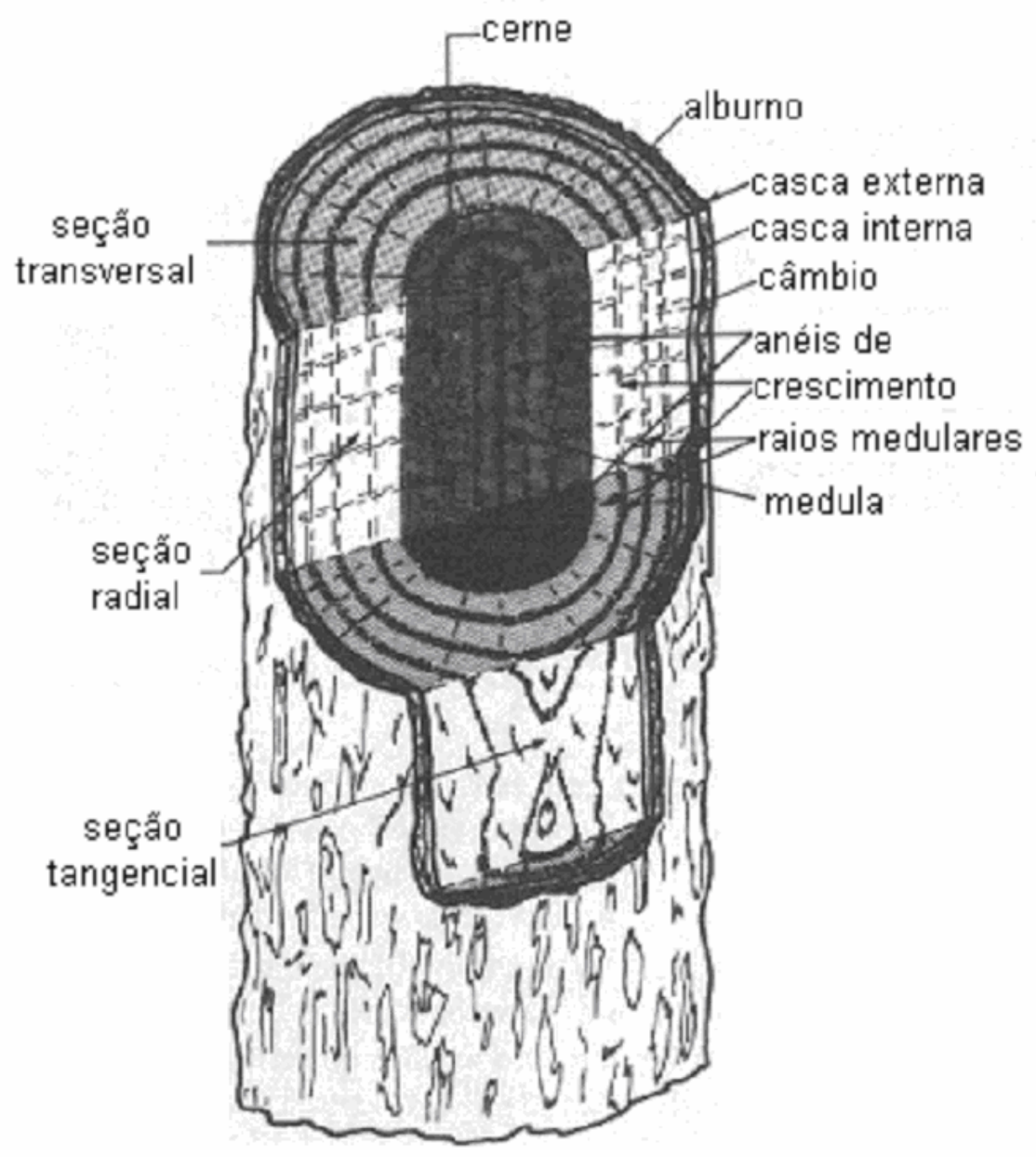

Figura 3.9 - As camadas constituintes da madeira (BODIG e JAYNE, 1982)

Os anéis de crescimento formam um conjunto chamado lenho. Recobrindo o lenho existe a casca da árvore. Entre o lenho e a casca tem-se o câmbio, que é responsável pelo crescimento celular da árvore.

O lenho pode ser dividido em duas partes: a primeira, denominada alburno, constituída de camadas mais novas e mais externas enquanto que a segunda, denominada cerne, é formada por camadas mais antigas, mais internas.

Segundo (OLIVEIRA, 2001) a madeira, por ser um material natural, possui grande variabilidade de suas características, por isso seu comportamento é determinado pela fisiologia das árvores. A geometria dos anéis de crescimento, a 
idade das diferentes camadas, os níveis de lenhificação das paredes das células componentes dos elementos anatômicos, a incidência de nós ou fibras reversas, a distribuição e a concentração dos constituintes celulares, influenciam nas propriedades mecânicas da madeira.

Segundo (BUCUR, 1995) a arquitetura da madeira é responsável pelo seu comportamento altamente anisotrópico e viscoelástico.

No presente estudo é usado o modelo ortotrópico, em nível macroscópico, associado a eixos ortogonais, o que implica em uma aproximação, pelo fato dos anéis de crescimento da madeira apresentarem uma orientação curvilínea. Além disto podemos considerar a madeira um material homogêneo como forma de aproximação.

\subsubsection{Características Mecânicas da Madeira}

Como já foi dito anteriormente, o autor deste trabalho busca a representação numérica dos ensaios realizados experimentalmente com cruzetas de madeira de Pinus elliotti e Eucalyptus citriodora, onde pode-se encontrar os resultados iniciais para as madeiras em estado natural em (ALTAFIM et al., 2004)

Para realizar a representação ortotrópica de madeiras através da equação 3.29, é preciso conhecer os módulos de elasticidade $E$ de cada uma dessas espécies.

As informações das características mecânicas das madeiras são responsáveis por informar corretamente o comportamento do material a ser simulado, frente ao software. 
Em se tratando das madeiras essas informações podem ser encontradas em (NBR7190, 1997), esta norma trás definições de como encontrar os valores para os módulos capazes de definirem os mais diversos tipos de madeira.

Inicialmente são mostrados na tabela 1 abaixo os Módulos de elasticidade para as madeiras utilizadas por (ALTAFIM et al., 2004).

Tabela 1 - Módulos de elasticidade paralelo às fibras, (ABNT), (1997, NBR7190)

\begin{tabular}{cc}
\hline Nome científico & $\begin{array}{c}\text { Módulo de elasticidade } \\
E_{w 0}(\mathrm{MPa})\end{array}$ \\
\hline Eucalyptus citriodora & 18421 \\
Pinus elliotti & 11889 \\
\hline
\end{tabular}

Como já foi visto, anteriormente, são necessários três módulos de elasticidade para compor a representação de um material ortotrópico, no caso a madeira. A (NBR7190,1997), traz somente o módulo de elasticidade na direção paralela às fibras $\left(E_{w 0}\right)$, e não traz os valores dos módulos de elasticidade na direção normal às fibras $\left(E_{w 90}\right)$. Assim permite-se adotar esse valor como sendo a vigésima parte do valor de $E_{w 0}$.

Na representação do material ortotrópico, também são necessários definir os módulos de elasticidade transversal $G$, que podem ser considerado $35 \%$ do valor de $E_{w 0}$,segundo (PLEPIS,1991).

Entretanto, este trabalho adotou-se o modelo de representação da madeira obtido por (MASCIA, 1991) em sua pesquisa, onde traz os coeficientes de elasticidade para algumas espécies brasileiras de madeira Pinus. Dessa forma 
chegou-se a representação das madeiras Pinus elliotti e Eucalyptus citriodora como mostra a tabela 2.

Tabela 2 - Valores dos coeficientes ortotrópicos das madeiras

\begin{tabular}{|c|c|c|c|c|c|c|c|c|c|}
\hline Madeira & $E_{L}(\mathrm{MPa})$ & $E_{R}(\mathrm{MPa})$ & $E_{T}(\mathrm{MPa})$ & $v_{L R}$ & $v_{R T}$ & $v_{L T}$ & $G_{L R}(\mathrm{MPa})$ & $G_{R T}(\mathrm{MPa})$ & $G_{L T}(\mathrm{MPa})$ \\
\hline $\begin{array}{l}\text { Eucalyptus } \\
\text { Citriodora }\end{array}$ & 18421 & 921,05 & 921,05 & 0,37 & 0,63 & 0,33 & 6447,35 & 6447,35 & 6447,35 \\
\hline $\begin{array}{l}\text { Pinus } \\
\text { Elliotti }\end{array}$ & 11889 & 594,45 & 594,45 & 0,37 & 0,63 & 0,33 & 4161,15 & 4161,15 & 4161,15 \\
\hline
\end{tabular}

A umidade é um fator que pode influenciar os valores dos módulos de elasticidade das madeiras, mas este trabalho adota que a classe de umidade para estes ensaios seja a classe 1, o que significa a umidade relativa do ar menor ou igual a $65 \%$ o que representa uma umidade de equilíbrio da madeira igual a $12 \%$.

\subsection{Cruzetas de Madeira}

A energia elétrica sempre esteve presente no planeta Terra na forma de descargas atmosféricas, também chamados de raios, muito comuns em chuvas e tempestades. Na antiga Grécia, Zeus, cujo nome de origem indo-européia significa resplandecente, brilhante, era associado ao trovão e ao raio.

Benjamin Franklin (1706-1790), da história americana, em suas experiências elétricas, conseguiu conduzir a descarga atmosférica através de fios e após esse fato realizou outros estudos envolvendo a eletricidade. Dessa forma criou-se à necessidade de desenvolver sistemas capazes de gerar, armazenar, transmitir e transformar a energia elétrica, desde sua geração até os locais de consumo. 
No Brasil a utilização da energia elétrica teve seu início no final do século XIX com o objetivo principal de iluminar as ruas e alimentar bondes dos centros urbanos. Há registros, em (CENTRO DA MEMÓRIA ELÉTRICA NO BRASIL, 2001) e (SILVA, 2003), do uso de energia elétrica no Brasil datados de 1883 em Diamantina-MG, gerada pela usina Hidrelétrica de Ribeirão do Inferno. Em 1889 entrou em operação a Usina Hidrelétrica de Marmelos, no Rio Paraibuna em Juiz de Fora considerada o "Marco Zero" do abastecimento ao consumo urbano de energia elétrica no Brasil e desde aquela época já era comum o uso de cruzetas como mostra o detalhe da figura 3.10 .

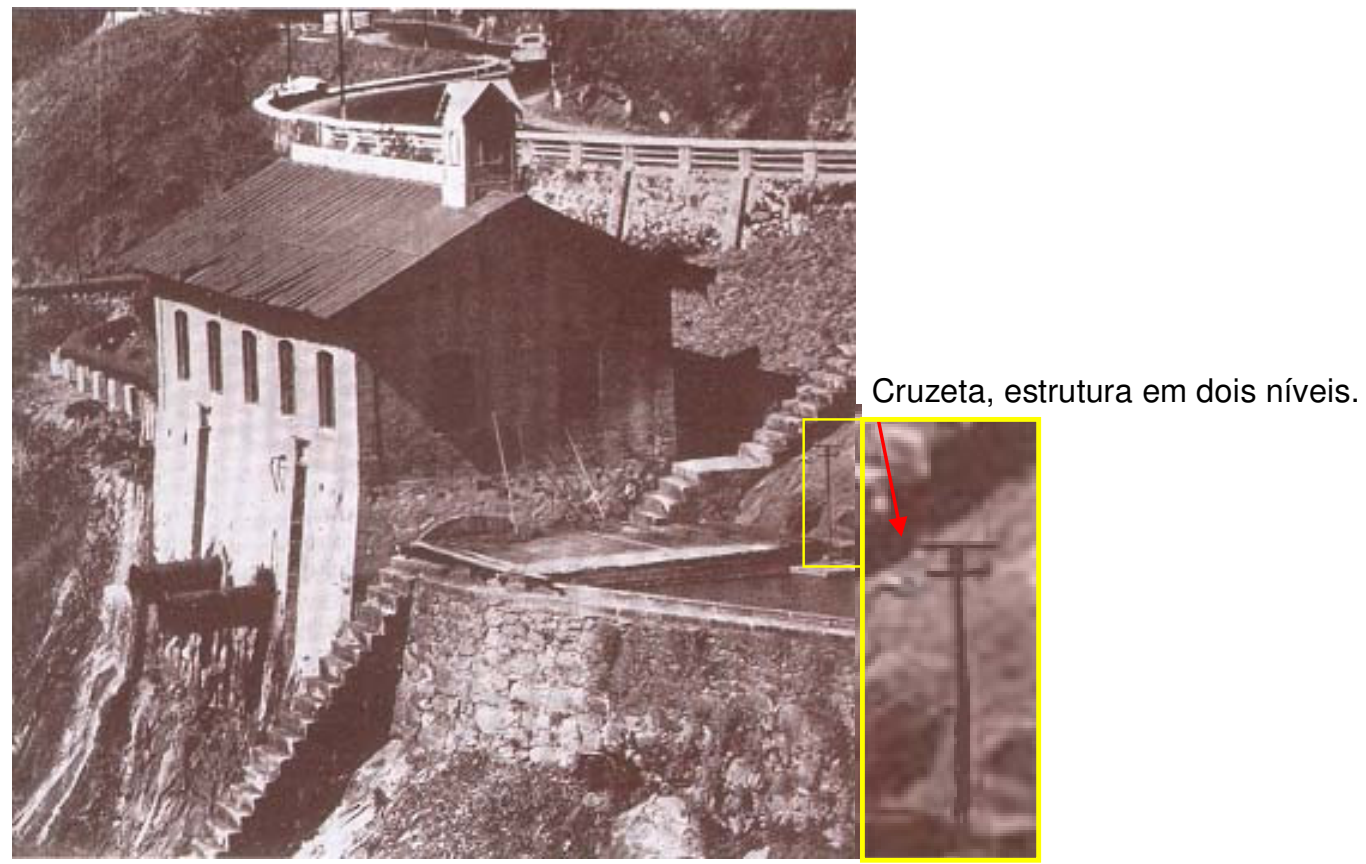

Figura 3.10 - Usina Hidrelétrica de Marmelos com destaque para a cruzeta (SILVA, 2003)

As cruzetas são fixadas em postes de concreto ou madeira e tem como função sustentar os cabos e os isoladores da rede elétrica de alta tensão (CPFL, 2003), no Brasil principalmente a tensão da rede de distribuição primária que é de 
$13.800 \mathrm{~V}$ ou $13,8 \mathrm{kV}$, e os cabos de rede secundária, cuja tensão de fase é de $127 \mathrm{~V}$ na freqüência padrão de $60 \mathrm{~Hz}$, geralmente preso ao mesmo poste, fixado através de isoladores. A figura 3.11 (a) destaca a cruzeta de madeira e em (b) mostra uma estrutura padronizada, embora simples, de distribuição de energia elétrica mostrando cada um de seus componentes.
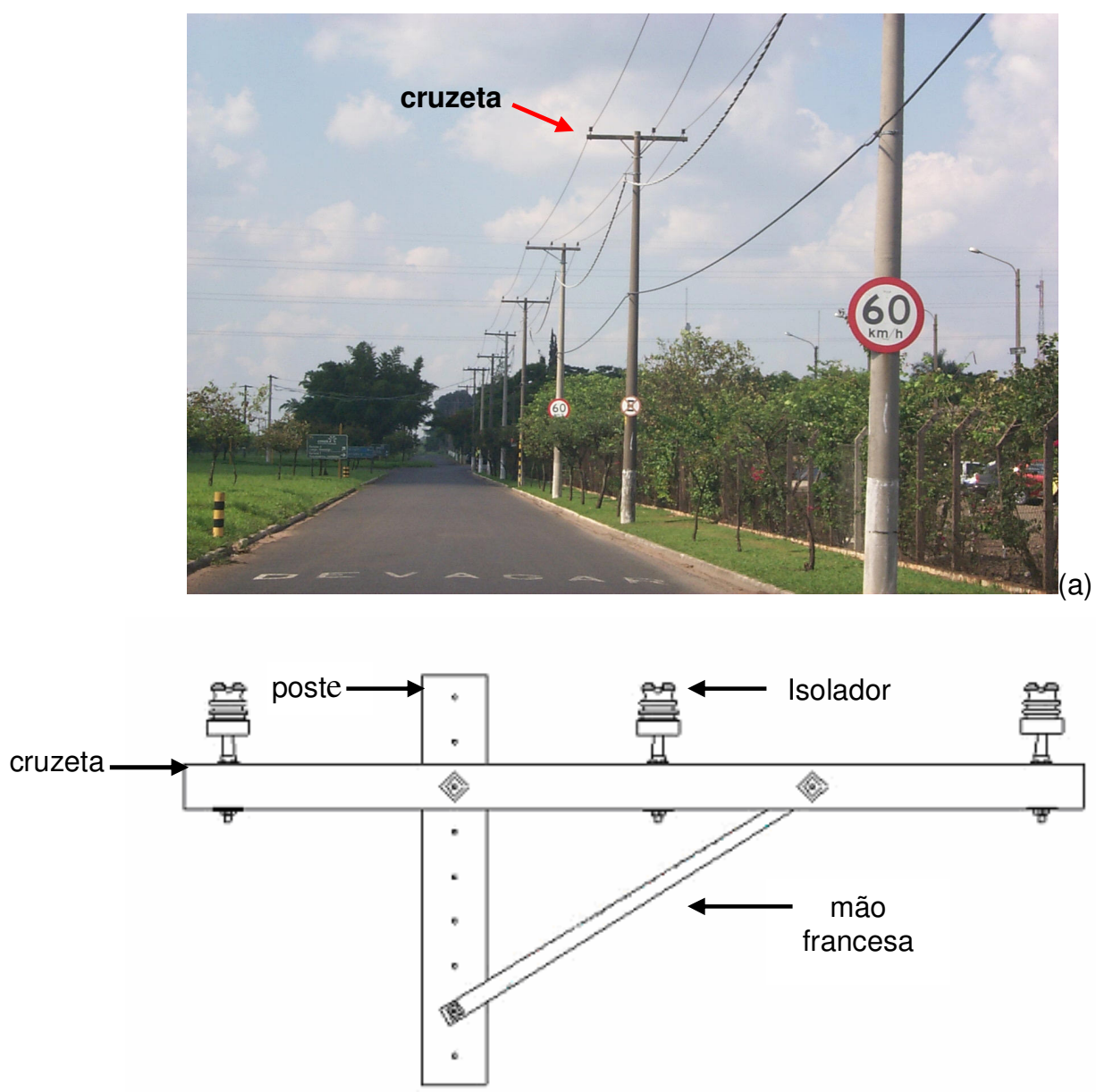

(b)

Figura 3.11 - (a) Rede aérea nua, (b) Estrutura padronizada para redes de distribuição de energia elétrica aérea (SILVA, 2003)

Este trabalho tomará como exemplo para estudo a cruzeta de madeira cujas dimensões e proporções podem ser vistas na figura 3.12. 

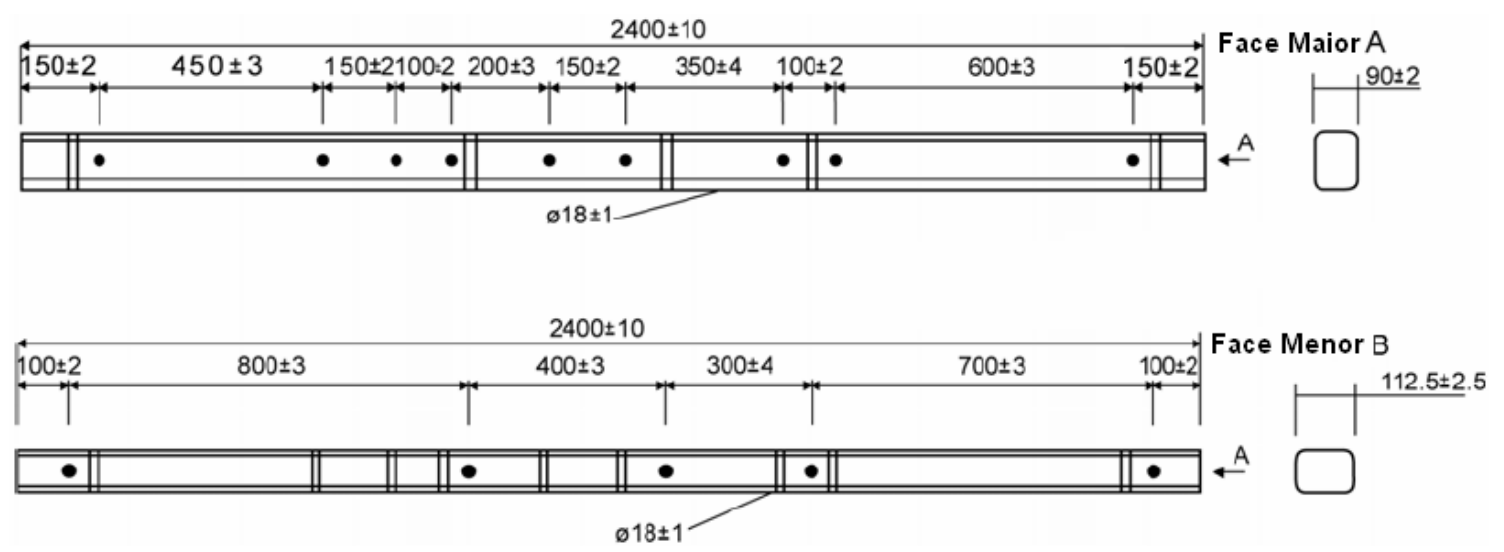

Figura 3.12 - Dimensões em mm da cruzeta de madeira (NBR8459, 1984)

Para que a cruzeta seja aprovada e liberada para uso, é necessário que ela passe por ensaios mecânicos previstos em (NBR8458, 1984), sendo que a cruzeta de 2400 milímetros seja ensaiada nas posições ou faces maior A e menor B.

A madeira é o material mais utilizado para a fabricação de cruzetas por ser de ótima relação resistência específica/densidade, podendo ser manufaturada com certa facilidade além de resistir bem aos esforços aos quais for submetida.

\subsection{Polímeros}

Os polímeros são macromoléculas formadas a partir de unidades estruturais mais pequenas (os monômeros), o número de unidades estruturais repetidas, numa macromolécula é chamado de grau de polimerização. Segundo (FOORT et al., 1984), os polímeros são constituintes básicos de todos os tipos de materiais vivos, sejam animais ou vegetais. Por muitos anos polímeros naturais como a borracha natural e a madeira, tiveram intensa aplicação. Com o aumento da demanda e a 
diversificação das aplicações, foram necessárias substituições desses polímeros naturais por polímeros sintéticos.

Sob o ponto de vista mecânico, os polímeros na sua grande maioria apresentam módulos de elasticidade inferiores aos dos metais. Alguns deles aceitam grande deformação elástica, sendo denominados elastômeros, (VANVLACK, 1970). Complementando essa idéia, (PLARK, 1980) mostra que os polímeros apresentam uma alta capacidade de alongamento antes de sofrerem ruptura e baixos valores de tensão e módulo de elasticidade $E$.

Os polímeros do tipo poliuretanas surgiram em 1937 e alcançaram grande importância durante a segunda Guerra Mundial e tiveram sua produção triplicada na década de 70, como é visto em (PLEPIS, 1991). Elas são obtidas da reação química entre um poliol e um isocianato. Certas poliuretanas possuem características químicas que the conferem biocompatibilidade e resistência, tornando-a um biomaterial de grande aplicabilidade no campo biológico.

A versatilidade das poliuretanas aumenta, a partir do momento que se viabilizam polióis derivados de óleos vegetais como matéria prima industrial, introduzindo soluções alternativas na área tecnológica, promovendo a utilização de novos materiais e novos insumos de grande interesse nacional (ARAUJO, 1992).

Como é mostrado por (VIANNA, 1997), um grupo liderado pelo Prof. Dr. Gilberto Chierice, do Instituto de Química Analítica da Escola de Engenharia de São Carlos da Universidade de São Paulo, iniciou em 1984, as pesquisas para o desenvolvimento de polióis e pré-polímeros derivados do óleo de mamona. O óleo da mamona (Ricinus communis), conhecido como "óleo de rícino", é na verdade um poliéster formado por três moléculas do ácido ricinoleico (ácido 12-hidróxi-oleico, $\mathrm{C}_{18}$ $\mathrm{H}_{34} \mathrm{O}_{3}$ ), cada uma delas com um grupo hidroxila $(-\mathrm{OH})$ livre no carbono 12 , 
adequado para a polimerização por meio das ligações uretanas. Os grupos hidroxila livres reagem com os grupos isocianatos (-NCO) contidas no pré-polímero formado após a reação com o difenilmetanodiisocianato (MDI) formando então poliuretanas.

\subsubsection{Resinas Poliuretanas}

As poliuretanas elastoméricas são materiais que têm destaque entre outros polímeros usados industrialmente, pois são preparados por espécies quimicamente ativas, como pode ser visto em (ARAUJO, 1992), que contêm radicais isiocianatos, que fazem parte de moléculas e compostos orgânicos mono, di, tri e polifuncionais, com polióis funcionalmente ativos, resultando em polímeros com diferentes características e com propriedades superiores.

Desenvolver resinas sintéticas é parte importante na obtenção de novos materiais, pois gera inovação de tecnologia resultando em materiais mais nobres, com alta resistência e mais leves. A versatilidade das poliuretanas, como materiais dedicados a diferentes ramos de aplicação industrial, ganha maior valor quando se faz uso de óleos vegetais como matéria-prima, principalmente se essa matéria prima é nacional.

Os aspectos que envolvem o controle da qualidade do desenvolvimento dessas resinas são:

- Funções de uso, 
- Condições de processamento e aplicação, e

- Qualidade de matéria prima e insumos.

Podemos citar fatores vantajosos no uso dessas resinas como:

- Economia,

- Tempo máximo e mínimo de processamento,

- Endurecimento e cura,

- Tensões superficiais,

- Endurecimento e penetração capilar.

Segundo (VIANNA, 1997), as características físicas e químicas dessas poliuretanas podem ser alteradas pela combinação em proporções diferentes do poliol e do pré-polímero, ou alterando-se o tipo do poliol e do pré-polímero. Sendo assim, as poliuretanas derivadas do óleo de mamona também podem ser obtidas em diferentes texturas, desde as mais flexíveis, como a dos elastômeros, até as mais rígidas, como a dos cimentos ósseos.

Para os propósitos do presente estudo, a composição ideal da poliuretana é o elastômero modelo, material já utilizado na confecção de isoladores á base de resina de óleo de mamona. Tal composição foi obtida com o emprego do óleo da mamona purificado difenilmetanodiisocianato, ou pré-polímero e do poliol na proporção de $1: 1,5$ respectivamente.

\subsubsection{Características Mecânicas da Resina Poliuretana Derivada do Óleo de Mamona RI3}


As resinas poliuretanas são caracterizadas por sua densidade e por suas propriedades mecânicas básicas, sendo consideradas um material isotrópico, pois possuem infinitos planos de simetria passando por um ponto dentro de sua estrutura, o que faz com que dentre as propriedades mecânicas destacarem-se a deformação elástica, a tensão de ruptura, o tempo de cura, os módulos de elasticidade, de flexão e compressão.

Entretanto, neste momento do trabalho serão usados, na caracterização da resina poliuretana à base de óleo de mamona tipo RI 3 pura, apenas o módulo de Elasticidade ( $E$ ) e o coeficiente de Poisson (v). Neste caso, foi adotado o valor de 0,38 para o coeficiente de Poisson segundo (SILVESTRE FILHO et. al., 2001), na representação mecânica da resina. Lembrando que para realizar a caracterização mecânica de RI3, baseou-se em (AMERICAN SOCYETY OF TESTING AND MATERIALS, 2003).

A primeira fase de ensaios de tração recebeu o nome de PE16, os quais foram realizados no Laboratório de Geosintéticos do Departamento de Geotecnia da Universidade de São Paulo, Campus São Carlos no dia 16 de julho de 2004. Neste dia foram ensaiados quatorze corpos de prova que, foram confeccionados no Laboratório de Alta Tensão do Departamento de Engenharia Elétrica da Escola de Engenharia de São Carlos da Universidade de São Paulo.

Os quatorze corpos de prova se dividem em três grupos, $A, B$ e $C$, classificados pelos tempos de cura, vistos na tabela 3.

Tabela 3 - Grupos dos corpos de prova separados por tempo de cura Grupo Corpos de prova Tempo de cura (horas)

\begin{tabular}{|c|c|c|}
\hline$A$ & 5 & 72 \\
\hline B & 5 & 96 \\
\hline$C^{*}$ & 4 & 120 \\
\hline
\end{tabular}


mostrado aqui pela sua representatividade.

A seguir são mostrados os procedimentos de preparação dos ensaios na fase 1

1. Confecção dos corpos de prova do tipo 1:

- Foi usada uma placa de vidro, por possuir uma superfície plana, no tamanho $400 \times 178 \mathrm{~mm}$, para servir de forma para ser despejada a resina $\mathrm{RI}$, ainda em estado líquido visando atingir a espessura esperada de $3 \mathrm{~mm}$.

- Depois depositado dentro de um recipiente plástico $140 \mathrm{~g}$ do prépolímero e $210 \mathrm{~g}$ do poliol, totalizando a mistura $350 \mathrm{~g}$ atendendo a relação de 1:1,5.

- Em seguida como auxílio do conjunto de misturador em câmara de vácuo MARCONI®, figura 3.13 , foi feita a mistura do pré-polímero mais o poliol, sobre um vácuo de $-685 \mathrm{~mm} \mathrm{Hg}$, por 4 minutos em seguida mais 2 minutos com somente vácuo. 


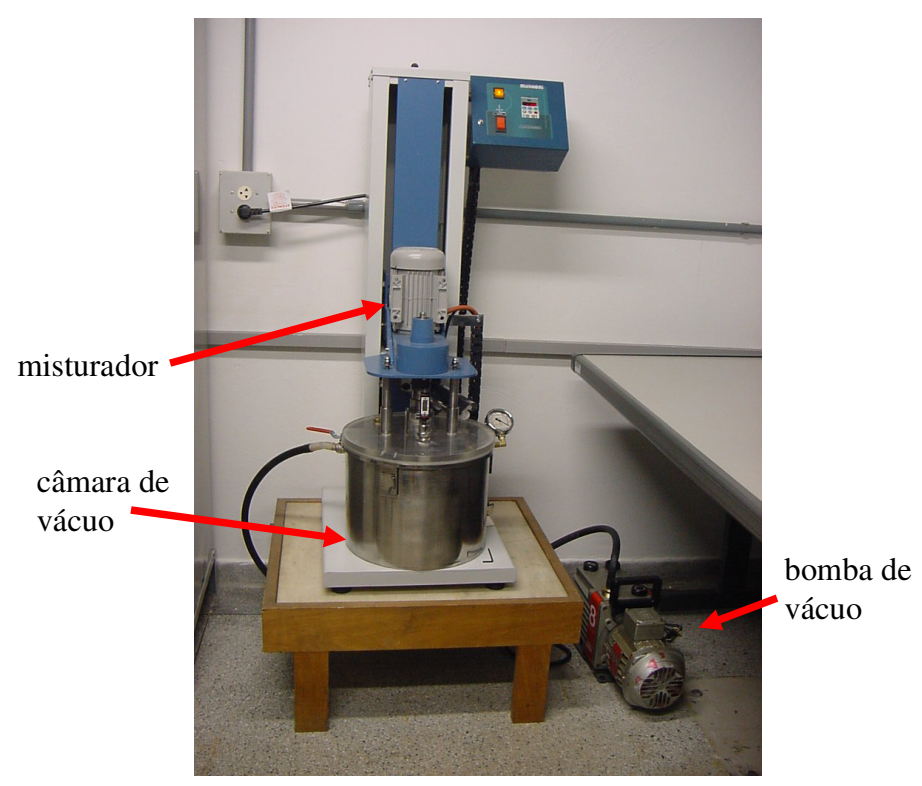

Figura 3.13 - conjunto de misturador em câmara de vácuo MARCONI®

- Despejar a resina sobre a forma de vidro até o nível desejado, colocar outra placa de vidro em cima e deixar em superfície plana e nivelada por 24 horas.

- Foi confeccionado um estampo para o corte dos corpos de prova do tipo 1, segundo (ASTM), (2003, D638-01).

- Após as 24 horas retirar da forma e cortar no mínimo cinco corpos de prova com auxílio de uma prensa hidráulica.

- O equipamento usado para o ensaio foi uma máquina universal de tração, EMIC® DL-3000 com capacidade máxima de $30 \mathrm{kN}$, com célula de tração de até $20 \mathrm{kN}$ ou $2000 \mathrm{~kg}$.

- Os corpos de prova foram presos nas garras pneumáticas com fixação de 1 pol $^{2}$, e tracionados a uma velocidade de $50 \mathrm{~mm} / \mathrm{minuto}$, figura 3.14 . 


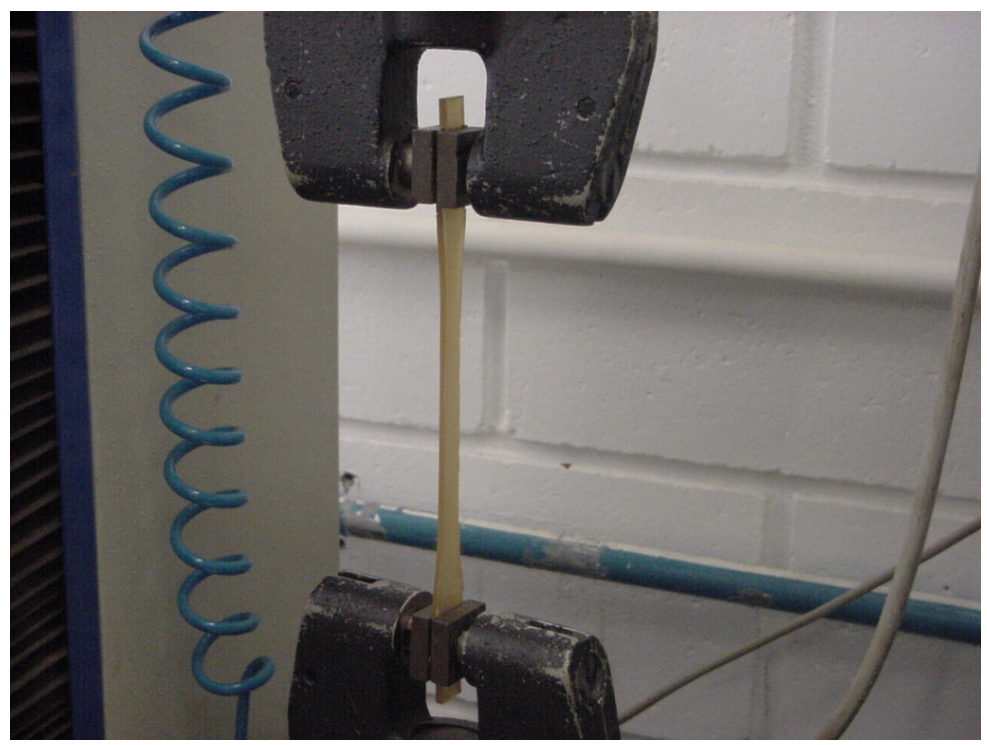

Figura 3.14 - Corpo de prova da resina RI3 sofrendo o ensaio de tração

Aqui cabe citar que os corpos de prova foram acondicionados à temperatura e umidade ambientes $23^{\circ}$ e $65 \%$, respectivamente, durante o tempo de cura esperado da resina $\mathrm{RI} 3$.

A média dos resultados do ensaio PE16 pode ser visualizada na tabela 4.

Tabela 4 - Média dos resultados dos ensaios de tração PE16 * ensaio com apenas 4 corpos de prova

\begin{tabular}{|c|c|c|c|c|c|}
\hline $\begin{array}{c}\text { Dia } \\
\text { 16/06/2004 } \\
\text { Ensaios }\end{array}$ & $\begin{array}{c}\text { Força } \\
\text { (N) }\end{array}$ & $\begin{array}{c}\text { Força por } \\
\text { Largura } \\
(\mathrm{N} / \mathrm{mm})\end{array}$ & $\begin{array}{c}\text { Deformação } \\
\text { Específica } \\
(\%)\end{array}$ & $\begin{array}{c}\text { Tensão } \\
\text { (MPa) }\end{array}$ & $\begin{array}{c}\text { Módulo de } \\
\text { Elasticidade } \\
\text { (MPa) }\end{array}$ \\
\hline A (72hs) & 81,45 & 14,51 & 180,00 & 5,22 & 4,21 \\
\hline B (96hs) & 94,42 & 16,62 & 149,10 & 6,25 & 7,66 \\
\hline${ }^{*} \mathrm{C}$ (120hs) & 106,00 & 18,98 & 127,30 & 6,73 & 13,75 \\
\hline
\end{tabular}

Fica evidente que à medida que se ensaiaram corpos de prova com tempo de cura maior, maior foi o módulo de elasticidade obtido. Em trabalhos futuros propõese a realização de ensaios que permitam obter um possível limite em tal parâmetro em função do tempo de cura. 
A segunda fase de ensaios de tração recebeu o nome de SEO, os quais foram realizados no Departamento de Engenharia de Materiais da Universidade Federal de São Carlos em outubro de 2004.

Nesta fase foram ensaiados seis corpos de prova, que foram confeccionados no Laboratório de Alta Tensão no Departamento de Engenharia Elétrica da Escola de Engenharia de São Carlos na Universidade de São Paulo, cerca de noventa dias antes. Totalizando por volta de 2160 horas de tempo de cura da resina RI3 pura.

Esta outra técnica de confecção de corpos de prova, neste caso, só permitiu que fosse feito um corpo de prova por vez. A seguir são mostrados os procedimentos de preparação usando essa outra técnica:

2. Outro tipo de confecção dos corpos de prova para a fase 2

- Neste caso utilizou-se um molde de silicone, já no formato do corpo de prova do tipo 1, que foi preenchido com a resina ainda líquida.

- Esse processo economizou muito mais resina, pois quase não existiu desperdício, pois apenas $10 \mathrm{~g}$ do pré-polímero e $15 \mathrm{~g}(1: 1,5)$ do poliol, foram misturados manualmente em um recipiente plástico.

- Em seguida, com o auxílio do conjunto de misturador em câmara de vácuo MARCONI®, figura 3.13 , foi feito o vácuo de $-685 \mathrm{~mm} \mathrm{Hg}$, por 4 minutos.

- A seguir, o molde foi preenchido com a resina RI3 ainda líquida e colocado por mais 2 minutos somente sob vácuo.

- Depois desta etapa a resina e o molde foram deixados em superfície plana e nivelada por 24 horas. Como só existia um molde disponível, só foi possível fazer um corpo de prova por vez. 
- Os ensaios foram realizados, em uma máquina universal de tração INSTRON® de $50 \mathrm{kN}$ e célula tração de até $20 \mathrm{kN}$.

- Os corpos de prova foram presos nas garras pneumáticas com fixação de 1 pol $^{2}$, e tracionados a uma velocidade de $50 \mathrm{~mm} /$ minuto.

Os resultados completos do SEO estão disponíveis na tabela 5 e representados no gráfico da figura 3.15.

Tabela 5 - Resultados dos ensaios de tração SEO

\begin{tabular}{ccccc}
\hline $\begin{array}{c}\text { Dia 9/08/2004 } \\
\text { Corpos de } \\
\text { prova números }\end{array}$ & $\begin{array}{c}\text { Força } \\
\mathbf{( N )}\end{array}$ & $\begin{array}{c}\text { Deformação } \\
\text { Específica } \\
\mathbf{( \% )}\end{array}$ & $\begin{array}{c}\text { Tensão } \\
\text { (Mpa) }\end{array}$ & $\begin{array}{c}\text { Módulo de } \\
\text { Elasticidade } \\
\text { (Mpa) }\end{array}$ \\
\hline 1 & 396,68 & 34,66 & 9,55 & $\mathbf{1 8 8 , 1 9}$ \\
2 & 482,59 & 34,62 & 12,90 & $\mathbf{3 6 0 , 9 9}$ \\
3 & 437,58 & 31,55 & 10,07 & $\mathbf{2 4 3 , 2 6}$ \\
4 & 420,72 & 35,68 & 11,44 & $\mathbf{3 2 3 , 0 2}$ \\
5 & 515,48 & 45,67 & 15,67 & $\mathbf{4 3 2 , 3 7}$ \\
6 & 482,89 & 31,45 & 11,81 & $\mathbf{3 6 2 , 2 9}$ \\
média & 455,89 & 35,61 & 11,91 & $\mathbf{3 1 8 , 3 5}$ \\
\hline
\end{tabular}




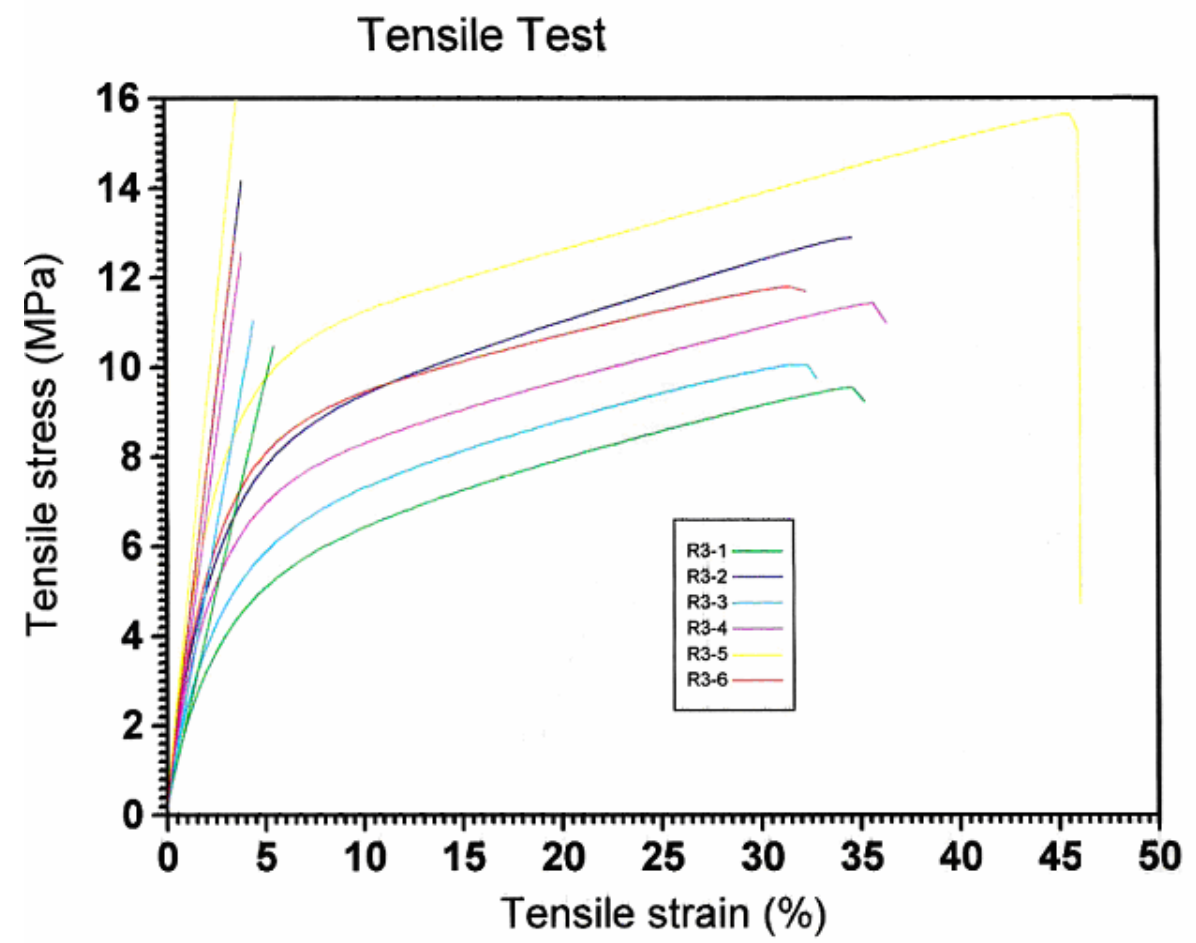

Figura 3.15 - Curvas dos resultados dos ensaios de tração SEO, imagem gerada pelo próprio software de leitura de dados do equipamento utilizado no ensaio.

Podemos novamente observar nos ensaios para a caracterização da resina RI3 pura, que seus módulos de elasticidade aumentam com o tempo de cura. 


\section{Capítulo 4}

\section{Método Proposto}

Este trabalho propõe uma metodologia para a busca de um modelo de simulação computacional capaz de representar a deformação sofrida por cruzetas de madeira, frente aos ensaios definidos pela norma (NBR8458,1984).

O ensaio de flexão consiste em submeter a cruzeta aos esforços definidos na tabela 6 sobre as áreas mostradas na figura 4.1 sobre a face maior $\mathrm{A}$ e a face menor B das cruzetas de madeira Pinus elliotti e Eucalyptus citriodora.

Tabela 6 - Forças aplicadas nos ensaios de flexão(NBR8458, 1984)

\begin{tabular}{|c|c|c|c|c|c|}
\hline Comprimento & Ensaio & Descrição do & Força & Flech & a (mm) \\
\hline$(\mathrm{mm})$ & conforme & carregamento & $(\mathrm{kN})$ & Máxima & Residual \\
\hline \multirow{2}{*}{2400} & \multirow{2}{*}{ Figura 4.1} & Normal & 3,92 & 115 & 5 \\
\hline & & Máximo & 5,49 & 163 & 8 \\
\hline
\end{tabular}




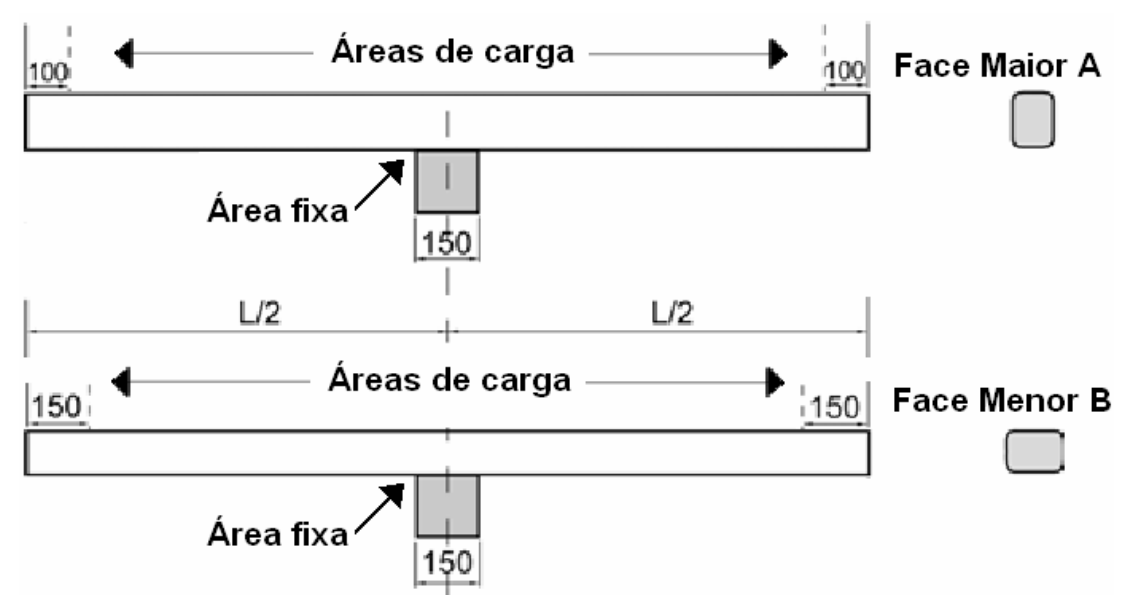

Figura 4.1 - Áreas de carga das cruzetas (ALTAFIM el. al., 2004b) dimensões em $\mathrm{mm}$

Utilizou-se um software para a simulação pelo Método dos Elementos Finitos, que é bastante utilizado para esse tipo de aplicação no meio científico e também comercial.

Levou-se em consideração na escolha do software, o fato dele já ser disponível para o uso para uso e, ensino e pesquisa no Departamento de Engenharia Mecânica da EESC-USP.

A seqüência dos principais passos seguidos como metodologia de pesquisa são mostrados no diagrama que consta da figura 4.2. 


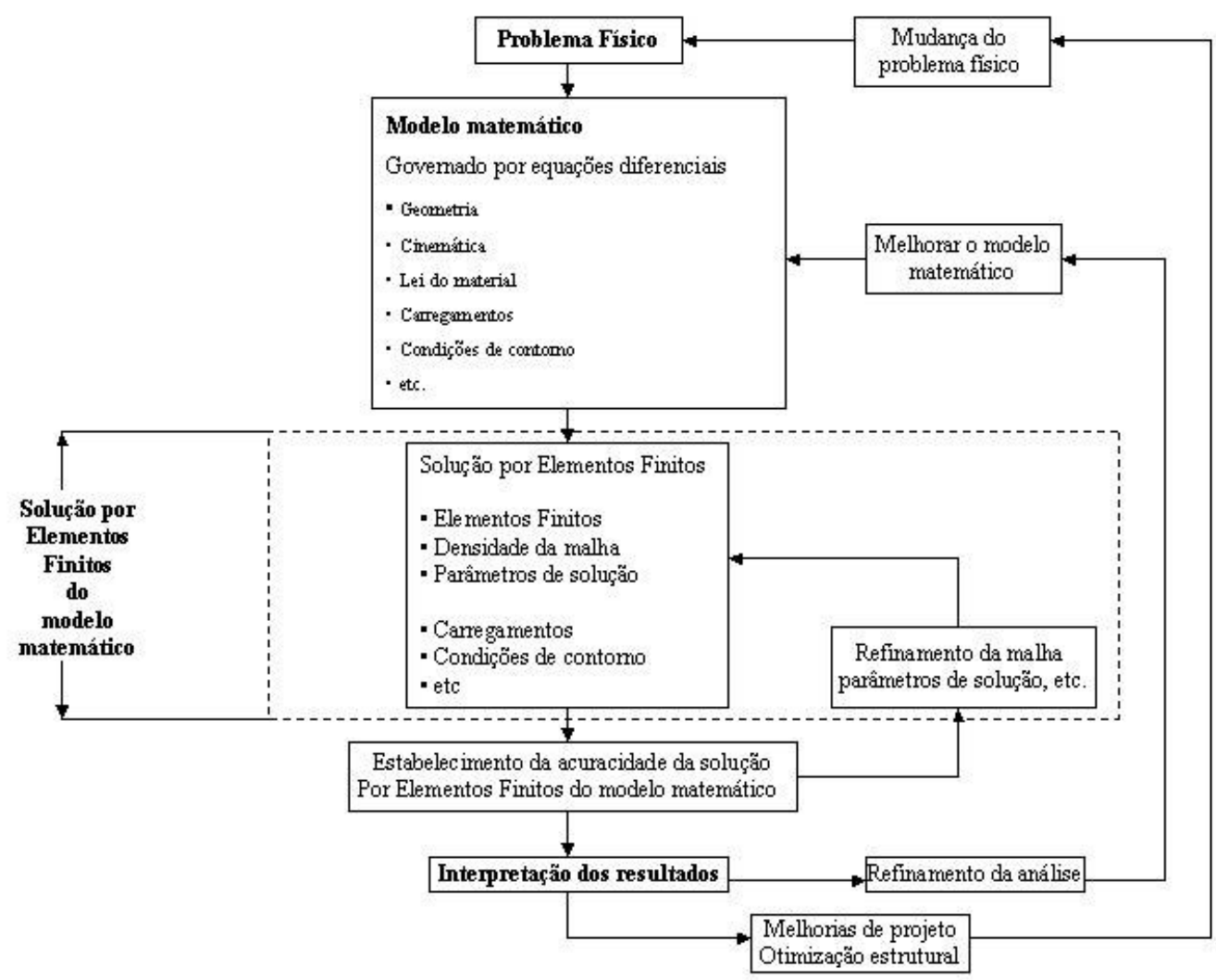

Figura 4.2 - Diagrama do processo de análise por Elementos Finitos (BATHE, 1996).

\subsection{Método dos Elementos Finitos}

Grande parte dos problemas de engenharia pode ser formulada através dos princípios gerais da mecânica do contínuo (MALVERN, 1969) e (LAI, RUBIN e KREMPL, 1993). Este ramo da mecânica trata a matéria como sendo um meio contínuo, sem vazios interiores, desconsiderando uma estrutura molecular. 
O conceito de contínuo permite a definição do ponto geométrico, de volume igual a zero, por um limite matemático tal como a definição de derivadas no cálculo diferencial. Assim, na mecânica do contínuo os princípios da física são descritos sob a forma de equações diferenciais. Os efeitos da constituição interna molecular dos materiais são levados em conta de forma macroscópica através de equações constitutivas do material.

A primeira fase no processo de modelagem computacional de um fenômeno físico consiste na identificação de fatores que influenciam de maneira relevante o problema. Isto implica a escolha adequada dos princípios físicos e das variáveis dependentes e independentes que descrevem o problema, resultando em um modelo matemático constituído por um conjunto de equações diferenciais.

A segunda fase do processo consiste em obter a solução do modelo matemático, tarefa esta atribuída aos métodos numéricos. O Método dos Elementos Finitos (MEF) é um deles, e é o que será usado neste trabalho.

As bases teóricas do MEF remetem ao Cálculo Variacional, considerando fortemente a análise de minimização de funcionais, os quais são relacionados à energia quando se tratam de sistemas físicos, como é visto em (SILVESTER; CHARI, 1970) e (SILVESTER; FERRARI, 1990).

O MEF teve suas utilizações originais na análise estrutural e com 0 surgimento dos primeiros computadores digitais no início da década de 50, como cita (CARDOSO, 2000), assim os métodos matriciais para a análise estrutural tiveram um grande desenvolvimento.

As primeiras aplicações envolviam apenas estruturas reticuladas, mas a crescente demanda por estruturas mais leves, tais como as encontradas na indústria 
aeronáutica e automobilística, conduziram ao desenvolvimento de métodos numéricos que pudessem ser utilizados na análise de problemas mais complexos.

Entre os trabalhos pioneiros nesta linha, podem-se citar os trabalhos de (THURNEL et al., 1956) e (ARGYRIS; KELSEY, 1960), segundo (ZIENKIEWICZ, 1970), que apresentam uma descrição mais detalhada do MEF nesta fase inicial.

O trabalho que marcou a aplicação do MEF na engenharia elétrica é creditado a (SILVESTER; CHARI, 1970). A partir de então, uma série de pesquisadores dedicou esforços no sentido de aplicá-lo na resolução dos maiores problemas de engenharia elétrica, que é o cálculo de campos eletromagnéticos presentes nos dispositivos e sistemas elétricos.

Na década de 70 o MEF teve suas aplicações estendidas a problemas de mecânica dos fluidos e, desde então, vem consolidando-se como um método mais geral de solução de equações diferenciais parciais espaciais. Todo o embasamento matemático deste método vem da utilização dos conceitos da análise de funcionais (RUDIN,1976), (KOLMOGOROV; FOMIN, 1982) e (REKTORYS, 1977).

Segundo (CARDOSO, 2000), o MEF vem se consagrando, há alguns anos como uma das mais poderosas ferramentas utilizadas na determinação das distribuições de campos eletromagnéticos em dispositivos e sistemas elétricos.

Sua popularização no meio científico e industrial nacional ocorreu na década de 80 , com a redução dos custos das estações de trabalho de alto desempenho e do desenvolvimento acelerado dos microcomputadores.

No Brasil o primeiro trabalho sobre a aplicação deste método na engenharia elétrica foi o desenvolvido na Escola Politécnica da Universidade de São Paulo EPUSP, como é visto em (JANISZEWSKI, 1978). A partir de então surgiram grupos de pesquisas em universidades brasileiras, destacando-se o Grupo de Concepção e 
Análise de Dispositivos Eletromagnéticos - GRUCAD da Universidade Federal de Santa Catarina, o Grupo de pesquisas da Universidade Federal de Minas Gerais e a Equipe de Simulação de Fenômenos Eletromagnéticos da Escola Politécnica da Universidade de São Paulo.

Simultaneamente ao aparecimento destes grupos, uma série de empresas do setor elétrico, impulsionadas pela exigência de qualidade em seus produtos e pela exigência de redução de custos de produção, começou a implementar em seus setores de pesquisa e desenvolvimento estas ferramentas computacionais, com o objetivo de atingir um grau de precisão superior em seus projetos.

Observa-se nos dias de hoje uma constante tendência no parque industrial nacional, bem como nas empresas geradoras de energia elétrica e concessionárias, à utilização de programas computacionais, com tecnologia Computer Aided Design / Computer Aided Engineering (CAD/CAE), baseados no MEF, para análise do desempenho dos mais diversos componentes elétricos tais como: motores/geradores elétricos, transformadores, linhas de transmissão, cruzetas, sistemas de aterramento, atuadores eletromagnéticos, cabos elétricos e etc.

As universidades brasileiras, a exemplo do que ocorreu nas universidades dos países desenvolvidos, foram as responsáveis pelo lançamento no mercado nacional dos primeiros produtos, como foi citado acima, visando atender às necessidades da comunidade acadêmica, no sentido de suprir as pesquisas neste setor, bem como assessorar o setor industrial em suas necessidades de estudos e projetos.

Desta forma surgiram os softwares: EFCAD, desenvolvido pelo GRUCAD da UFSC, o LMAG-2D e o GROUND-3D, desenvolvidos pela equipe de simulação de 
Fenômenos Eletromagnéticos da EPUSP, bastante difundidos no setor acadêmico e industrial brasileiro.

O software escolhido para este trabalho já é comercialmente difundido e também nos centros de pesquisa como na Escola de Engenharia de São Carlos EESC: O Advanced Engineering Simulation ou ANSYS $\AA_{\text {, }}$, que utiliza o MEF para a resolução de problemas envolvendo campos magnéticos ou elétricos, transmissão de calor, análise de comportamento de fluidos, análise mecânica, entre outras.

Para se utilizar pacotes de programas computacionais baseados no MEF é necessário seguir alguns procedimentos de entrada de informações, pois como todo método de simulação é necessário conhecer o software para não cometer erros de inserção de dados ou valores. Do mesmo modo, é importante saber interpretar as informações de resposta mostradas pelo software escolhido para realização da análise.

Este método, ainda nos dias de hoje, exige muita memória dos computadores, chegando a utilizar toda a capacidade de processamento e memória disponíveis no hardware, o que exige uma certa demanda de tempo no processamento do problema proposto.

Cabe ao usuário conhecer e interpretar o problema para construir um modelo representativo capaz de fornecer o resultado esperado dentro de um tempo coerente de processamento.

O MEF em geral é dividido em três fases de processamento, como é visto em (ATIQUE, 2001) que são: 
1. Pré-processamento;

Esta fase é reservada para a entrada de informações, grandezas, dados, escolha do elemento, escolha do tipo de material, construção da geometria, criação da malha de elementos, valores envolvidos em termos de condições de contorno, excitações e tipo de simulações a serem realizadas.

2. Processamento;

Reservado ao esforço computacional na resolução do problema.

3. Pós-Processamento.

Destinado à análise das respostas fornecidas depois que houver terminado o processamento, captura de informações, imagens e tabelas com valores esperados.

Maiores informações sobre o MEF podem ser encontradas em (SILVESTRE, 2001), (CARDOSO, 2000) e (SILVESTER; CHARI, 1970).

As simulações foram feitas utilizando dois elementos para análise mecânica: uma para análise estrutural de sólidos em três dimensões (SOLID45) e outro para análise elástica de casca (SHELL63), mais detalhes sobre os elementos são encontrados em (ANSYS, 1995).

No Apêndice B é realizada uma descrição detalhada dos procedimentos envolvidos no uso do ANSYS®. 


\subsection{Entrada de Dados}

A nomenclatura usada para os eixos do programa ANSYS® é a dos eixos cartesianos $(X, Y, Z)$, assim é necessário reescreverem-se os eixos de simetria elástica $S=(L, R, T)$. Substituindo esses valores subscritos na equação 3.27 temos a representação para a madeira:

$$
S_{i j}=\left[\begin{array}{cccccc}
\frac{1}{E_{X}} & -\frac{v_{Y X}}{E_{Y}} & -\frac{v_{Z X}}{E_{Z}} & 0 & 0 & 0 \\
-\frac{v_{X Y}}{E_{X}} & \frac{1}{E_{Y}} & -\frac{v_{Z Y}}{E_{Z}} & 0 & 0 & 0 \\
-\frac{v_{X Z}}{E_{X}} & -\frac{v_{Y Z}}{E_{Y}} & \frac{1}{E_{Z}} & 0 & 0 & 0 \\
0 & 0 & 0 & \frac{1}{G_{X Y}} & 0 & 0 \\
0 & 0 & 0 & 0 & \frac{1}{G_{Y Z}} & 0 \\
0 & 0 & 0 & 0 & 0 & \frac{1}{G_{Z X}}
\end{array}\right]
$$

Dessa forma, é possível entender melhor como serão adicionadas as características dos materiais com representação ortotrópica, ou seja, as madeiras.

A primeira representação para o Eucalyptus citriodora e o Pinus elliotti utilizada foi baseada em (NBR7190, 1997) e (FURLANI, 1995) mostrada nas tabela 7.

Tabela 7 - Valores dos coeficientes ortotrópicos das madeiras (baseado na tabela 2)

\begin{tabular}{cccccccccc}
\hline Madeira & $E_{X}(\mathrm{MPa})$ & $E_{Y}(\mathrm{MPa})$ & $E_{Z}(\mathrm{MPa})$ & $v_{X Y}$ & $v_{Y Z}$ & $v_{X Z}$ & $G_{X Y}(\mathrm{MPa})$ & $G_{Y Z}(\mathrm{MPa})$ & $G_{X Z}(\mathrm{MPa})$ \\
\hline $\begin{array}{c}\text { Eucalyptus } \\
\text { citriodora }\end{array}$ & 18421 & 921,05 & 921,05 & 0,37 & 0,63 & 0,33 & 6447,35 & 6447,35 & 6447,35 \\
$\begin{array}{c}\text { Pinus } \\
\text { elliotti }\end{array}$ & 11889 & 594,45 & 594,45 & 0,37 & 0,63 & 0,33 & 4161,15 & 4161,15 & 4161,15 \\
\hline
\end{tabular}


Fazendo, então, uso desses dados, foram realizadas as simulações do ensaio previsto em (NBR8458,1984), para as cruzetas onde a malha dos elementos foi devidamente mapeada com 3840 elementos, para melhor desempenho computacional, o que economizou tempo e esforço computacional sem perder sua representatividade.

Em destaque nas tabelas 8 e 9 a seguir estão os resultados obtidos neste trabalho através das simulações computacionais.

Tabela 8- Comparação dos resultados reais e simulados para Eucalyptus citriodora. (ALTAFIM et al., 2004a)

\begin{tabular}{ccccc}
\hline Cruzeta de 2,4 m & Face A 400 kgf & Face B 400 kgf & Face A 560 kgf & Face B 560 kgf \\
\hline $\begin{array}{c}\text { Deslocamento real } \\
(\mathrm{mm})\end{array}$ & 5,73 & 7,95 & 8,12 & 11,08 \\
$\begin{array}{c}\text { Deslocamento } \\
\text { simulado }(\mathrm{mm})\end{array}$ & $\mathbf{9 , 8 5}$ & $\mathbf{1 4 , 8 1}$ & $\mathbf{1 3 , 8 0}$ & $\mathbf{2 0 , 7 3}$ \\
\hline
\end{tabular}

Tabela 9 - Comparação dos resultados reais e simulados para Pinus elliotti. (ALTAFIM et al., 2004a)

\begin{tabular}{ccccc}
\multicolumn{5}{c}{ Pinus elliotti. (ALTAFIM et al., 2004a) } \\
\hline $\begin{array}{c}\text { Cruzeta de 2,4 m } \\
\begin{array}{c}\text { Deslocamento real } \\
(\mathrm{mm})\end{array}\end{array}$ & Face A 400 kgf & Face B 400 kgf & Face A 560 kgf & Face B 560 kgf \\
$\begin{array}{c}\text { Deslocamento } \\
\text { simulado (mm) }\end{array}$ & $\mathbf{1 5 , 2 7}$ & 24,30 & 25,14 & 33,63 \\
\hline
\end{tabular}

Alguns resultados deste trabalho contribuíram com (ALTAFIM et al. 2004a).

É perceptível que os resultados das simulações foram melhores para a madeira Pinus elliotti do que para a Eucalyptus citriodora. Este fato demonstra claramente que existe uma influência dos parâmetros adotados na simulação para cada uma das madeiras ensaiadas. No caso do Eucalyptus citriodora, as peças ensaiadas que deveriam estar ao natural, estavam impregnadas com óleo, possivelmente para proteção contra ataques de fungos ou insetos. 
Segundo (STOLF, 2000), essas impregnações aumentam a resistência mecânica das madeiras.

\subsection{Abordagem Numérica}

A abordagem numérica usada para representar as madeiras na simulação das cruzetas, apenas usando o elemento sólido, como mostrado no item anterior, mostrou ter boa representatividade sendo inclusive apresentado em (ALTAFIM et.al., 2004a).

Agora, como segundo passo, este trabalho quer estabelecer alguns caminhos na busca do modelo de representação da interação que ocorre entre a camada e resina que foi impregnada nas as cruzetas e a malha, conforme mostrado em (ALTAFIM et al., 2004a).

Para buscar a melhor representatividade do modelo da simulação das cruzetas é necessário fazer algumas considerações :

- Encontrar o número ótimo de elementos necessários para que a malha gerada para o modelo da cruzeta tenha resultado representativo.

- Definir a representatividade dos modelos simulados, o modelo com os furos ou o modelo sem os furos da cruzeta para escolher àquele que otimize o processo de simulação.

- Desenvolver um modelo com alto grau de refinamento da malha para simulação. 
- Fazer a simulação para as madeiras Eucalyptus citriodora e Pinus elliotti para as forças nominal e máxima,

Os itens a seguir são de muita importância:

- Considerando que a força aplicada às cruzetas impregnadas com resina poliuretana derivada do óleo de mamona, no ensaio de flexão é 3,92 kN, para o carregamento normal, e 5,49 kN para o carregamento máximo. O resultado do ensaio de flexão será somente influenciado pelo produto da profundidade de penetração $\boldsymbol{P}$ com o módulo de elasticidade $\boldsymbol{E}$ do material compósito madeira/resina.

- (ALTAFIM et al., 2004) usou o pincelamento para fazer a impregnação da resina poliuretana derivada do óleo de mamona nas cruzetas de madeira. Por não saber exatamente qual é a profundidade real $\boldsymbol{P}$ de penetração da resina na madeira e por não ser possível neste trabalho determinar exatamente qual é este valor, este trabalho atribuiu arbitrariamente três valores para $\boldsymbol{P}$ : sendo $1,00 \mathrm{~mm}, 0,50 \mathrm{~mm}$ e $0,25 \mathrm{~mm}$. Lembrando que estes são valores estimados e não valores reais.

- O Valor do módulo de Elasticidade $\boldsymbol{E}$ da camada formada por material compósito madeira/resina foi variado de entre 65 e 270 GPa, para os valores de $\boldsymbol{P}$ com o intuito de encontrar o módulo que 
pudesse resultar num menor erro para o modelo de simulação proposto.

\subsubsection{Número ótimo de elementos da malha}

A simulação do modelo construído no $A N S Y S \circledR$ tem sua resposta variando em função do número de elementos contidos no modelo, e quanto maior é o número de elementos, maior é a tendência do resultado convergir para o valor final correto.

Simulações realizadas com esse intuito mostram que para o caso da simulação de resistência à flexão das cruzetas não existiu variação significativa dos resultados em função do número de elementos, como mostra a tabelas 10 e 11.

Tabela 10 - Valores dos deslocamentos para Pinus elliotti

\begin{tabular}{|c|c|c|c|c|}
\hline Madeira & Força (kN) & Face & № de Elementos & Deslocamento $(\mathrm{mm})$ \\
\hline \multirow{13}{*}{ Pinus elliotti } & \multirow{7}{*}{3,92} & \multirow{4}{*}{$A$} & 896 & 15,311 \\
\hline & & & 1568 & 15,08 \\
\hline & & & 6272 & 15,082 \\
\hline & & & 15680 & 15,266 \\
\hline & & \multirow{3}{*}{ B } & 896 & 22,508 \\
\hline & & & 1568 & 22,543 \\
\hline & & & 6272 & 22,547 \\
\hline & \multirow{6}{*}{5,49} & \multirow{3}{*}{ A } & 896 & 21,027 \\
\hline & & & 1568 & 21,105 \\
\hline & & & 6272 & 21,109 \\
\hline & & \multirow{3}{*}{$B$} & 896 & 31,422 \\
\hline & & & 1568 & 31,551 \\
\hline & & & 6272 & 31,556 \\
\hline
\end{tabular}


Tabela 11 - Valores dos deslocamentos para Eucalyptus citriodora

\begin{tabular}{ccccc}
\hline Madeira & Força (kN) & Face & № de Elementos & Deslocamento (mm) \\
\hline & & & 896 & 9,82 \\
& & $\mathrm{~A}$ & 1568 & 9,728 \\
& \multirow{3}{*}{3,92} & & 6272 & 9,73 \\
\cline { 3 - 4 } & & & 896 & 14,485 \\
& $\mathrm{~B}$ & 1568 & 14,454 \\
& & 6272 & 14,547 \\
\cline { 3 - 4 } & & & 896 & 13,457 \\
& $\mathrm{~A}$ & 1568 & 13,616 \\
& & 6272 & 13,618 \\
& & & 896 & 20,273 \\
& & & 1568 & 20,356 \\
& & & 6272 & 20,36 \\
\hline
\end{tabular}

Assim, conclui-se que, neste trabalho, qualquer que seja o número de elementos de malha da cruzeta maior ou igual e 896 elementos, o modelo não apresenta grandes variações em seus resultados.

\subsubsection{Enriquecendo o Modelo}

Foram realizadas simulações no $A N S Y S \circledast$ para modelos da cruzeta com e sem os orifícios existentes na cruzeta real, para que fosse possível avaliar qual das malhas de elementos geradas tem melhor representatividade de resultados.

O ANSYS® tem como processo de criação primeiramente o desenho do modelo gerado com o auxílio de suas ferramentas de 
desenho, e em seguida ainda no pré-processamento existe a opção de se criar as malas de maneira livre ou mapeada.

A malha criada de maneira livre, como o próprio nome diz, é gerada automaticamente pelo software e a única intervenção que o usuário pode fazer é definir o tamanho dos elementos que farão parte da malha, logo quanto menor for o tamanho do elemento, maior será o número de elementos gerados para o modelo. A figura 4.3 mostra a variação dessas malhas geradas de maneira livre.
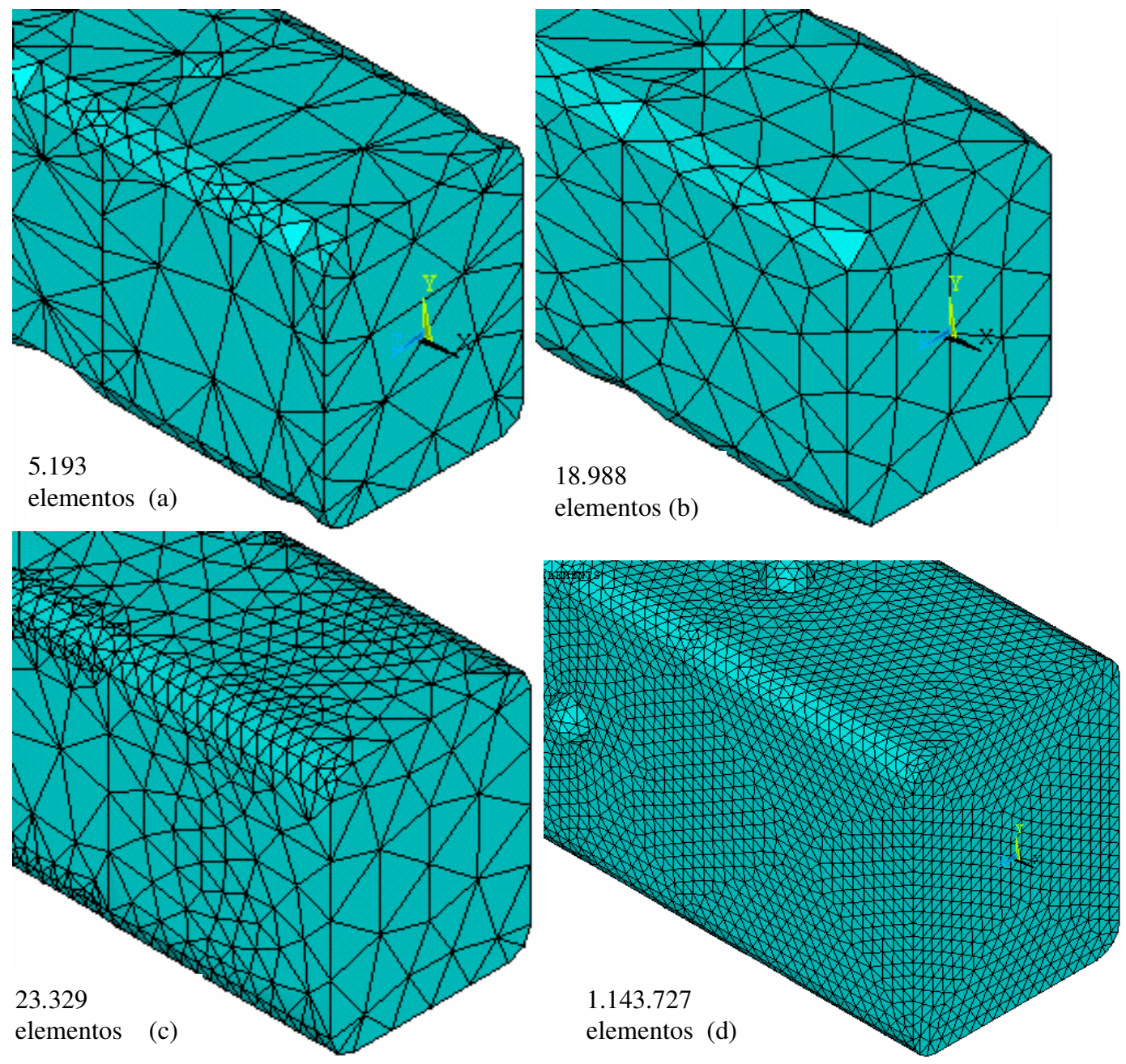

Figura 4.3 - Malhas de elementos geradas de maneira livre:

O modelo (d) não foi simulado. 
Já as malhas mapeadas necessitam atuação mais efetiva do usuário, e elas tem a vantagem, segundo (MORENO, 2000), de conferir melhores resultados nas simulações através do MEF, pois as malhas livres, nos casos de análises estruturais, usam elementos de ordem superior que possuem midnodes, isso aumenta o grau de liberdade das matrizes a serem calculadas e, também, a necessidade de maior capacidade de processamento.

Dessa forma buscou-se construir modelos de simulação com malhas de elementos criadas de maneira mapeada vistos na figura 4.4.

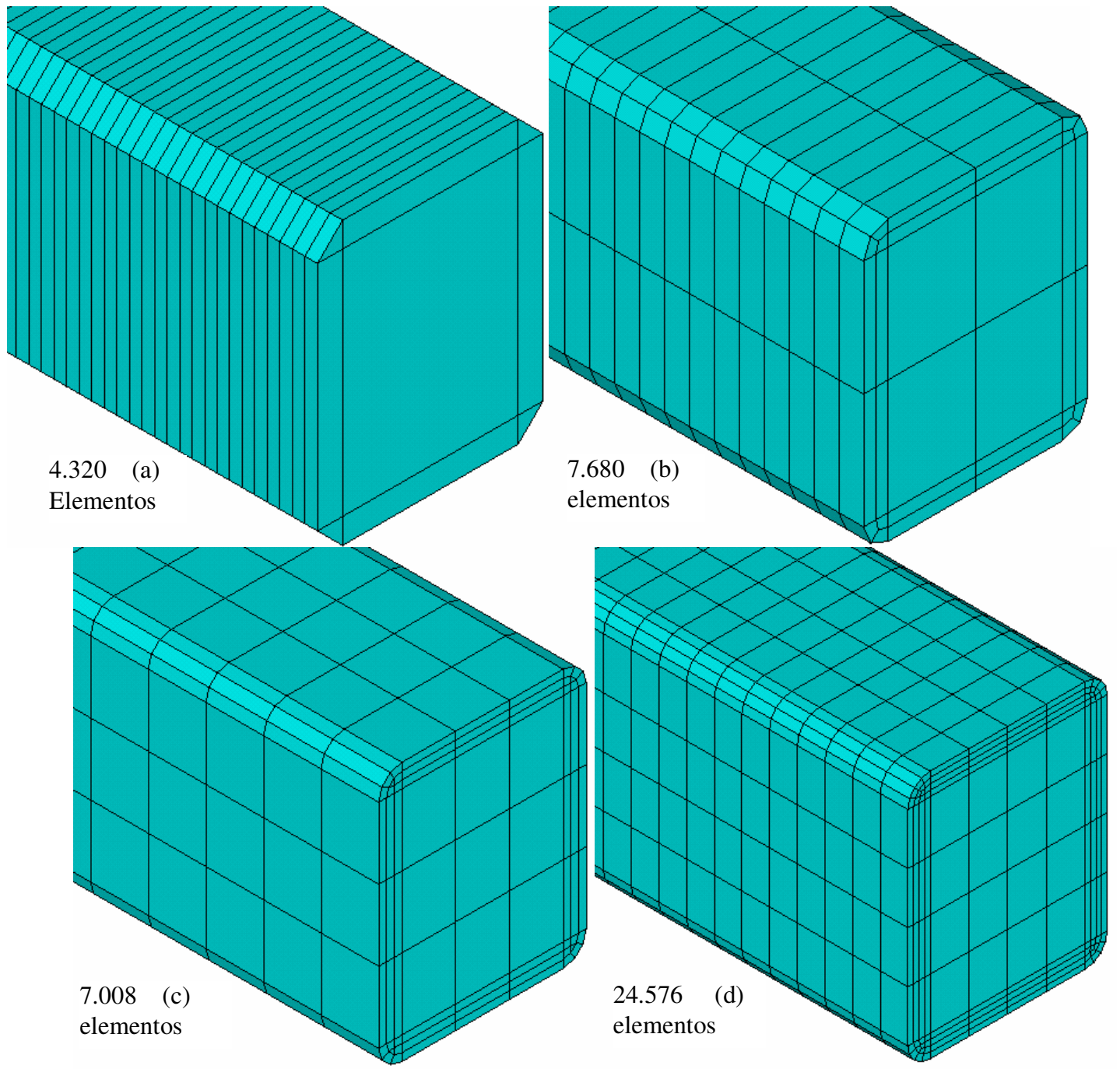

Figura 4.4 - Malhas de elementos geradas de maneira Mapeada O modelo (d) foi o escolhido para as simulações das tabelas 14 a17 
As simulações de modelos com malha mapeada trazem maior confiabilidade, para o caso de análise de problemas estruturais, pois os elementos estão simetricamente alinhados e bem posicionados.

A escolha de qual modelo deve ser usado nas simulações considera a construção da malha como sendo o fator de decisão para este caso, pois a construção da malha contendo os furos é mais rápida quando é feita por malha livre, porém os resultados são questionáveis, já a construção de uma malha mapeada com os orifícios será objetivo descrito adiante.

Contudo adota-se neste trabalho a modelagem da cruzeta através de malha mapeada, porém não contendo os orifícios definidos em (NBR8459, 1984).

\subsubsection{Modelo com alto grau de refinamento de malha}

Como já foi dito anteriormente, é objetivo deste trabalho a construção de um modelo capaz de representar o ensaio de resistência a flexão para cruzetas de madeira, assim, considera-se importante desenvolver um modelo com alto grau de refinamento.

Dessa forma, foi construído um modelo utilizando a função que cria a malha dos elementos por extrusão de áreas já mapeadas, esse processo foi demorado, contudo, foi possível construir o modelo de simulação que é mostrado na figura 4.5. 

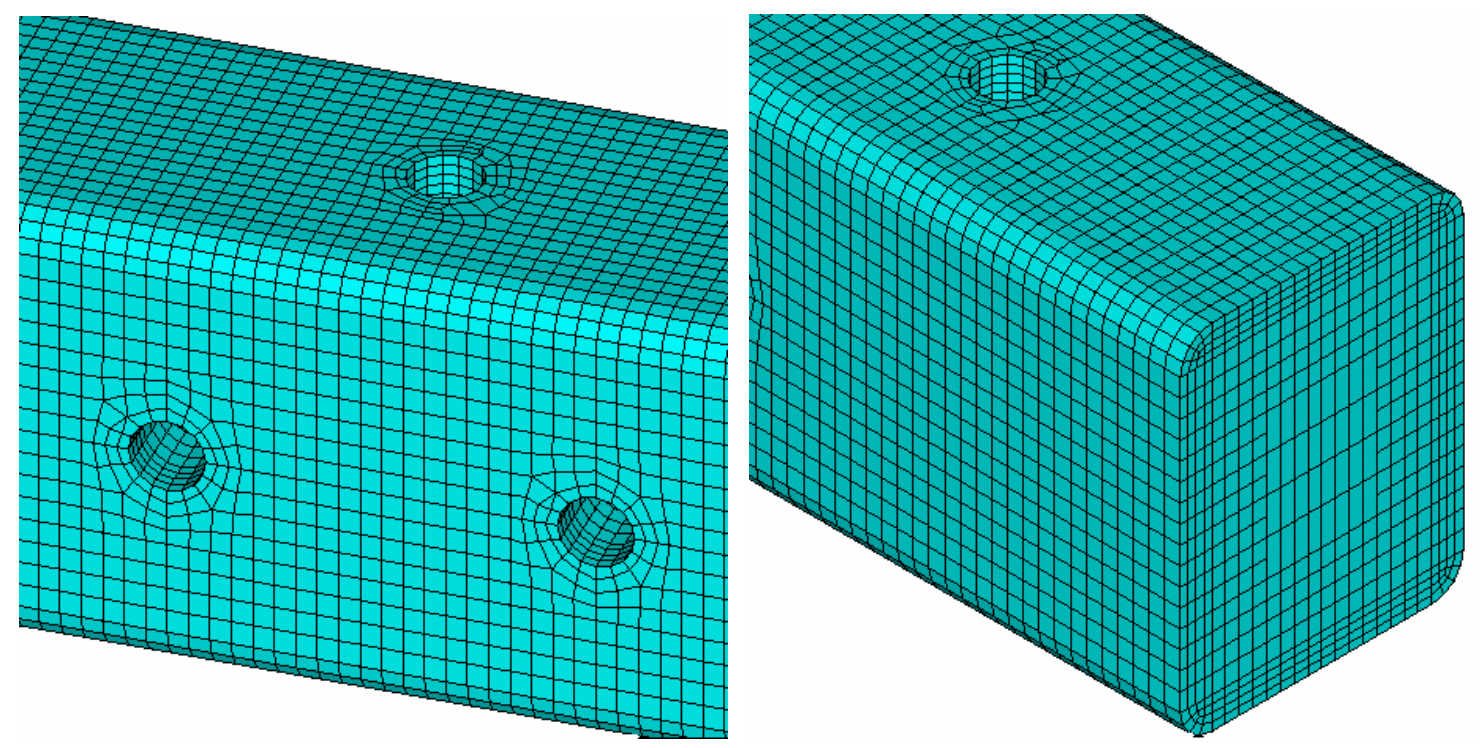

Figura 4.5 - Malha refinada com 256.996 elementos gerada por extrusão de áreas, incluindo os orifícios.

Após a criação dos modelos realizou-se a simulação destes no ANSYS $\circledast$ descritos no capitulo 5 . 


\section{Capítulo 5}

\section{Simulações}

Para a realização das simulações no ANSYS ${ }^{\circledR}$ utilizou-se um computador com a seguinte configuração:

- Processador Pentium 4® com 30 Gb de HD e 512 Mb de RAM.

O tempo de simulação variou com a quantidade de elementos existentes no modelo simulado, de 1 à 35 minutos para os modelos com menos de 100.000 elementos e de 40 à 90 minutos para valores até 2.500 .000 elementos. Algumas simulações não foram concluídas, aparentemente por insuficiência de capacidade de processamento.

Este capítulo tem por função mostrar, de maneira simples, como foram feitas as simulações que buscam representar o ensaio de resistência à flexão da cruzeta de madeira de 2,4 m exigidos pela (NBR8458, 1984). 
O modelo utilizou elementos estruturais para representar a cruzeta de madeira, bem como a sua camada de material compósito formado pela interface da madeira impregnada com resina.

Para representar a madeira usou-se o elemento SOLID45 (volumétrico), já a camada de resina foi representada pelo elemento SHELL63 (plano), ambos encontrados na biblioteca de elementos do ANSYS®.

A primeira hipótese $\left(1^{a} H\right)$ : simular a madeira e a resina como dois materiais distintos, com regiões muito bem definidas e apenas uni-los através de sua área de contato.

Isso significa dizer que a madeira, considerada o material de número 1 (MAT1), que fica na parte interna do modelo, foi representada pela malha de elementos do tipo sólido (SOLID45).

Já a resina poliuretana derivada de óleo de mamona, considerada como o material de número 2 (MAT2), está na parte externa do modelo e também foi representada pela malha de elementos do tipo sólido.

A espessura da camada do MAT2 foi considerada neste modelo como tendo o valor de $10 \mathrm{~mm}$, pois valores inferiores a este causaram erros na representação numérica do modelo. A figura 5.1 (a) mostra a representação. 

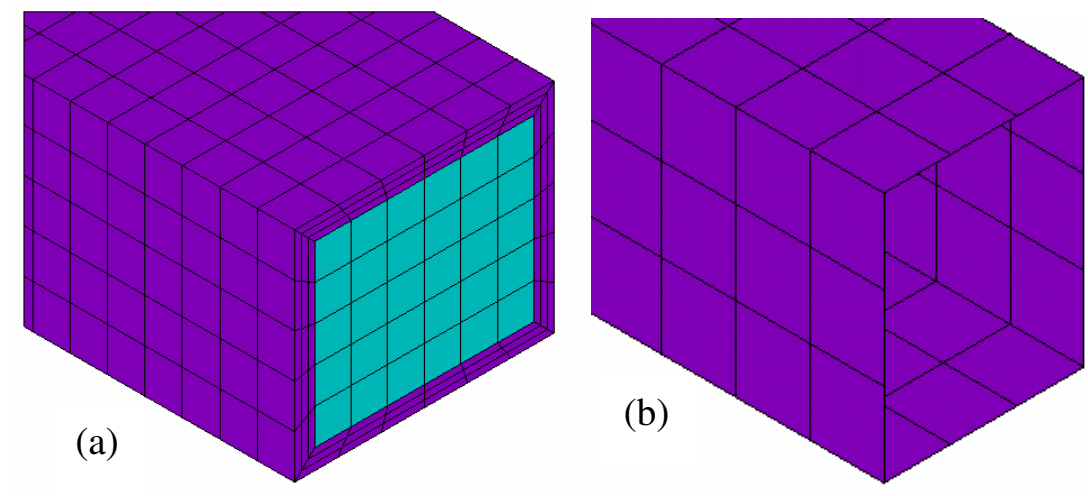

Figura 5.1 - (a)Malha representando a madeira recoberta com resina, face $B$ (b) Malha representando apenas a camada de resina, face $\mathrm{A}$

Na segunda hipótese $\left(2^{2} H\right)$ : o modelo também foi construído com malha de elementos sólidos para MAT1, já MAT2 passa a ser representado pelo elemento tipo casca (SHELL63), com espessura $10 \mathrm{~mm}$, para que seus resultados fossem comparados com os modelo anterior.

A representação apenas da malha gerada com os elementos casca pode ser vista na figura 5.1 (b).

Já a terceira hipótese $\left(3^{\underline{a} H}\right)$ constou de estudos a respeito de um módulo de elasticidade efetivo do compósito madeira/resina, que redundasse em resultados de simulação coerentes com resultados experimentais dos ensaios das madeiras impregnadas com a resina $\mathrm{R} \mid 3$.

De qualquer forma, foram realizadas simulações em que se variam, principalmente, os módulos de elasticidade, para $1^{a} \mathrm{H}$ e $2^{2} \mathrm{H}$ de acordo com os adquiridos nos ensaios já mostrados (PE16 e SEO) e $3^{\text {a }}$ H variando os valores de $\boldsymbol{E}$ buscando alcançar o melhor para a representação do ensaio de flexão de cruzetas de madeira segundo (NBR8458, 1984) e comparando com os resultados experimentais de (ALTAFIM et al., 2004a) com o intuito de validar o modelo de simulação desenvolvido neste trabalho.. 
Para representar o módulo de elasticidade $E$ foi adotado para $1^{a} H$ e $2^{a} H$ o valor mostrado na tabela 12

Tabela 12 - Módulo de elasticidade $E$ ensaiado

\begin{tabular}{cc}
\hline $\begin{array}{c}\text { Média dos ensaios } \\
\text { das tabelas } \mathbf{4} \text { e } \mathbf{5}\end{array}$ & $\begin{array}{c}\text { Módulo de elasticidade } \\
\text { das resina (MPa) }\end{array}$ \\
\hline$E(S E O)$ & $318,35^{*}$ \\
\hline Valor extraído da tabela 5
\end{tabular}

No próximo item são exibidos e discutidos os resultados encontrados para as hipóteses citadas.

\subsection{Resultados}

Os resultados mostrados a seguir trazem a representação das interpretações das respostas fornecidas pelo software ANSYS®, para os modelos de simulação de cruzetas de madeira impregnadas com a resina RI3. Pode-se perceber que os resultados não são significativos, o que mostra a necessidade do melhoramento do modelo de simulação, bem como novas simulações realizadas no ANSYS®.

$\mathrm{Na}$ tabela 13 estão os resultados obtidos para a primeira e segunda hipóteses, considerando a madeira Pinus elliotti ensaiada na posição da face A.

Tabela 13 - Comparação entre os resultados simulados e os resultados reais para Pinus eliiotti impregnada com $R / 3$

\begin{tabular}{ccccc}
\hline $\begin{array}{c}\text { Módulos de } \\
\text { elasticidade }\end{array}$ & $\begin{array}{c}\mathbf{1}^{\mathbf{a}} \\
\text { Hipótese } \\
\text { flexão } \\
(\mathbf{m m})\end{array}$ & $\begin{array}{c}\mathbf{2}^{\mathbf{a}} \\
\text { Hipótese } \\
\text { flexão } \\
(\mathbf{m m})\end{array}$ & $\begin{array}{c}\text { Flexão real } \\
\text { com } \\
\text { resina(mm) }\end{array}$ & $\begin{array}{c}\text { Flexão real } \\
\text { sem } \\
\text { resina(mm) }\end{array}$ \\
\hline$E$ & 16,10 & 16,73 & 9,12 & 17,62 \\
\hline
\end{tabular}

A figura 5.2 é a resposta para a $2^{\mathrm{a}} \mathrm{H}$ considerando $E=318,35 \mathrm{MPa}$. O resultado também é uma representação de como foram visualizadas as respostas das simulações do ensaio de flexão realizadas. 
$\mathrm{rWX}$

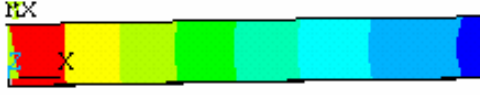

DEFORMAÇÃ̃O MÁXIMA = 17,002 mm

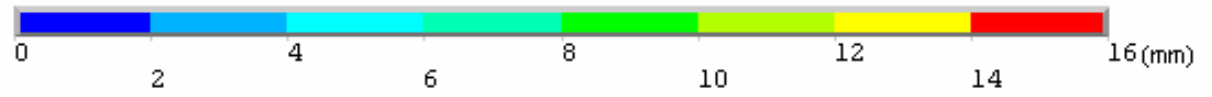

Figura 5.2 - Resposta para a $2^{a} H$ considerando $E=318,35 \mathrm{MPa}$, face $\mathrm{A}$

Lembrando que não foram acrescentados mais resultados à tabela 13 como, por exemplo, simulações com a madeira Eucalyptus citriodora, ou outras espessuras da camada de resina ligada à madeira devido à baixa representatividade dos resultados obtidos, o que significa que esta modelagem não é representativa, talvez devido à imprecisão dos dados obtidos na literatura. A espessura de $10 \mathrm{~mm}$, exagerada, foi definida neste valor para se tentar obter alguma representatividade da interação da camada de compósito que reveste a cruzeta, mesmo assim não foram obtidos resultados significativos.

Comparando os resultados dos ensaios para as madeiras em estado natural e dos ensaios para as madeiras impregnadas com a resina $R \mid 3$, conforme tabelas 14 a 17, houve aumento considerável na resistência à flexão. Entretanto as simulações computacionais apresentaram resultados mais representativos nas madeiras em estado natural, principalmente no Pinus elliotti, do que para as madeiras impregnadas com a resina RI3. Por outro lado, os resultados dos ensaios para o Eucalyptus citriodora, suposto em estado natural, que, no entanto, era impregnado com óleo (ALTAFIM, et al., 2004b), foram consideravelmente diferentes dos obtidos através da simulação. 
Com relação às madeiras impregnadas com a resina $\mathrm{RI}$, o incremento na resistência à flexão nos casos das duas madeiras, pode ser justificado pelo estudo realizado em (STOLF, 2000), conforme mostra o gráfico da figura 5.3, onde são comparados os desempenhos de corpos-de-prova de madeira em estado natural e de compósito de madeira/polímero, numa situação análoga à encontrada neste trabalho, na região de fronteira entre a camada de resina e o corpo da cruzeta.

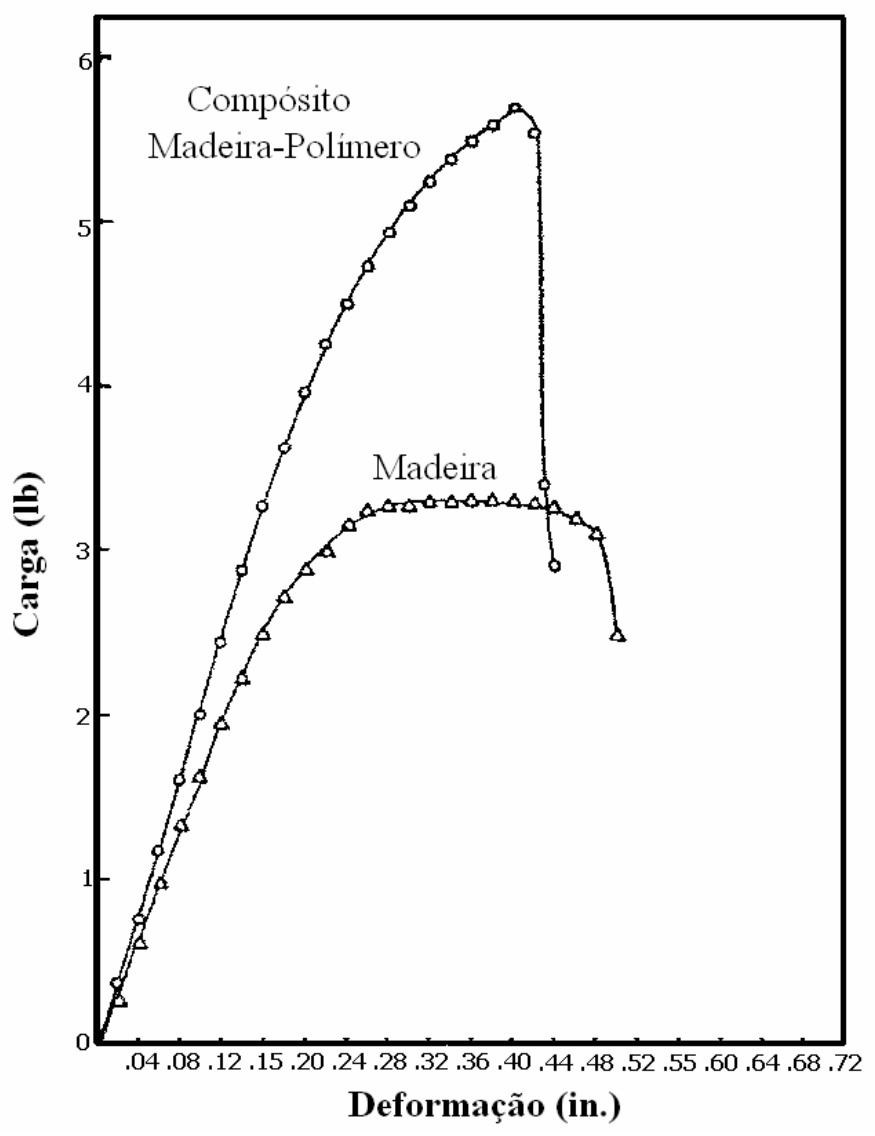

Figura 5.3 - Comparação entre deformação de corpos-de-prova de madeira tratada e não tratada no teste de flexão (STOLF, 2000)

Neste trabalho não foi possível realizar ensaios com o compósito já citado, assim os módulos de elasticidade nos casos das duas madeiras impregnadas com a resina RI3 não foram obtidos, prejudicando então as simulações correspondentes. 
O gráfico da figura 5.3 mostra um substancial incremento na resistência à flexão, o que leva a se prever a existência de um módulo de elasticidade efetivo do compósito madeira/resina, consideravelmente maior que o da madeira em estado natural.

Assim, foram realizadas simulações levando em conta valores de módulos de elasticidade crescentes arbitrados até se atingir razoavelmente os resultados dos ensaios das madeiras impregnadas com a resina RI3. Tais resultados são, também, mostrados nas tabelas 14 a 21 .

O modelo de malha mapeada foi formado por 24.576 elementos estruturais de volume e 15.616 elementos estruturais de casca totalizando 40.192 elementos, resultando em tempos de processamento computacional razoáveis.

A tabela 14 exibe os resultados obtidos nas simulações da cruzeta de Pinus elliotti, para o ensaio de flexão com carregamento normal.

Tabela 14 - Deslocamentos para a simulação da cruzeta de Pinus elliotti-3,92 kN

\begin{tabular}{c|c|c|c|c|c|c|c|c}
\hline \multirow{2}{*}{$\begin{array}{c}\text { No de } \\
\text { Elementos }\end{array}$} & Tempo (min) & \multirow{2}{*}{$\begin{array}{c}\text { E da Madeira } \\
\text { (GPa) }\end{array}$} & \multicolumn{2}{|c|}{$\begin{array}{c}\text { Deslocamento } \\
\text { Real }(\mathbf{m m})\end{array}$} & $\begin{array}{c}\text { Deslocamento } \\
\text { simulado } \\
\text { (mm) }\end{array}$ & \multicolumn{2}{|c}{ Erro \% } \\
\cline { 4 - 9 } & & & $\mathbf{A}$ & $\mathbf{B}$ & $\mathbf{A}$ & $\mathbf{B}$ & $\mathbf{A}$ & $\mathbf{B}$ \\
\hline 24576 & 5 & 11,889 & 17,62 & 24,3 & 15,891 & 23,574 & $-9,82$ & $-2,99$ \\
\hline & 3 & 10,7 & & & 17,657 & 26,196 & 0,02 & 12,15 \\
\hline
\end{tabular}

\begin{tabular}{|c|c|c|c|c|c|c|c|c|c|c|}
\hline \multirow[t]{2}{*}{$\begin{array}{c}\text { № de } \\
\text { Elementos }\end{array}$} & \multirow[t]{2}{*}{$\begin{array}{c}\text { Tempo } \\
\text { (min) }\end{array}$} & \multirow{2}{*}{$\begin{array}{c}E \text { da } \\
\text { Madeira } \\
\text { (GPa) }\end{array}$} & \multirow{2}{*}{$\begin{array}{c}\text { Espessura } \\
\text { Simulada } \\
(\mathrm{mm})\end{array}$} & \multirow{2}{*}{$\begin{array}{c}\text { E da } \\
\text { Camada } \\
\text { (GPa) } \\
\end{array}$} & \multicolumn{2}{|c|}{$\begin{array}{l}\text { Deslocamento } \\
\text { Real }(\mathrm{mm})\end{array}$} & \multicolumn{2}{|c|}{$\begin{array}{l}\text { Deslocamento } \\
\text { simulado (mm) }\end{array}$} & \multicolumn{2}{|c|}{ Erro \% } \\
\hline & & & & & A & B & A & B & A & B \\
\hline \multirow{9}{*}{40192} & 10 & \multirow{9}{*}{10,7} & 1 & 65 & \multirow{9}{*}{9,12} & \multirow{9}{*}{13,25} & 9,146 & 13,245 & 0,28 & -0 \\
\hline & 16 & & \multirow{6}{*}{0,5} & 85 & & & 10,703 & - & 17,35 & - \\
\hline & 10 & & & 95 & & & 10,312 & - & 13,07 & - \\
\hline & 13 & & & 120 & & & - & 13,703 & - & 3,41 \\
\hline & \multirow{2}{*}{7} & & & 130 & & & 9,146 & 13,246 & 0,28 & -0 \\
\hline & & & & 140 & & & - & 12,818 & - & $-3,3$ \\
\hline & 10 & & & 150 & & & - & 12,418 & - & $-6,3$ \\
\hline & \multirow{2}{*}{7} & & \multirow{2}{*}{0,25} & 260 & & & 9,146 & 13,246 & 0,28 & -0 \\
\hline & & & & 270 & & & - & 13,029 & - & $-0,8$ \\
\hline
\end{tabular}


A tabela 15 exibe os resultados obtidos nas simulações da cruzeta de Eucalyptus citriodora, para o ensaio de flexão com carregamento normal.

Tabela 15 - Deslocamentos para a simulação da cruzeta de Eucalyptus citriodora - 3,92 kN

\begin{tabular}{c|c|c|c|c|c|c|c|c}
\hline \multirow{2}{*}{$\begin{array}{c}\text { No de } \\
\text { Elementos }\end{array}$} & Tempo (min) & \multirow{2}{*}{$\begin{array}{c}\text { E da Madeira } \\
\text { (GPa) }\end{array}$} & \multicolumn{2}{|c|}{$\begin{array}{c}\text { Deslocamento } \\
\text { Real (mm) }\end{array}$} & $\begin{array}{c}\text { Deslocamento } \\
\text { simulado } \\
\text { (mm) }\end{array}$ & \multicolumn{3}{|c}{ Erro \% } \\
\cline { 3 - 9 } & & A & B & A & B & A & B \\
\hline 24576 & 2 & 18,421 & 5,73 & 7,95 & 10,256 & 15,215 & 78,98 & 91,38 \\
\cline { 5 - 9 } & 2 & 36,824 & & & 5,128 & 7,607 & $-10,5$ & $-4,31$ \\
\hline
\end{tabular}

\begin{tabular}{|c|c|c|c|c|c|c|c|c|c|c|}
\hline \multirow{2}{*}{$\begin{array}{c}\text { № de } \\
\text { Elementos }\end{array}$} & \multirow{2}{*}{$\begin{array}{c}\text { Tempo } \\
(\min )\end{array}$} & \multirow{2}{*}{$\begin{array}{c}E \text { da } \\
\text { Madeira } \\
\text { (GPa) }\end{array}$} & \multirow{2}{*}{$\begin{array}{c}\text { Espessura } \\
\text { Simulada } \\
(\mathbf{m m})\end{array}$} & \multirow{2}{*}{$\begin{array}{c}E \text { da } \\
\text { Camada } \\
(\mathrm{GPa})\end{array}$} & \multicolumn{2}{|c|}{$\begin{array}{c}\text { Deslocamento } \\
\text { Real (mm) }\end{array}$} & \multicolumn{2}{|c|}{$\begin{array}{l}\text { Deslocamento } \\
\text { simulado }(\mathrm{mm})\end{array}$} & \multicolumn{2}{|c|}{ Erro \% } \\
\hline & & & & & A & B & A & B & A & B \\
\hline \multirow{3}{*}{40192} & \multirow{3}{*}{7} & \multirow{3}{*}{36,824} & 1 & 65 & \multirow{3}{*}{4,79} & \multirow{3}{*}{6,21} & \multirow{3}{*}{4,13} & \multirow{3}{*}{6,063} & \multirow{3}{*}{$-13,8$} & \multirow{3}{*}{$-2,4$} \\
\hline & & & 0,5 & 130 & & & & & & \\
\hline & & & 0,25 & 260 & & & & & & \\
\hline
\end{tabular}

A tabela 16 exibe os resultados obtidos nas simulações da cruzeta de Pinus elliotti, para o ensaio de flexão com carregamento máximo.

Tabela 16 - Deslocamentos para a simulação da cruzeta de Pinus elliotti - 5,49 kN

\begin{tabular}{c|c|c|c|c|c|c|c|c}
\hline \multirow{2}{*}{$\begin{array}{c}\text { No de } \\
\text { Elementos }\end{array}$} & Tempo (min) & \multirow{2}{*}{$\begin{array}{c}\text { E da Madeira } \\
\text { (GPa) }\end{array}$} & \multicolumn{2}{|c|}{$\begin{array}{c}\text { Deslocamento } \\
\text { Real (mm) }\end{array}$} & $\begin{array}{c}\text { Deslocamento } \\
\text { simulado } \\
\text { (mm) }\end{array}$ & \multicolumn{3}{|c|}{ Erro \% } \\
\cline { 5 - 9 } & & & A & B & A & B & A & B \\
\hline \multirow{2}{*}{24576} & 2 & 11,889 & 25,14 & 33,63 & 22,248 & 33,003 & $-11,5$ & $-1,86$ \\
\cline { 6 - 9 } & & 10,7 & & & 24,72 & 33,671 & $-1,67$ & 0,12 \\
\hline
\end{tabular}

\begin{tabular}{|c|c|c|c|c|c|c|c|c|c|c|}
\hline \multirow{2}{*}{$\begin{array}{c}\text { № de } \\
\text { Elementos }\end{array}$} & \multirow{2}{*}{$\begin{array}{c}\text { Tempo } \\
\text { (min) }\end{array}$} & \multirow{2}{*}{$\begin{array}{c}\text { E da } \\
\text { Madeira } \\
\text { (GPa) }\end{array}$} & \multirow{2}{*}{$\begin{array}{c}\text { Espessura } \\
\text { Simulada } \\
(\mathrm{mm})\end{array}$} & \multirow{2}{*}{$\begin{array}{c}E \text { da } \\
\text { Camada } \\
\text { (GPa) }\end{array}$} & \multicolumn{2}{|c|}{$\begin{array}{c}\text { Deslocamento } \\
\text { Real (mm) }\end{array}$} & \multicolumn{2}{|c|}{$\begin{array}{l}\text { Deslocamento } \\
\text { simulado (mm) }\end{array}$} & \multicolumn{2}{|c|}{ Erro \% } \\
\hline & & & & & A & B & A & B & A & B \\
\hline \multirow{3}{*}{40192} & \multirow{3}{*}{7} & \multirow{3}{*}{10,7} & 1 & 65 & \multirow{3}{*}{12,55} & \multirow{3}{*}{18,12} & \multirow{3}{*}{13,593} & \multirow{3}{*}{19,657} & \multirow{3}{*}{8,31} & \multirow{3}{*}{8,48} \\
\hline & & & 0,5 & 130 & & & & & & \\
\hline & & & 0,25 & 260 & & & & & & \\
\hline
\end{tabular}


A tabela 17 exibe os resultados obtidos nas simulações da cruzeta de Eucalyptus citriodora, para o ensaio de flexão com carregamento máximo.

Tabela 17 - Deslocamentos para a simulação da cruzeta de Eucalyptus citriodora - 5,49 kN

\begin{tabular}{|c|c|c|c|c|c|c|c|c|}
\hline \multirow[t]{2}{*}{$\begin{array}{c}\text { № de } \\
\text { Elementos }\end{array}$} & \multirow[t]{2}{*}{ Tempo (min) } & \multirow[t]{2}{*}{$\begin{array}{c}\text { E da Madeira } \\
(\mathrm{GPa})\end{array}$} & \multicolumn{2}{|c|}{$\begin{array}{l}\text { Deslocamento } \\
\text { Real (mm) }\end{array}$} & \multicolumn{2}{|c|}{$\begin{array}{l}\text { Deslocamento } \\
\text { simulado } \\
(\mathrm{mm})\end{array}$} & \multicolumn{2}{|c|}{ Erro \% } \\
\hline & & & A & B & A & B & A & B \\
\hline \multirow{2}{*}{24576} & \multirow{2}{*}{2} & 18,421 & \multirow{2}{*}{8,12} & \multirow{2}{*}{11,08} & 14,359 & 21,301 & 76,83 & 92,25 \\
\hline & & 36,842 & & & 7,179 & 10,65 & $-11,6$ & $-3,88$ \\
\hline
\end{tabular}

\begin{tabular}{|c|c|c|c|c|c|c|c|c|c|c|}
\hline \multirow{2}{*}{$\begin{array}{c}\text { № de } \\
\text { Elementos }\end{array}$} & \multirow{2}{*}{$\begin{array}{c}\text { Tempo } \\
\text { (min) }\end{array}$} & \multirow{2}{*}{$\begin{array}{c}\text { E da } \\
\text { Madeira } \\
\text { (GPa) }\end{array}$} & \multirow{2}{*}{$\begin{array}{c}\text { Espessura } \\
\text { Simulada } \\
(\mathrm{mm})\end{array}$} & \multirow{2}{*}{$\begin{array}{c}E \text { da } \\
\text { Camada } \\
(\mathrm{GPa})\end{array}$} & \multicolumn{2}{|c|}{$\begin{array}{c}\text { Deslocamento } \\
\text { Real (mm) }\end{array}$} & \multicolumn{2}{|c|}{$\begin{array}{l}\text { Deslocamento } \\
\text { simulado }(\mathrm{mm})\end{array}$} & \multicolumn{2}{|c|}{ Erro \% } \\
\hline & & & & & A & B & A & B & A & B \\
\hline \multirow{3}{*}{40192} & \multirow{3}{*}{7} & \multirow{3}{*}{36,842} & 1 & 65 & \multirow{3}{*}{6,56} & \multirow{3}{*}{8,6} & \multirow{3}{*}{5,782} & \multirow{3}{*}{8,489} & & \\
\hline & & & 0,5 & 130 & & & & & $-11,9$ & $-1,3$ \\
\hline & & & 0,25 & 260 & & & & & & \\
\hline
\end{tabular}

\subsection{Discussões}

Os modelos de representação $1^{a} H$ e $2^{a} H$, trouxeram uma resposta à simulação com pouca variação de flexão, mesmo com variação do módulo de elasticidade e grande espessura da camada de resina.

Assim, para conseguir alcançar a representatividade desejada para $3^{a} \mathfrak{H}$, passa a ser necessária a busca de maiores informações sobre o módulo de elasticidade do compósito madeira/resina, bem como a profundidade de penetração dessa resina na madeira, tornando possível a determinação dos parâmetros que farão com que o modelo se torne representativo. 
Para tentar buscar maneiras de compreender como e com qual intensidade acontece a impregnação, acredita-se ser possível estabelecer uma relação de profundidade de impregnação, através do conhecimento da capacidade higroscópica das madeiras e da fluidez da resina em seu estado líquido.

É importante salientar que, quando da impregnação da madeira com resina, fatores secundários podem influenciar nas respostas da madeira frente aos ensaios de flexão normativos, como pode ser visto em (STOLF, 2000).

Levando em consideração que a cruzeta de madeira é um material fibroso, quando ela é flexionada, conforme (NBR8458,1984), sua estrutura sofre tração nas fibras superiores e compressão nas inferiores, ver figura 5.4. Existe assim uma movimentação entre essas fibras que acabam se rompendo por esforço ou por fadiga. Desta forma podemos supor que, quando a resina penetra entre essas fibras e passa para seu estado sólido, a adesão entre os dois materiais é grande a ponto de impedir ou dificultar o movimento entres as fibras da madeira, retardando o rompimento.

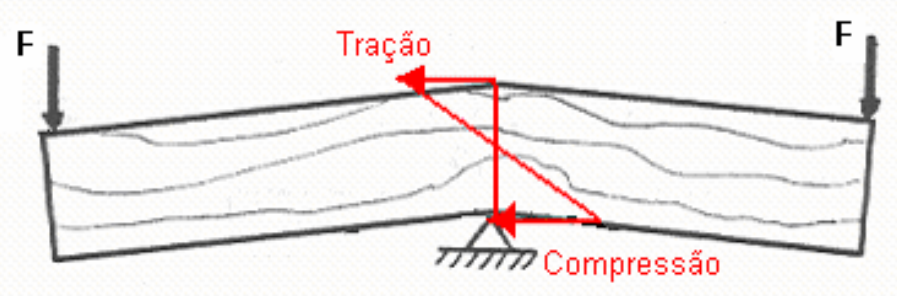

Figura 5.4 - Distribuição de forças na flexão das fibras da madeira

Segundo (STOLF, 2000), a impregnação da madeira com polímero altera significativamente sua tenacidade e foi possível observar fraturas poliméricas com pouca ou nenhuma deformação plástica, ou seja, mostrou que fatores microscópicos influenciam, para melhor, a capacidade de reação da madeira ao esforço. 
Além disso, o aumento da umidade do ambiente pode juntamente com a impregnação da resina, melhorar os valores da tenacidade no sentido tangencial e radial, segundo (SALES, 1991).

O software permite a utilização de elementos que podem representar camadas com espessuras variadas com planos diferentes de simetria mecânica, o que parece ser mais uma opção a ser estudada e testada na busca do modelo de simulação computacional, capaz de representar, de maneira satisfatória, o ensaio de flexão para cruzetas de madeira impregnadas com resinas.

Conjecturas a respeito do valor efetivo do módulo de elasticidade das madeiras e para a camada de interligação (compósito) madeira/resina foram realizadas, baseando-se nos resultados experimentais obtidos em (ALTAFIM et. al.,2004a), sendo apresentados na tabela 18 e 19.

Tabela 18 - Módulos de elasticidade efetivos para Pinus elliotti e Eucalyptus citriodora

\begin{tabular}{cccc}
\hline Madeira & $\begin{array}{c}\text { Módulos de } \\
\text { elasticidade } \\
\text { reais (GPa) }\end{array}$ & $\begin{array}{c}\text { Módulo de } \\
\text { elasticidade } \\
\text { arbitrado (GPa) }\end{array}$ & $\begin{array}{c}\text { Razão entre os } \\
\text { módulos de } \\
\text { elasticidade }\end{array}$ \\
\hline $\begin{array}{c}\text { Pinus elliotti } \\
\begin{array}{c}\text { Eucalyptus } \\
\text { citriodora }\end{array}\end{array}$ & 11,889 & 10,7 & 0,9 \\
\hline
\end{tabular}

Tabela 19 - Módulos de elasticidade efetivos para a camada de compósito

\begin{tabular}{cc}
\hline $\begin{array}{c}\text { Módulo de elasticidade } \\
\text { arbitrado do compósito } \\
\text { (GPa) }\end{array}$ & $\begin{array}{c}\text { Espessura da } \\
\text { camada de } \\
\text { compósito (mm) }\end{array}$ \\
\hline 65 & 1,0 \\
130 & 0,5 \\
260 & 0,25 \\
\hline
\end{tabular}




\section{Capítulo 6}

\section{Conclusões e Sugestões de Trabalhos Futuros}

Conforme os resultados das simulações, juntamente com os resultados experimentais obtidos em (ALTAFIM et al. 2004a), bem como as correspondentes discussões, conforme apresentado nos Capítulo 4 e 5, podem ser registradas as seguintes conclusões:

- Não foram detectadas variações significativas dos valores das deformações na simulação dos ensaios de flexão para as hipóteses $1^{\text {a }} \mathrm{H}$ e $2^{\mathrm{a}} \mathrm{H}$ sugeridas, o que já demonstra que esta modelagem não tem representatividade para este caso de madeiras impregnadas com resina.

- As respostas das simulações foram representativas para as cruzetas da madeira Pinus elliotti, não impregnadas com resina. Por outro lado, para o Eucalyptus citriodora presume-se que a impregnação com óleo descrita em (ALTAFIM et al., 2004a) pode ter influenciado nos valores reais do módulo de elasticidade, 
diferenciando-o de seus valores colhidos na literatura para realizar a simulação computacional.

- A opção que permanece é a de buscar maiores informações a respeito da interação na interface madeira/resina tentando caracterizá-la como um compósito, onde os valores dos coeficientes mecânicos precisam ser levantados. Logo, se torna imprescindível conhecer a espessura da camada de compósito e a proporção entre a madeira e a resina poliuretana na região delimitada, com o mesmo objetivo de realizar nova tentativa de construção de um novo modelo de simulação computacional. Importante também será uma análise com base em ensaios que envolvam amostras da região de penetração da resina na madeira.

- Os ensaios realizados para o levantamento do modulo de elasticidade da resina $\mathrm{RI}$, mostram uma tendência de crescimento deste módulo em função do tempo de cura da resina. Assim, sugerem-se estudos futuros para encontrar a estabilidade do valor do módulo de elasticidade após tempos de cura elevados.

Uma contribuição importante deste trabalho é encontrada no APÊNDICE B, que trata de como utilizar o ANSYS®, com detalhes que facilitam sua compreensão e utilização por parte de usuários iniciantes. 


\section{BIBLIOGRAFIA}

AGÊNCIA BRASIL, 04 MAIO 2004. Florestal Estatístico/ Radiobrás. Disponível em <http://www.radiobras.gov.br/materia_i_2004.php?materia=176322\&editoria=>, Acesso em 27 nov. 2004.

Agência Nacional de Energia Elétrica. Regime das Concessões de Serviços Públicos da Energia Elétrica. Brasília: ANEEL, 1996. 427p.

ALTAFIM, R. A. C.; SILVA, J. F. R.; GONZAGA, D. P. ; MURAKAMI, C. R.; GODOY, J. P. M.; BASSO, H. C.; BUENO, B. S.; CALIL JR, C.; SARTORI, J. C.; ALTAFIM, R. A. P.; SILVEIRA, A. Timber Cross-Arms Coated with Polyurethane Resin - Tests and Mechanical Simulations. Porto Alegre: XVI Congresso Brasileiro de Engenharia e Ciência dos Materiais, 2004a, 12 p.

ALTAFIM, R. A. C.; SILVA, J. F. R.; BASSO, H. C.; CALIL JR, C. ; SARTORI, J. C.; MURAKAMI, C. R.; ALTAFIM, R. A. P.; CHIERICE, G. O.; SILVEIRA, A. Study of Timber Coated with Polyurethane Resin: Electrical and Mechanical Tests. São Carlos: XVI Seminário Nacional de Distribuição de Energia Elétrica. 2004b, 10 p.

AMERICAN SOCIETY OF TESTING AND MATERIALS. D 638-01. West Conshohocken: ASTM. 2003. 13p.

ANSYS USER'S MANUAL. Theory Manual. Livermore: Livermore Software Technology Corporation. 1998. 498 p.

ARAUJO, L.C.R. Características Química, Térmica e Mecânica de Poliuretanas Elastoméricas Baseadas em Materiais Oleoquímicos. São Carlos: Instituto de Química de São Carlos- USP, 1992. 101 p. 
ARGYRIS, J. H.; KELSEY, S. Energy Theorems and Structural Analysis. London: Butterworth Scientific Publications, 1960.

ASSOCIAÇÃO BRASILEIRA DE NORMAS TÉCNICAS. NBR 8458 - Cruzetas de Madeira para Redes de Distribuição de Energia Elétrica. Rio de Janeiro: ABNT. 1984. $13 \mathrm{p}$.

ASSOCIAÇÃO BRASILEIRA DE NORMAS TÉCNICAS. NBR 8459 - Cruzetas de Madeira - Dimensões. Rio de Janeiro: ABNT. 1984. 4 p.

ASSOCIAÇÃO BRASILEIRA DE NORMAS TÉCNICAS. NBR 7190 - Projeto de Estruturas de Madeira. Rio de Janeiro: ABNT.1997. 107 p.

ATIQUE JÚNIOR, W. Aplicação do Método dos Elementos Finitos à Análise de Dispositivos Elétricos. São Carlos: EESC - USP. 2001.125 p.

BATHE, K. J. Finite Element Procedures. Upper Saddle River: Prentice Hall. 1996. $1036 \mathrm{p}$.

BODIG, J.; JAYNE, B.A. Mechanics of Wood and Wood Composites, New York: Van Nostrand Reinhold. 1982. 712 p.

BONOMO, A. Estudo Sobre Isoladores Poliméricos à Base de Resinas Poliuretanas para Ambiente Externo. São Carlos: EESC- USP. 2003. 113 p.

BUCUR, V. Acoustics of Wood. New York: CRC Press Inc.1995.

CARDOSO, J.R. Introdução ao Método dos Elementos Finitos Para Engenheiros Eletricistas. São Paulo: Publicação Independente. 70 p. 
CARLGREN, F. Rudolf Steiner 1861-1925. Dornach: Goetheanum School of Spiritual Science, 1964. 123p.

CAUWELAERT, F.V. Deformation of Anisotropc Body. Journal of the Engineering Mechanics Division of the ASCE. 1977. 823-835 p.

CENTRO DA MEMÓRIA ELÉTRICA NO BRASIL, Energia Elétrica no Brasil Breve Histórico 1880-2001. Rio de Janeiro. 2001

COMPANHIA PAULISTA DE FORÇA E LUZ. Cruzetas de Madeira Preservada e não Preservada para Redes Aéreas de Distribuição de Energia. São Paulo: CPFL. 2003. 28 p.

COWIN, S. C. Identification of Materials Symmetry for Anisotropic Elastic Materials. Quaterly Journal of Mechanics and Applied Mathematics. 1987. 451-476 p.

ELEKTRO (1995). Norma de Cruzetas de Madeira de 2400 mm. Campinas.

FOORT, J. et al. Methods and Materials for External Prostheses - Present and Future. Official Journal of the International Rehabilitation Medicine Associaton, 1984.

FURLANI, J.E. Um Estudo Sobre a Variação Numérica do Coeficiente de Piosson na Madeira Considerando a Anisotropia do Material, Campunas: UNICAMP. 1995. 144 p.

GRAYBEAL, W.; POOCH, W. Simulation: Principles and Methods. Massachusetts: Winthrop Publishers Inc, 1980. 246p

GUINESS. Guiness Book do Brasil - O Livro dos Recordes. São Paulo: Editora Três. 2004 
HARVARD, D. G.; PERRY, O. C. Lattice Tower Member Fatigue and its Control Using a Novel Damping Scheme. Ontario, Canada: IEEE. 2000

JANISZEWSKI, J. M. Método dos Elementos Finitos Aplicado a Problemas de Campos Eletromagnéticos Estáticos. São Paulo: Escola Politécnica Universidade de São Paulo. 1978.

KOLMOGOROV, A. N.; FOMIN, S. V. Elementos da Teoria das Funções e de Análise Funcional. Moscou: Ed. Mir. 1982.

LAI, W. M.; RUBIN, D.; KREMPL, E. Introduction to Continuum Mechanics. Butterworth-Heinemann. 1993

LAWRENCE, K.L. ANSYS Tutorial. release 7.0 (and release 6.1)

LEKHNITSKII, S.G. Theory of Elastricity of an Anisotropic Body. Moscou: Mir, 1981. 10-98 p.

LOVE, A.E. A Treatise on the Theory of Elasticty. New York: Dover Publications, $1944182 \mathrm{p}$.

MALVERN, L. E. Introduction to the Mechanics of a Continuous Media. PrenticeHall.1969

MASCIA, N.T. Considerações à Respeito da Anisotropia na Madeira, Escola de Engenharia de São Carlos. São Carlos: Universidade de São Paulo. 1991.

MURAKAMI, C. R. Aplicações das Resinas Poliuretanas Derivadas do Óleo de Mamona, Como Materiais Isolantes Elétricos. São Carlos, EESC- USP. 2002.

MURAKAMI, C. R.; ALTAFIM, R. A.; ARAUJO, L. C. R.; NETO, S. C.; CHIERICE, G. 
O. Uso de Resinas Poliuretanas derivadas do Óleo de Mamona na Fabricação de Isoladores Poliméricos. Ciudad Del Leste, Paraguay: Escola de Engenharia de São Carlos e Instituto de Química de São Carlos- USP, VIII ERLAC.

MORENO, M. E. Desenvolvimento e Implementação de Metodologia de Otimização da Geometria do Blank em Processos de Conformação de Chapas Metálicas. São Carlos, EESC- USP. 2000. 88 p.

OLIVEIRA, F. G. R. Estudo de Propriedades Mecânicas de Dicotiledôneas por Meio de Ensaio Não-Destrutivo Utilizando Equipamentos de Ultra-Som. São Carlos: Escola de Engenharia de São Carlos, Universidade de São Paulo, São Carlos. 2001.

OSTROSABLIN, N. I. On the Structure of Elastic Tensor and the Classification of Anisotropic Materials. Journal of Applied Mechanics and Technology Phisycs. 1986. 600-607 p.

PARK, J. B. Biomaterials: An Introduction, Polymeric Materials. New York: Plenum Press. 1980.

PLEPIS, A. M. G.; Característica Térmica e Viscoelástica de Resinas Poliuretanas Derivadas de Óleo de Mamona. São Carlos: Instituto de Química de São Carlos - USP. 1991.

REKTORYS, K. Variational Methods in Mathematics, Science and Engineering. D. Reidel Publishing Company. 1977.

RUDIN, W. Principles of Mathematical Analysis. McGraw-Hill.1976

SALES, A. Características de Resistência Mecânica de Algumas Espécies de Eucalipto do estado de São Paulo. São Carlos: EESC-USP. 1991. 
SILVA, José F. R. Cruzetas Para Redes de Distribuição de Energia Elétrica à Base de Polipropileno. São Carlos: EESC- USP. 2003. 86 p.

SILVA, J. F. R.; ALTAFIM, R. A. C.; MURAKAMI, C. R.; BASSO, H. C.; BUENO, B. S.; SARTORI, J. C.; ALTAFIM, R. A. P.; SILVEIRA, A.; HIRAKAWA, W.; ITOKAZU, C.; BENVENUTI, A. Cruzetas de Madeira Resinada como Alternativa para o Sistema Aéreo de Distribuição de Energia Elétrica. São Carlos: Elektro Eletricidade e Serviços S.A., Campinas, Escola de Engenharia de São Carlos, Universidade de São Paulo. 2004.

SILVESTER, P.; CHARI, M. V. K. Finite Solution of Saturable Magnetic Field Problems. IEEE Transaction on PAS, 89(7):1642-50. 1970

SILVESTER, P.; FERRARI, R. Finite Element for Eletrical Engineer. Cambridge/UK: Cambridge University Press, 1990.

SILVESTRE FILHO, G. D. Comportamento Mecânico do Poliuretano derivado de Óleo de mamona Reforçado por Fibra de Carbono: Contribuição para o Projeto de Hastes de Implante Quadril. São Carlos: Escola de Engenharia de São Carlos, Departamento de Engenharia Mecânica, São Carlos - USP. 2001.

SILVESTRE FILHO, G. D.; PURQUERIO, B. M.; CARVALHO, J.; SANTOS, N. C.; CHIERICE, G. O. Desenvolvimento de uma Metodologia de Fabricação para Hastes de Implante Ortopédico em Compósito Polimérico. Curitiba: 1ำ Congresso Brasileiro de Engenharia de fabricação - COBEF.

STACK, J. R.; HARLEY, R. G.; SPRINGER, P.: MAHAFFEY, J. A. Estimation of Wooden Cross-Arm Integridy Using Artificial Neural Networks and Laser Vibrometry. IEEE, Transactions on Power Delivery. 2003.

STOLF, D. O. Tenacidade da Madeira. São Carlos: EESC-USP. 2000. 
TURNER, M. R.; CLOUGH, R.; MARTIN, H.; TRPP, L. Stiffness and Deflection Analisys of Complex Structures. J. Aero. Sci., 23, no. 9, pp. 805-823. 1956

VANVLACK, L. H. Princípio de Ciência de Materiais. São Paulo: Editora Edgard Blucher Ltda.1970;

VIANNA, D. L. Estudo comparativo da Resistência Mecânica da "Poliuretana Derivada do Óleo de Mamona" Submetida à ensaios de Tração. Ribeirão Preto: Faculdade de Medicina de Ribeirão Preto, EESC -USP. 1997.

ZIENKIEWICZ, O. C. The Finite Element Method: From Intuition to Generality, Appl. Mech.1970. 249-256 p. 


\title{
TIMBER CROSS-ARMS COATED WITH POLYURETHANE RESIN - TESTS AND NUMERICAL SIMULATIONS
}

\author{
R. A.C. Altafim $^{1 *}$ J.F.R. Silva ${ }^{2}$ D.P. Gonzaga ${ }^{1}$ C.R. Murakami ${ }^{1} \quad$ J.P.M. Godoy ${ }^{1}$

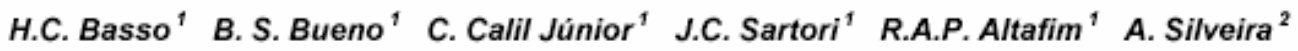 \\ ${ }^{\prime}$ Sảo Carlos School of Engineering - University of São Paulo - São Carlos, SP, Brazil \\ ${ }^{2}$ Power Utility - Elektro S.A., Campinas, SP, Brazil \\ *C.P. 359, 13566-590 São Carlos - SP, Brazil \\ *altafim@sel.eesc.sc.usp.br
}

\begin{abstract}
Brazil's electric power utilities have commonly employed native timbers as the main material for manufacturing cross-arms for distribution lines. However, the increasingly high costs of these timbers and Brazil's new environmental laws have contributed to change this situation, spurring research on new materials for application in transmission and distribution systems. This paper discusses two reforested wood species, Pinus elliottii and Eucalyptus citriodora, coated with castor oil-based polyurethane resins, as an alternative material for distribution line cross-arms, from the standpoint of their mechanical and electrical properties and their low cost. Numerical simulations and a complete description of the entire coating process are also part of this work.
\end{abstract}

Key-words: timber cross-arm, polymers, electrical and mechanical tests, computer simulations.

\section{INTRODUCTION}

The increasingly high cost of native timber and new environmental laws have contributed to the emergence of alternative materials for the production of mechanical supports for transmission and distribution lines [1]. Norway, for example, has been using laminated woods for over twenty years, first for cross-arms in distribution lines and later for complete 66 and $134 \mathrm{kV}$ transmission line structures [2]. In the early 1990s, in the US, Union Electric (U.E) also evaluated alternatives for solid wood products, whose prices have increased steadily over the last decade, particularly those of cross-arms. U.E has found that laminated wood cross-arms can offer an economically feasible alternative at a cost equal to or lower than solid sawn cross-arms [3]. In this context, although laminated wood is an alternative material for Brazil, reforested Pinus elliotti and Eucaliptus citriodora, which satisfy the strength, electrical and thermal requirements for solid sawn cross-arms [4], are also economically viable, provided they receive special protective surface treatment against fungi and microorganisms.

This paper presents and discusses reforested Pinus elliotti and Eucalipto citriodora crossarms coated with a castor oil-based polyurethane resin - Ricinus communis $[5,6,7]$. The first part of this work consisted of countless computer simulations to establish limits for mechanical testing. These 
tests, combined with electrical tests, confirmed that this new surface treatment increases the lifetime of cross-arms under environmental conditions. The mechanical and electrical properties of these polyurethane-coated cross-arms were also analyzed, proving that the product is market competitive and ecologically acceptable.

\section{NUMERICAL COMPUTER SIMULATION}

Simulations of the mechanical behavior of reforested timber cross-arms were carried out using the ANSYS 6.1 software program based on the finite element method (FEM), which is currently one of most widely employed numerical computer methods for magnetic and electrical field calculations [8]. To reduce the processing time in these simulations, the thin layer of polyurethane resins was not included; instead, a mesh containing 3890 elements was employed.

In the preprocessing phase, the standard cross-arm [9] illustrated in Figure 1 was drawn using the solid generation system, after which the meshes were generated by the aforementioned software. The contour conditions for the bending test (see figure 4) were introduced in a subsequent step. The processing was executed in static regime, using a model without holes and with sharp edges. Figure 2 shows a simulation in which $5.49 \mathrm{kN}$ (560 kgf) [9] were applied on the points indicated.

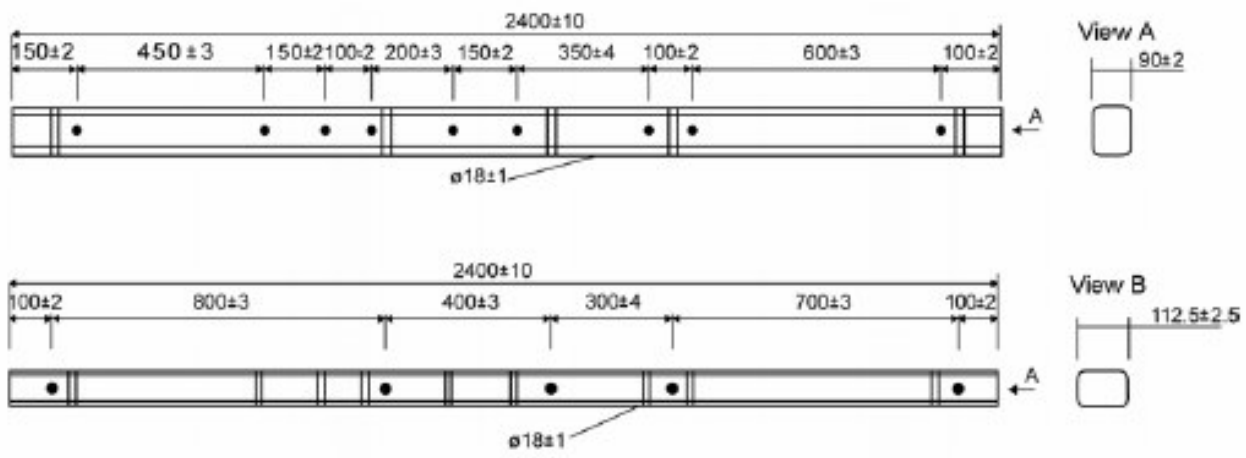

Figure 1. 2.4 meter long wooden cross-arm with standards holes.

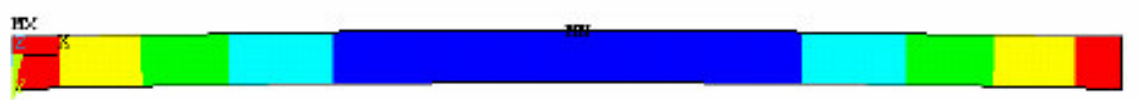

Maximum displacement $(M X)=13.80 \mathrm{~mm}$ (View A)

Figure 2. Example of ANSYS cross-arm simulation, in which a force of $5.49 \mathrm{kN}$ (560 kgf) was applied at the two points indicated (View A). 


\section{EXPERIMENTAL METHODS AND PROCEDURES}

\section{$\underline{\text { Samples }}$}

All the samples used in this research were made of the reforested species Eucalyptus citriodora and Pinus elliotti, whose average rigidity and strength values are listed in Table 1, which also shows other native woods used for cross-arms [4].

Table 1. Average values of rigidity and strength [4].

\begin{tabular}{cccc}
\hline Wood & $\begin{array}{c}\rho_{\text {ap }}{ }^{(1)} \\
\mathbf{k g} / \mathbf{m}^{3}\end{array}$ & $\begin{array}{c}\mathbf{E}^{(2)} \\
\mathbf{M P a}\end{array}$ & $\begin{array}{c}\mathbf{F}_{\mathbf{n}}{ }^{(5)} \\
\mathbf{M P a}\end{array}$ \\
\hline Eucalyptus citriodora & 999 & 18421 & 3.9 \\
Pinus elliotti & 560 & 118889 & 2.5 \\
Hymenaea spp & 1074 & 23607 & 3.2 \\
Bagassa guianensis & 940 & 19583 & 3.9 \\
\hline Tabebuia serratifolia & 1068 & 18011 & 3.1 \\
\hline (1) $\rho_{\text {ap }}=$ apparent specific mass at 12\% of humidity \\
(2) $\mathrm{E} \quad=$ elasticity modulus \\
(3) $\mathrm{F}_{\mathrm{n}} \quad=$ normal fiber tensile strength
\end{tabular}

\section{Resin coating process}

All the wood destined for testing was dried at room temperature and coated with resin without filler. The resin, dubbed RI 3, was prepared by weighing the polyol on a semi-analytic scale, to which the pre-polymer was added in a mass proportion of 1:1.5. These two components were mixed for about $3 \mathrm{~min}$ in a vacuum below 100 mbar to extract air bubbles. A homogeneous 1 -mm thick layer of resin was applied with a brush or a piece of cotton on the wood surface under environmental conditions of $25^{\circ} \mathrm{C}$ and a relative humidity of $50 \%$.

\section{Young's Modulus of Elasticity of the Resin}

Five 3-mm thick samples of RI 3 were allowed to cure for 120 hours, after which they were subjected to tensile mechanical tests, in accordance with the ASTM D638 standard [10]. For these tests, which yield the resin's Young's modulus and the maximum rupture strength, a universal EMIC machine was used, applying a force of $30 \mathrm{kN}$ and test velocity of $50 \mathrm{~mm} / \mathrm{min}$. Figure 3 depicts an example of the samples. 


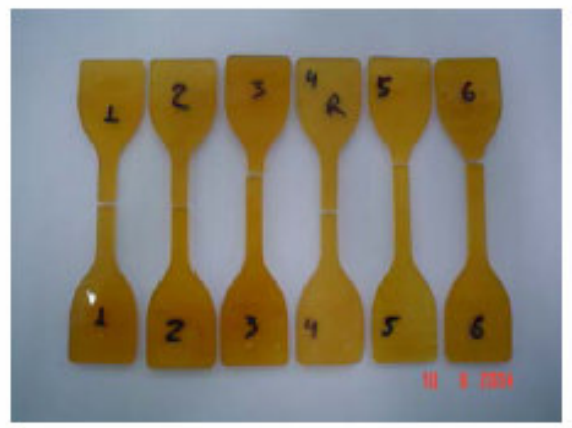

Figure 3. Samples used to determine the resin's modulus of elasticity.

\section{Shear tests}

To verify the adherence of resin on the timber, five samples prepared according to ASTM D6392-99 specifications [11] were subjected to a shear test 24 hours after the gluing process. Each sample consisted of two rectangular pieces of timber with dimensions of $2 \times 15 \mathrm{~cm}$, glued along one of their edges with RI3 resin. The gluing area was $600 \mathrm{~mm}^{2}$ and $0.2 \mathrm{~mm}$ thick. The tests were carried out in an EMIC ${ }^{8}$ universal testing machine at a maximum capacity of $100 \mathrm{kN}$ and a speed $5.0 \mathrm{~mm} / \mathrm{min}$.

\section{Mechanical tests}

The samples for the mechanical tests were prepared on a full scale with dimensions of $90 \mathrm{x}$ $112.5 \times 2.400 \mathrm{~mm}$ and with standards holes, as illustrated by the diagram in Figure 2. These tests involved impregnated and non-impregnated wood. To identify the different samples during these tests, they were given the same codes as those of the electrical tests.

The bending strength properties were measured based on the ABNT standard [9], using a VICKERS ${ }^{8-}$ model XG 06 F 20 hydraulic machine, a Mitutoyo ${ }^{\circ}$ comparative clock - model BBY 051, No. $3058 \mathrm{~F}$ and a Templec $\circledast$ humidity and temperature meter. The tests were conducted at a temperature of $21^{\circ} \mathrm{C}$ and relative air humidity of $61 \%$. Figure 4 shows a detail of these tests

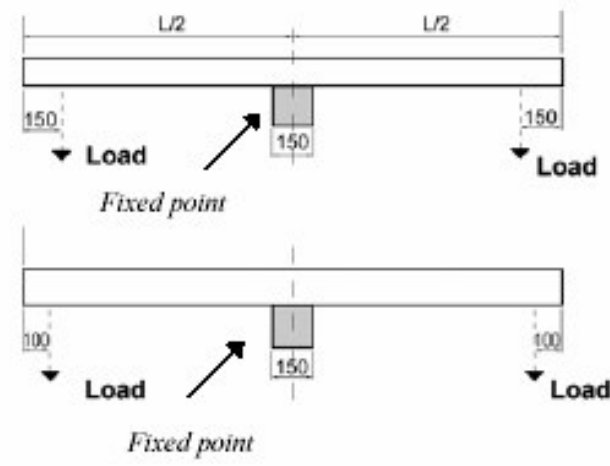

Figure 4. Detail of the bending test: (a) situation B; (b) situation A. 


\section{Electrical Tests}

The electrical tests for surface resistivity, $\rho_{\mathbf{s}}$, and dielectric dissipation factor, $\tan \delta$, were carried out on $50 \times 120 \times 6 \mathrm{~mm}$ resin-coated samples of Eucalyptus citriodora impregnated with oil (CT), nonimpregnated Eucalipytus citriodora (CN), and non-impregnated Pinus elliotti (PN). These tests, each of which involved five samples, were conducted according to the ASTM standard [12, 13, 14].

Similarly prepared samples were used to evaluate resistance to tracking and erosion under severe ambient conditions. Ammonium chloride (0.1\%) with Antrox $(0.002 \%)$, with a conductivity of $2.53 \mathrm{mS} / \mathrm{cm}$, was used as a contaminating solution. In preparation for this test, five samples were sandpapered and cleaned with isopropyl alcohol. The operator defined the initial test voltage, which was increased in increments of $250 \mathrm{~V}$ per hour until the end of the test, determined by the failure of several samples.

\section{RESULTS}

\section{$\underline{\text { Simulation results }}$}

To define limits and parameters, the results of the simulation were analyzed before conducting the mechanical bending tests. Tables 2 and 3 compare some of these simulations and list the results of the mechanical bending tests.

Table 2. Comparison of bending test results and simulations for Eucaliptus citriodora cross-arms.

\begin{tabular}{ccccc}
\hline 2,4 m Cross-arm & $\begin{array}{c}\text { Situation A } \\
\mathbf{3 . 9 2} \mathbf{~ k N}\end{array}$ & $\begin{array}{c}\text { Situation B } \\
\mathbf{3 . 9 2} \mathbf{~ k N}\end{array}$ & $\begin{array}{c}\text { Situation A } \\
\mathbf{5 . 4 9} \mathbf{~ k N}\end{array}$ & $\begin{array}{c}\text { Situation B } \\
\mathbf{5 . 4}\end{array}$ \\
\hline $\begin{array}{c}\text { Measured displacement } \\
\text { (mm) }\end{array}$ & 5.73 & 7.95 & 8.12 & 11.08 \\
$\begin{array}{c}\text { Displacement resulting from } \\
\text { ANSYS simulation } \\
\text { (mm) }\end{array}$ & $\mathbf{9 . 8 5}$ & $\mathbf{1 4 . 8 1}$ & $\mathbf{1 3 . 8 0}$ & $\mathbf{2 0 . 7 3}$ \\
\hline $\begin{array}{c}\text { Maximum displacement } \\
\text { from standard NBR 8458 }\end{array}$ & 115 & 115 & 163 & 163 \\
(mm) & & & \\
\hline
\end{tabular}


Table 3. Comparison of bending test results and simulations for Pinus elliottii.

\begin{tabular}{|c|c|c|c|c|}
\hline 2,4 m Cross-arm & $\begin{array}{c}\text { Situation A } \\
3.92 \mathrm{kgf}\end{array}$ & $\begin{array}{c}\text { Situation B } \\
3.92 \mathrm{kgf}\end{array}$ & $\begin{array}{c}\text { Situation A } \\
5.49 \mathrm{kN}\end{array}$ & $\begin{array}{c}\text { Situation B } \\
5.49 \mathrm{kN}\end{array}$ \\
\hline $\begin{array}{c}\text { Measured displacement } \\
(\mathrm{mm})\end{array}$ & 17.62 & 24.30 & 25.14 & 33.63 \\
\hline $\begin{array}{l}\text { Displacement resulting from } \\
\text { ANSYS simulation } \\
(\mathrm{mm})\end{array}$ & 15.27 & 22.95 & 21.38 & 32.13 \\
\hline $\begin{array}{l}\text { Maximum displacement } \\
\text { from standard NBR } 8458 \\
(\mathrm{~mm})\end{array}$ & 115 & 115 & 163 & 163 \\
\hline
\end{tabular}

\section{Experimental results}

The results of the mechanical tensile tests to determine the resin's modulus of elasticity and the tensile rupture strength are shown in Table 4.

Table 4. Results of mechanical tensile tests of Resin RI 3 cured for 120 hours.

\begin{tabular}{ccccc}
\hline $\begin{array}{c}\text { Sample } \\
\text { identification }\end{array}$ & $\begin{array}{c}\text { Maximum } \\
\text { strength } \\
(\mathbf{N})\end{array}$ & $\begin{array}{c}\text { Specific strain } \\
\text { of the device } \\
(\%)\end{array}$ & $\begin{array}{c}\text { Traction stress } \\
\text { (MPa) }\end{array}$ & $\begin{array}{c}\text { Young's } \\
\text { modulus of } \\
\text { elasticity }\end{array}$ \\
\hline 1 & 97.13 & 117.1 & 5.092 & 10.00 \\
2 & 108.9 & 135.7 & 7.842 & 12.73 \\
3 & 109.3 & 126.5 & 6.946 & 18.00 \\
4 & 109.2 & 129.9 & 7.042 & 14.27 \\
Average value & $\mathbf{1 0 6 . 1}$ & $\mathbf{1 2 7 . 3}$ & $\mathbf{6 . 7 3 0}$ & $\mathbf{1 3 . 7 5}$ \\
Standard Deviat. & $\mathbf{5 . 6 6 1}$ & $\mathbf{6 . 1 1 5}$ & $\mathbf{1 7 . 2 9}$ & $\mathbf{2 4 . 2 7}$ \\
(\%) & & & & \\
\hline
\end{tabular}

Tables 5,6 and 7 give the shear test results for oil impregnated and non-impregnated Eucaliptus citriodora and Pinus elliottii, glued with RI 3 resin with a cure time of 48 hours and glued area of 600 $\mathrm{mm}^{2}$. 
Table 5: Results of the shear test - oil impregnated and non-impregnated Eucaliptus citriodora.

\begin{tabular}{cccc}
\hline Sample identification & $\begin{array}{c}\text { Maximum strength } \\
(\mathrm{KN})\end{array}$ & $\begin{array}{c}\text { Specific strain of the } \\
\text { device } \\
(\mathbf{\%})\end{array}$ & $\begin{array}{c}\text { Strength/Width } \\
(\mathbf{N} / \mathbf{m})\end{array}$ \\
\hline 1 & 3.012 & 0.5481 & 125.5 \\
2 & 2.765 & 0.7041 & 120.2 \\
3 & 3.917 & 1.238 & 170.3 \\
4 & 3.651 & 1.311 & 158.7 \\
5 & 2.893 & 0.9469 & 125.8 \\
Average Value & $\mathbf{3 . 2 4 8}$ & $\mathbf{0 . 9 4 9 7}$ & $\mathbf{1 4 0 . 1}$ \\
Standard Deviat. (\%) & $\mathbf{1 5 . 5 9}$ & $\mathbf{3 4 . 7 4}$ & $\mathbf{1 6 . 2 5}$ \\
\hline
\end{tabular}

Table 6: Shear test results - oil-impregnated Eucaliptus citriodora.

\begin{tabular}{cccc}
\hline Sample identification & $\begin{array}{c}\text { Maximum strength } \\
\mathbf{( k N )}\end{array}$ & $\begin{array}{c}\text { Specific strain of the } \\
\text { device } \\
(\%)\end{array}$ & $\begin{array}{c}\text { Strength/Width } \\
(\mathbf{N} / \mathbf{m})\end{array}$ \\
\hline 1 & 2.724 & 0.4383 & 110.3 \\
2 & 2.552 & 0.4419 & 103.3 \\
3 & 2.245 & 0.5572 & 91.63 \\
4 & 1.760 & 0.3295 & 74.88 \\
5 & 2.877 & 0.5621 & 122.4 \\
Average Value & $\mathbf{2 . 4 3 2}$ & $\mathbf{0 . 4 6 5 8}$ & $\mathbf{1 0 0 . 5}$ \\
Standard Deviat. (\%) & $\mathbf{1 8 . 2 2}$ & $\mathbf{2 0 . 8 0}$ & $\mathbf{1 8 . 0 8}$ \\
\hline
\end{tabular}

Table 7: Shear test results - Pinus elliottii.

\begin{tabular}{cccc}
\hline Sample identification & $\begin{array}{c}\text { Maximum strength } \\
(\mathbf{k N})\end{array}$ & $\begin{array}{c}\text { Specific strain of the } \\
\text { device } \\
(\%)\end{array}$ & $\begin{array}{c}\text { Strength/Width } \\
(\mathbf{N} / \mathbf{m})\end{array}$ \\
\hline 1 & 3.075 & 1.249 & 130.8 \\
2 & 3.194 & 1.018 & 135.9 \\
3 & 2.993 & 1.076 & 127.4 \\
4 & 2.273 & 0.7685 & 96.73 \\
5 & 2.712 & 1.415 & 115.4 \\
Average Value & $\mathbf{2 . 8 4 9}$ & $\mathbf{1 . 1 0 5}$ & $\mathbf{1 2 1 . 2}$ \\
Standard Deviat. (\%) & $\mathbf{1 2 . 9 1}$ & $\mathbf{2 2 . 0 9}$ & $\mathbf{1 2 . 9 1}$ \\
\hline
\end{tabular}

As shown in Tables 5,6 and 7, the polyurethane resin adhered very well to the wood, withstanding an average shearing strength of more than $2,40 \mathrm{kN}$ over a glued area of $600 \mathrm{~mm}^{2}$. Another important point was that the impregnation resin presented a shiny surface with only a very 
slight change in the wood color. These two characteristics are important to increase the mechanical strength and harmonize the structure with the natural surroundings.

The bending test data for $3.92 \mathrm{kN}$ and $5.49 \mathrm{kN}$ listed in Tables 8 and 9 , respectively, indicate that oil-impregnated Eucalyptus citriodora displays excellent mechanical bending strength and a displacement value well below the maximum displacement allowed by the NBR- 8458 standard. However, although its displacement value was lower than the maximum displacement recommended by the NBR 8458 standard, Pinus elliottii broke during the test at points where the wood contained a knot. Even so, the mechanical bending strength of both these wood species increased further with the application of polyurethane resin coating.

Table 8. Load bending test at $3.92 \mathrm{kN}$ (400 kgf).

\begin{tabular}{cccc}
\hline $\begin{array}{c}\text { 2.4 meter } \\
\text { Cross-arm }\end{array}$ & $\begin{array}{c}\text { Displacement measured } \\
(\mathbf{m m})\end{array}$ & $\begin{array}{c}\text { Maximum displacement } \\
\text { allowed by NBR 8458 } \\
(\mathbf{m m})\end{array}$ \\
\cline { 2 - 4 } $\begin{array}{c}\text { Eucalyptus citriodora } \\
\text { Oil-impregnated } \\
\text { Eucalyptus citriodora } \\
\text { Oil-impregnated and } \\
\text { polyurethane resin coated } \\
\text { Pinus elliottii } \\
\text { in its natural state }\end{array}$ & 5.73 & 7.95 & 115 \\
\hline $\begin{array}{c}\text { Pinus elliottii } \\
\text { in its natural state and } \\
\text { polyurethane resin coated }\end{array}$ & 17.62 & 24.30 & 115 \\
\hline
\end{tabular}


Table 9. Bending load test for $5.49 \mathrm{kN}$ (560 kgf).

\begin{tabular}{|c|c|c|c|}
\hline \multirow[t]{2}{*}{$\begin{array}{l}2.4 \text { meter } \\
\text { Cross-arm }\end{array}$} & \multicolumn{2}{|c|}{$\begin{array}{l}\text { Displacement measured } \\
(\mathrm{mm})\end{array}$} & \multirow{2}{*}{$\begin{array}{l}\text { Maximum displacement } \\
\text { allowed by NBR } 8458 \\
(\mathrm{~mm})\end{array}$} \\
\hline & A & B & \\
\hline $\begin{array}{c}\text { Eucalyptus citriodora } \\
\text { Oil-impregnated }\end{array}$ & 8.12 & 11.08 & 163 \\
\hline $\begin{array}{l}\text { Eucalyptus citriodora } \\
\text { Oil-impregnated and } \\
\text { polyurethane resin coated }\end{array}$ & 6.56 & 8.60 & 163 \\
\hline $\begin{array}{c}\text { Pinus elliottii } \\
\text { in its natural state }\end{array}$ & 25.14 & 33.63 & 163 \\
\hline $\begin{array}{l}\text { Pinus elliottii } \\
\text { in its natural state and } \\
\text { polyurethane resin coated }\end{array}$ & 12.55 & 18.12 & 163 \\
\hline
\end{tabular}

* Rupture of the sample occurred during the test

Table 10, which lists the bending strength values, indicates that Eucalyptus citriodora shov an excellent performance, with a bending strength approximately $150 \%$ higher than the minim bending strength admitted by the ABNT standard. Again, although the bending strength of $P i$ elliottii was greater than the minimum bending strength recommended by the ABNT standard, its ve is low; hence, this species cannot be recommended for this type of application.

Table 10. Cross-arm bending strength.

\begin{tabular}{ccc}
\hline $\begin{array}{c}\text { Cross-arm made of } \\
\text { (N) }\end{array}$ & $\begin{array}{c}\text { Bending strength } \\
\text { Oil-impregnated }\end{array}$ & $\begin{array}{c}\text { Minimum Bending Strength } \\
\text { allowed by the ABNT } \\
\text { (N) }\end{array}$ \\
$\begin{array}{c}\text { Eucalyptus citriodora } \\
\text { Oil-impregnated and } \\
\text { polyurethane resin coated } \\
\text { Pinus elliottii } \\
\text { in its natural state }\end{array}$ & 20.162 & 7.845 \\
\hline $\begin{array}{c}\text { Pinus elliottii } \\
\text { in its natural state and } \\
\text { polyurethane resin coated }\end{array}$ & $13.896^{*}$ & 7.845 \\
\hline * Rupture of the sample occurred during the test & 7.845 \\
\hline
\end{tabular}

* Rupture of the sample occurred during the test 
An analysis of the results of the electrical tests shown in Table 11 and of the results reported by reference [6] reveals that, in this impregnation process, the resin's electrical characteristics predominate over the wood's electrical characteristics, indicating the strong influence of the superficial resin layer.

Table 11. Electrical characteristics of wood coated with polyurethane resin.

\begin{tabular}{cccc}
\hline $\begin{array}{c}\text { Wood coated with } \\
\text { polyurethane resin }\end{array}$ & $\begin{array}{c}\text { Surface } \\
\text { Resistivity } \\
\left(\Omega \mathbf{1 0}^{15}\right)\end{array}$ & $\begin{array}{c}\text { Dielectric } \\
\text { dissipation } \\
\text { factor tan } \delta) \\
\text { for 1.5kV }\end{array}$ & $\begin{array}{c}\text { Dielectric } \\
\text { dissipation } \\
\text { factor (tan } \delta) ~ \\
\text { for } \mathbf{2 . 0 ~ k V}\end{array}$ \\
\hline $\begin{array}{c}\text { Eucalyptus citriodora } \\
\text { oil-impregnated }\end{array}$ & 1.2 & 0.032 & 0.03 \\
\hline $\begin{array}{c}\text { Pinus elliottii } \\
\text { in its natural state }\end{array}$ & 1.2 & 0.032 & 0.03 \\
\hline
\end{tabular}

Table 12 shows the results of the test to evaluate tracking and erosion resistance under severe environmental conditions, according to the ASTM D2303 standard.

Table 12. Tracking and erosion resistance under severe environmental conditions.

\begin{tabular}{ccc}
\hline $\begin{array}{c}\text { Wood coated with } \\
\text { polyurethane resin }\end{array}$ & Failure Voltage (kV) & Failure mode \\
\hline $\begin{array}{c}\text { Eucalyptus citriodora } \\
\text { Oil-impregnated }\end{array}$ & 2.0 & Tracking within \\
\hline Pinus elliottii & 2.25 & Tracking within \\
in its natural state & & $2-3 \mathrm{~h}$ \\
\hline
\end{tabular}

\section{CONCLUSIONS}

An analysis of Table 1 reveals the excellent mechanical properties of reforested Eucalyptus citriodora compared with native tropical wood species and with reforested Pinus elliottii. These excellent properties were confirmed by cross-arm mechanical tests, which indicated a bending strength for this application approximately three times superior to the minimum established by the ABNT standard. The results of the tests on this wood species coated with resin were even better. Eucalyptus citriodora impregnated with preservative oil showed a 10- to 30-year longer lifetime under natural weathering conditions. Since polyurethane resin has good hydrophobic and adherence properties, i.e., it is waterproof, wood coated with this resin will remain dry and, if not in contact with fungi or parasites, its mechanical strength and lifetime can be prolonged for many more years. Aging 
tests are being initiated to determine the average lifetime of Eucalyptus citriodora cross-arms coated with polyurethane resin.

Although Pinus Elliottii coated with resin also passed the mechanical tests, its many weak points concentrated at its knots requires it be selected with special care. These weaknesses may limit its application for cross-arm purposes.

Since these resins keep the wood dry, the electrical resistivity of wood, which normally varies greatly with moisture content, especially below the fiber saturation point, remains stable at values of about $10^{14}$ to $10^{16} \Omega \mathrm{m}$, improving the electrical characteristics of these cross-arms. The resistances to tracking and erosion under severe weathering tests also showed a positive impact on the electrical characteristics of these cross-arms, increasing their Basic Impulse Insulation Level-BIL.

With regard to the simulations, it can be concluded that they simply the preparation for mechanical testing and provide a good approximation of mechanical results. However, simulations of large structures coated with a thin layer of resin may sometimes lead to inaccurate results. To minimize this problem, many more elements are usually required than the number employed here, representing a significant increase in computer memory and processing time. New simulations are ongoing to optimize these two parameters.

To conclude, timber cross-arms coated with polyurethane resin may be an economically and technically viable alternative for electric power distribution systems.

\section{ACKNOWLEDGMENTS}

This work was accomplished with the collaboration of the Laboratory of Analytical Chemistry, São Carlos Institute of Chemistry (IQSC-USP), the Institute of Electrical Engineering (IEE) - University of São Paulo (USP), the Wood Structures and Geosciences Laboratories at EESC-USP, COMPANHIA ICOTEMA LTDA, and funded by CNPq, a Brazilian research support foundation and by ELEKTROANEEL, Brazil.

\section{REFERENCES}

1. Silva, J. F. R. Relatório Técnico sobre vida útil de cruzetas em sistemas de Distribuiçăo de Energia. Relatório Técnico: Elektro - Eletricidade e Serviços S.A., Campinas, Brasil, pp. 80, 2001 (in Portuguese)

2. Asböll, E. Laminated wood structures in Norwegian Transmission Lines. Overhead Line Design and Construction: Theory and Practice. International Conference, November, pp. 36-39, 1988.

3. Liebel, S.A; Mueller, R.E. Douglas Fir Cross-arms Solid Sawn vs. Laminated Comparison. Transmission and Distribution Conference, Proceedings of the 1994 IEEE Power Engineering Society, April, pp. 581-586, 1994.

4. ABNT - Brazilian Standard - Project of Wood Structures - NBR - 7190, August, 1997.

5. Altafim, R.A.C.; Murakami, C.R.; Claro Neto, S.; Araújo, L.C.R.; Chierice, G.O. The effects of fillers on the service properties of polyurethane resins. Materials Research Magazine, São Carlos, Brazil, April-June, vol. 6, no. 2, pp. 187-191, 2003. 
6. Gonzaga, D.P.; Murakami, C.R.; Chierice, G.O.; Altafim, R.A.C. Electrical characterization of castor oil resins. In: International Symposium on Electrical Insulation (ISEI), Arlington, Virginia, June 7-10, EUA, v. 1, pp.181-185, 1998.

7. Claro Neto, S. Physical and chemical characterization of castor-oil derived polyurethanes used in bone implants. Doctoral Thesis, São Carlos Institute of Chemistry, University of São Paulo, São Carlos, Brazil, 1997

8. Sylvester, P.; Ferrari, R. Finite Element for Electrical Engineer. Cambridge/UK, Cambridge University Press, 1990

9. ABNT - Brazilian Standard - Wood Cross-arm for Power Distribution System - NBR - 8458, August 1990 .

10. American Society For Testing And Materials, ASTM D638 - Standard Test Method for Tensile Properties of Plastics. West Conshohocken, USA, 1996.

11. American Society for Testing and Materials, ASTM D6392 - Standard Test Method for Determining the Integrity of Nonreinforced Geomembrane Seams Produced using ThermoFusion Methods. West Conshohocken, USA, 1999.

12. American Society for Testing and Materials, ASTM D149 - Standard Test Methods for Dielectric Breakdown Voltage and Dielectric Strength of Electrical Insulating Materials at Commercial Power Frequencies. Philadelphia, 1978

13. American Society for Testing and Materials, ASTM D150-78 - Standard Test Methods for A-C Loss Characteristics and Permittivity (Dielectric Constant) of Solid Electrical Insulation Materials. Philadelphia, 1978

14. American Society for Testing and Materials, ASTM D257-78 - Standard Test Methods for DC Resistance or Conductance of Insulating Materials. Philadelphia, 1978. 


\section{APÊNDICE B}

\section{Como Usar do ANSYS $\AA$}

Este anexo tem por objetivo auxiliar os interessados na familiarização e no uso do software ANSYS®, na elaboração de modelos para simulação de fenômenos eletromagnéticos, esforços mecânicos e transmissão térmica.

\subsection{Introdução}

O ANSYS® é um software que tem como base a simulação de modelos matemáticos através do Método do Elementos Finitos, método este já mundialmente difundido e capaz de ser aplicado nas mais diversas situações, com por exemplo no cálculo de deformações mecânicas, de fluxo de campos eletromagnéticos, gradientes de transmissão de calor e movimentação de fluidos. Assim serão exemplificados á frente.

De uma maneira geral as simulações através do método dos elementos finitos podem ser separadas em três fases: 
Pré-processamento;

Processamento;

Pós-Processamento.

A seguir uma breve descrição de cada etapa.

Pré-processamento: onde são feitas as entradas das variáveis a serem analisadas, sempre considerando o tipo de análise a ser feita onde se deve caracterizar o tipo de material a ser simulado. No caso de uma simulação mecânica, é necessário definir quantos são os graus de liberdade do material, definindo, por exemplo, que se trata de um material isotrópico, logo é representado por um valor de módulo de elasticidade, além de seu coeficiente de Poisson.

1.1.1. Escolher qual dos elementos disponíveis na biblioteca de elementos do ANSYS $\AA$ é aquele que possui as melhores características capazes de fornecer a melhor resposta para a análise a ser realizada, e construir a malha dos elementos que será responsável pela melhor representação do modelo.

1.1.2. Definir os pontos onde serão aplicadas as forças e onde serão os pontos de apoio do modelo da simulação, e aplicar as referias forças com direção e intensidades determinadas.

É importante manter um padrão de unidades e ordens de grandezas bem definidos para que não sejam induzidos erros de entrada nas simulações.

Processamento: esta fase está reservada às matrizes de análise matemática que fazem o processamento matemático das informações de entrada em cada um dos pontos dos elementos do modelo. 
Pós-Processamento: Essa é a última das etapas e é responsável pela interpretação das informações obtidas após o cálculo matemático computacional, onde deve ser escolhido o melhor filtro, mostrado adiante, que traga a resposta desejada, com por exemplo, o valor da deformação ocorrida na direção do eixo Y.

Mais detalhes de cada uma dessas etapas são mostrada a seguir:

\subsection{Reconhecendo a Área de Trabalho}

As figuras a seguir mostram como é a divisão das ferramentas que compõem a área de trabalho do usuário do software ANSYS®.

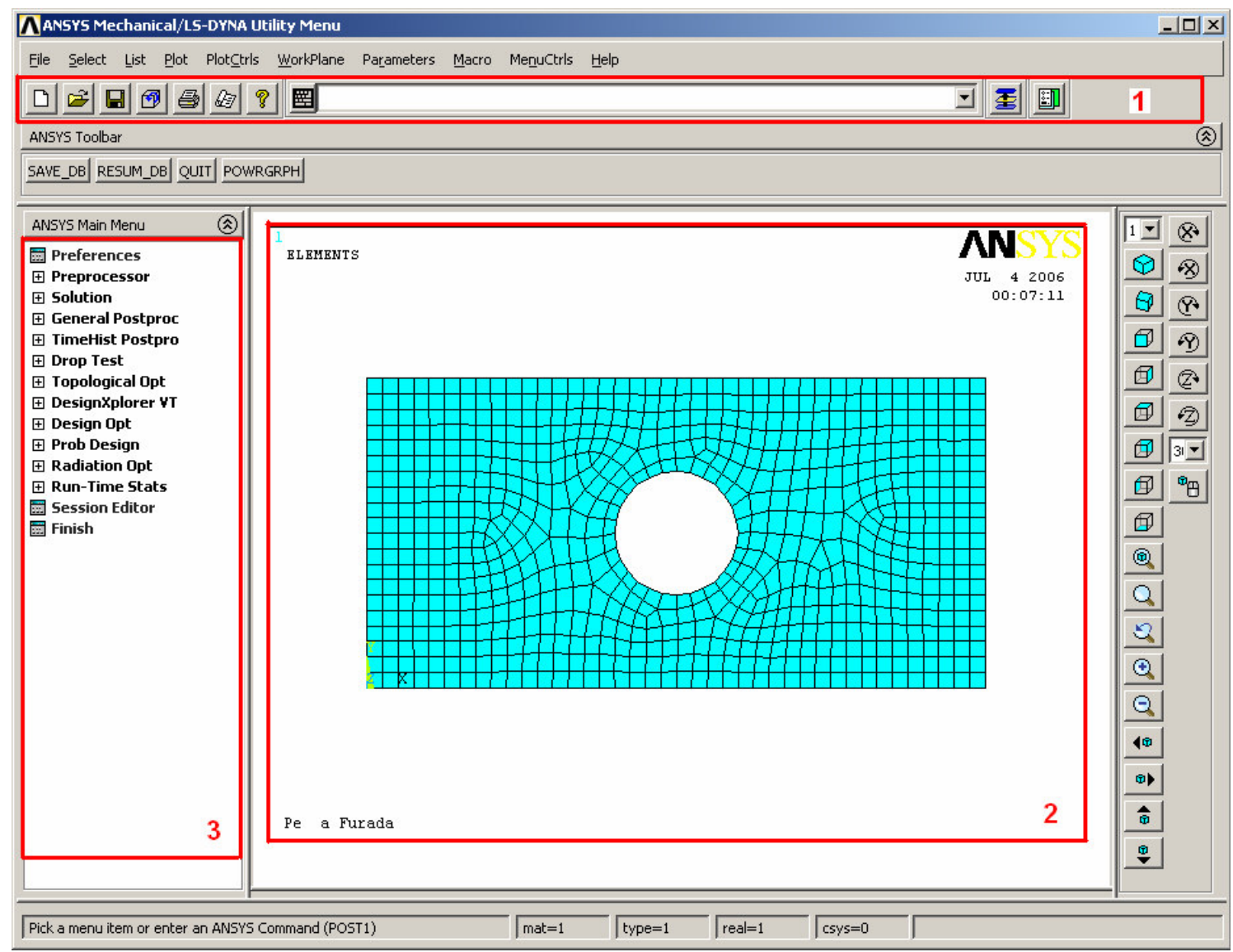

Figura B1 - Tela Inicial do ANSYS® 
Pode-se utilizar a figura B1 para demonstrar a distribuição das funções

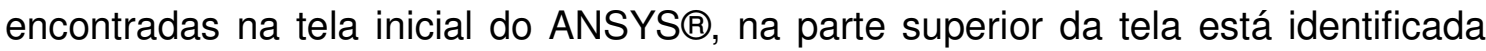
pelo número 1, trata da barra de ferramentas de arquivo do ANSYS $\AA_{\text {que contem os }}$ botões descritos a seguir:

- Nova Análise (New Analisys)

- Abrir arquivo de análise (Open ANSYS File),

- Salvar analise (Save Analysys),

- Movimenta, aproximar e girar (Pan-Zoom-Rotate),

- Captura imagem (Image Capture),

- Gerador de relatórios (Report Generator),

- Ajuda (ANSYS Help),

- Linha de comandos (ANSYS Command Prompt),

- Mostrar e ocultar janelas (Raise Hidden), e

- Gerenciador de contatos(Contact Manager).

A parte que está em destaque e marcada com o número 2 é a tela de visualização do modelo, cada mudança feita no desenho do modelo será mostrada cada vez que a visualização do desenho for atualizada. Nesta tela também são mostrados os resultados das análises feitas pelo software por meio de uma escala de cores que variam pelo contorno do modelo, de acordo com a o comportamento do modelo frente ao tipo de análise escolhida pelo usuário. Esta parte será mais bem vista na análise dos resultados. 
E, finalmente, a parte destacada como 3 é o Menu Principal do ANSYS $\AA_{\text {, e é }}$ neste menu que estão incluidos todos os comandos e parâmetros que regem as analises realizadas dentro deste programa de simulação por elementos finitos.

O menu principal é dividido pelos seguintes sub menus:

- Preprocessor

- Solution

- General Postproc

- TimeHist Postpro

- Drop Test

- Topological Opt

- ROM Tool

- DesignXplorer VT

- Design Opt

- Prob Design

- Radiation Opt

- Run-Time Stats

- Session Editor

- Finish

Este manual básico irá abordar os três primeiros itens por se tratar de um tutorial de nível básico, mas esse conhecimento inicial deverá servir de impulso para o conhecimento dos outros itens. 


\subsection{Unidades}

É importante conhecer e escolher muito bem quais são as unidades que estão sendo consideradas nas simulações, pois as unidades estão diretamente ligadas à credibilidade dos resultados das simulações realizadas neste software.

Neste manual é sugerido que sempre sejam usadas as unidades do sistema internacional SI que são:

Gerais

- Comprimento

[m]

- Massa

- Temperatura

- Tempo

- Pressão

Unidades mecânicas

- Densidade

- Módulo de elasticidade

- Densidade de stress

- Coeficiente de expansão

Unidades termais

- Capacidade de calor

$[\mathrm{J} / \mathrm{kg} \mathrm{K}]$

- Condutividade térmica

$\left[\mathrm{kg} / \mathrm{m}^{3}\right]$

$[\mathrm{m} / \mathrm{m} \mathrm{K}]$

$[\mathrm{W} / \mathrm{m} \mathrm{K}]$ [kg]

$[\mathrm{K}]$

[s]

$[\mathrm{Pa}]=\left[\mathrm{N} / \mathrm{m}^{2}\right]$

$[\mathrm{Pa}]=\left[\mathrm{N} / \mathrm{m}^{2}\right]$

$[\mathrm{Pa}]=\left[\mathrm{N} / \mathrm{m}^{2}\right]$ 
- Razão de geração de calor $\left[\mathrm{W} / \mathrm{m}^{3}\right]$

Assim, todas as unidades que estiverem diferentes dessas unidades, deverão ser convertidas para essas unidades, a fim de que os resultados fiquem padronizados e não possam causar erros ou enganos nos resultados das simulações.

O comando /STATUS fornece as informações de como estão definidos os parâmetros no ANSYS® no momento, incluindo as unidades especificadas internamente.

\subsection{Exemplo de Simulação Mecânica}

Primeiramente, é necessário entender-se o problema, para que venha a ser interpretado da melhor maneira, com muita clareza, a fim facilitar na construção de um modelo de simulação.

Todas as vezes que forem iniciadas novas simulações, serão necessários cálculos analíticos ou resultados experimentais para que possam existir comparações e resultados. Dessa maneira pode-se afirmar o tipo de análise, as unidades, escalas e os fatores, etc.

Como exemplo consideremos uma versão simples usada para mostrar o problema da tração de uma placa retangular com um furo, mostrada na figura B2 a seguir: 


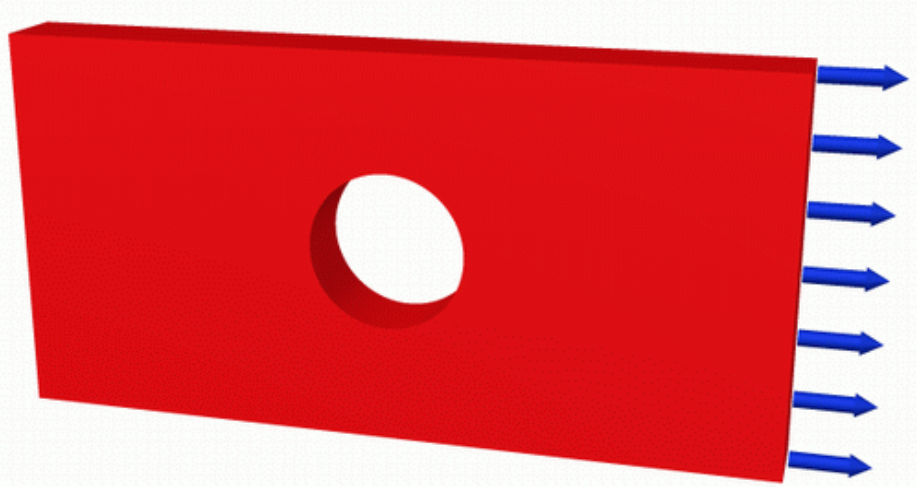

Figura B2 - Modelo de placa sendo tracionada

\section{Pré-processamento: Definindo o Problema}

1. Dando um nome à análise

\section{Menu de utilidades $>$ File $>$ Change Title}

Pose ser interessante ao capturar a imagem da simulação feita no ANSYS® para aplicação em relatórios ou até para impressão, e existe um caminho para mudar a cor do fundo de preta para branca. Que é:

\section{Menu de utilidades $>$ PlotCtrls $>$ Style $>$ Colors $>$ Reverse Vídeo}

2. Construindo a Geometria

As operações boleanas ajudam a criar os mais complicados modelos de sólidos. Esses procedimentos fazem com que se torne fácil a combinação de formas geométricas simples criando assim corpos complexos. A subtração será usada na criação desse modelo, mas de 
qualquer forma várias outras operações boleanas estão presentes no ANSYS.

2.2 Criando a forma retangular principal em termos de área

Preprocessor $>$ Modeling $>$ Create $>$ Áreas $>$ Rectangle $>$ By 2 Corners

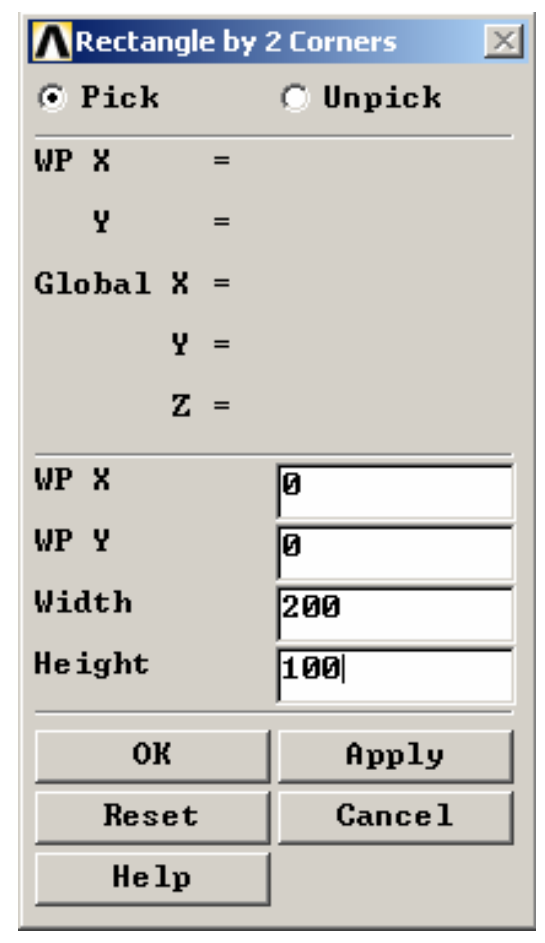

Figura B3 - Janela de criação de retângulo

preencha na janela com mostrado na figura b3, isso criará um retângulo onde o canto esquerdo possuirá as coordenadas 0,0,0 e o topo direito terá as coordenadas $200,100,0$

(a alternativa para a linha deste comando é BLC4,0,0,200,100)

\subsection{Criando o Círculo}

$$
\text { Preprocessor }>\text { Modeling }>\text { Create }>\text { Áreas }>\text { Circle }>\text { Solid Circle }
$$




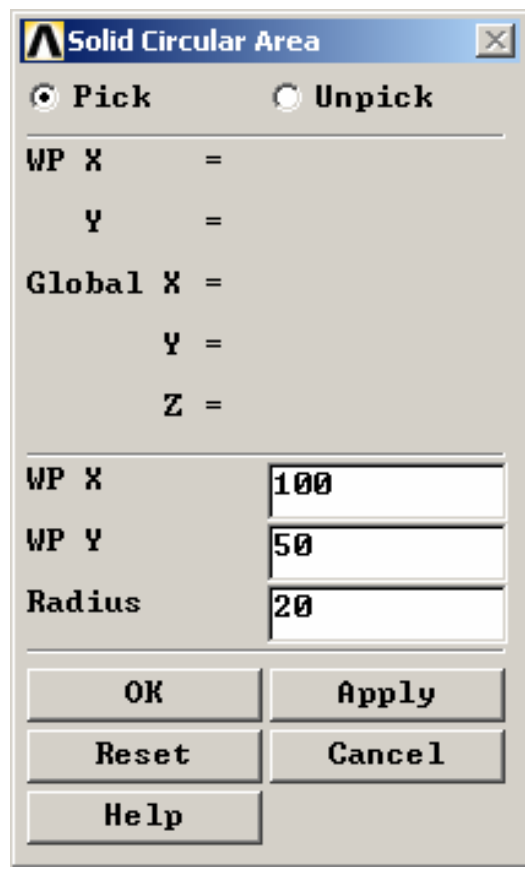

Figura B4 - Janela de criação de circunferência

Mais uma vez, ao preencher a janela com as informações mostradas na figura teremos a formação cada circunferência.

(linha de comando CYL4,100,50,20)

\subsection{Subtração}

Agora, subtraindo a área da circunferência da área do retângulo teremos a figura B5. 


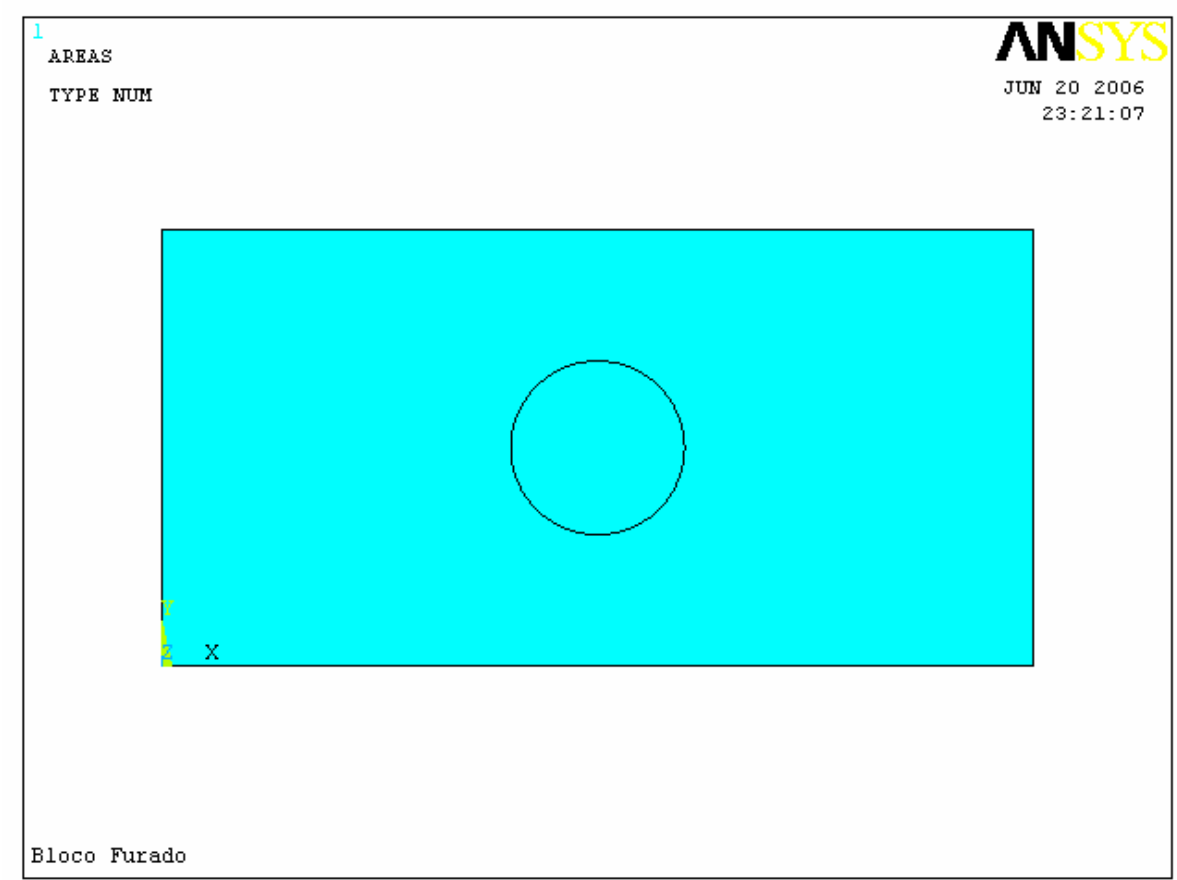

Figura B5 - Visão das duas áreas

Para executar a operação boleana, selecione no menu Preprocessor:

\section{Modeling $>$ Operate $>$ Booleans $>$ Subtract $>$ Areas}

Neste instante a janela 'Subtract Áreas' irá aparecer, e a nova janela irá mostrar a seguinte mensagem: [ASBA] Pick or enter base areas from which to subtract vista na figura 6 . 


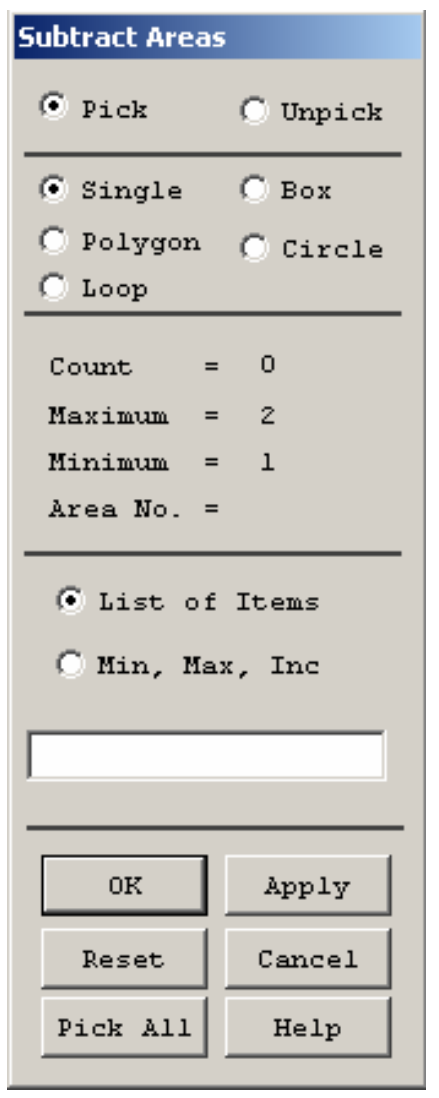

Figura B6 - Janela de subtração de área

Atenção, pois este comando necessita de duas confirmações antes de ser executado, pois várias áreas ou entidades podem ser subtraídas de uma entidade maior de uma só vez.

Assim, a seqüência de comando exige que selecione-se primeiro com o cursor a unidade a qual será feita a subtração, confirma-se em 'OK.

Para selecionar-se a área base (o retângulo) clicando sobre a imagem. Perceba que a área irá fica da cor pink uma vez que for selecionada.

Neste caso, a janela de múltiplas entidades, veja na figura B7, irá aparecer, pois as duas imagens das áreas, também chamadas de entidades, possuem seu centro geométrico coincidentes, vistas deste ângulo de visualização. Se a janela de múltiplas entidades não aparecer, segue-se a diante e seleciona-se o botão 'OK encerra-se a primeira confirmação. 


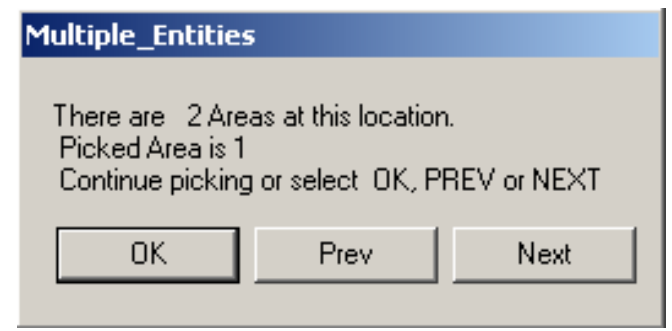

Figura B7 - Janela de múltiplas entidades

Percebe-se que toda a área do retângulo está selecionada, em seguida seleciona-se a área a ser subtraída, a circunferência, assim encerra-se a segunda confirmação com o botão 'OK'.

Tem-se então a figura B8

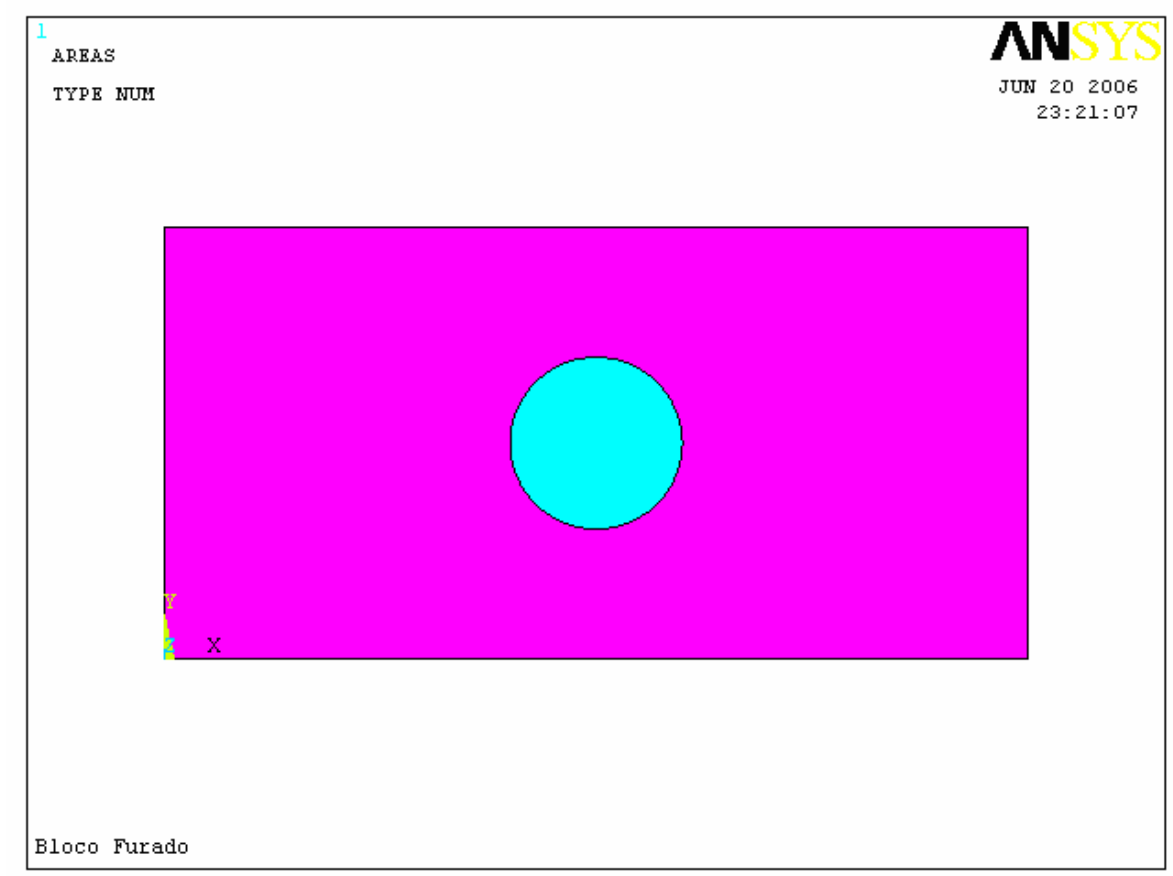

Figura B8 - áreas selecionadas para o comando de subtração

Finalmente na janela da figura B6 confirma se a operação de subtração de áreas, e criando-se o retângulo furado.

(a alternativa para este comando é ASBA,1,2) 


\section{Definindo o Tipo de Elemento da Malha}

A escolha do tipo de elemento a ser usado é o momento onde se define qual será o tipo de análise a ser feita, pois cada tipo de elemento foi criado para atender uma necessidade de representação das grandezas físicas de um material. Para simulações de ordem mecânica como deformação, condução térmica, atrito, pressão, ressonância, aerodinâmica, etc. Também de ordem e elétrica como campos elétricos e campos ou fluxos magnéticos.

Existem elementos para cada um dos casos citados e estes são encontrados na ajuda ou help do ANSYS®, cabe ao usuário definir qual dos elementos disponíveis é melhor aplicado na sua simulação.

Agora, aqui é necessário definir-se o tipo de elementos a serem usados no problema:

\section{Preprocessor Menu $>$ Element Type $>$ Add/Edit/Delete}

Primeiramente selecione $\mathrm{o}$ item add, para adicionar o seguinte tipo de elemento 'Solid (sobre o cabeçalho Strutural) e o elemento Quad 82, como mostrado nas figuras B9 e B10. 


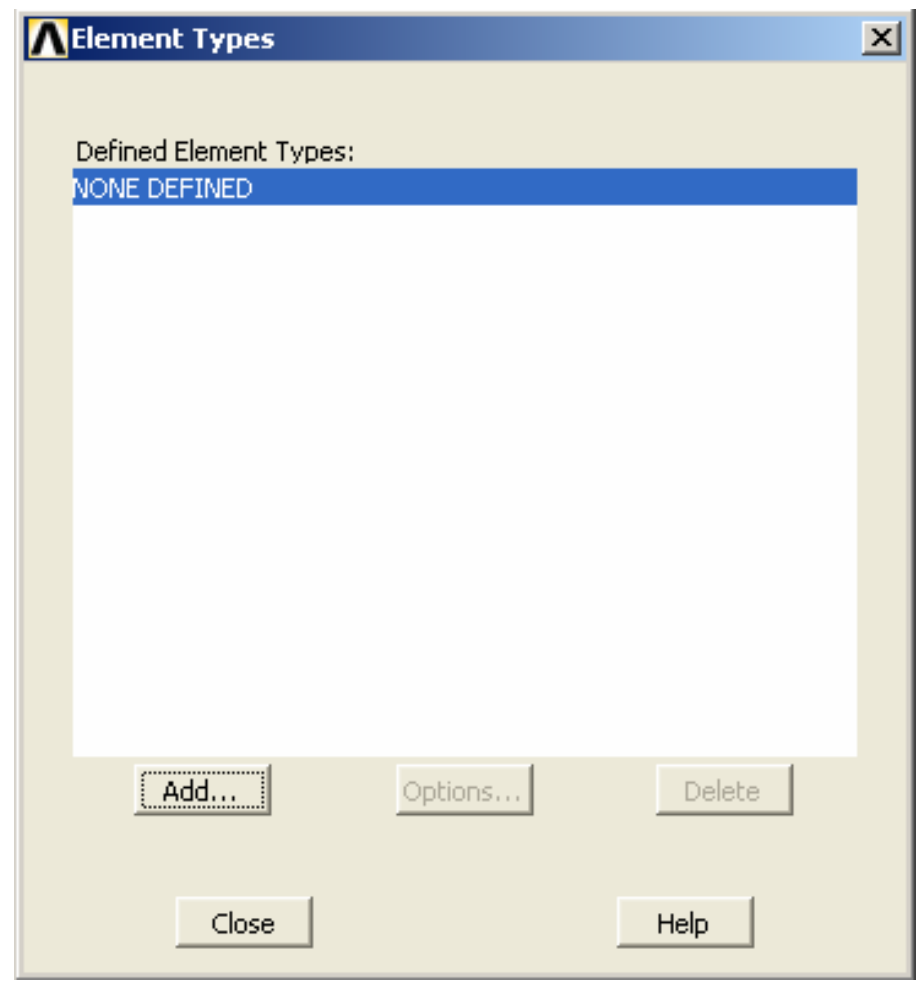

Figura B9 - janela de elementos já selecionados para a simulação

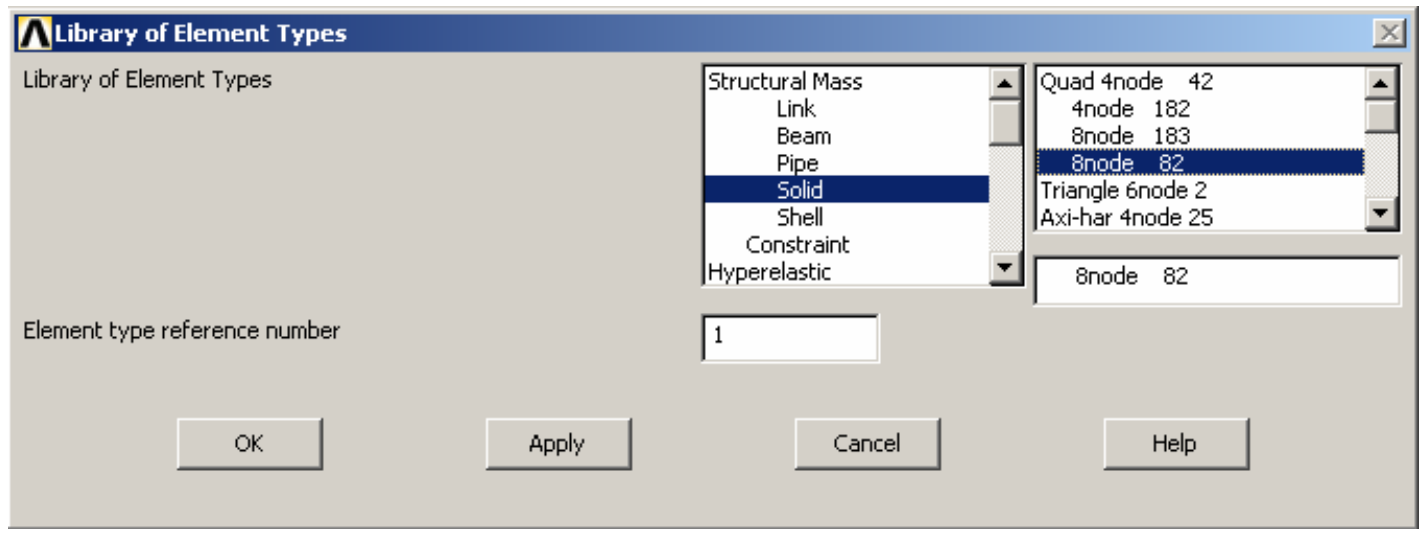

Figura B10 - Janela da biblioteca de tipos de elementos disponíveis no ANSYS ${ }^{8}$

PLANE 82 é um elemento volumétrico que possui oito nós, mais bem ajustáveis para contornos curvos. Cada elemento possui maiores explicações e detalhes na "Ajuda do ANSYS®". 
Neste exemplo precisa-se selecionar um plano de stress, voltando na figura B9 tem-se que selecionar o botão 'Opções' e na seqüência selecionar dentro das opções K3 e escolha a opção Plane strs w/thk como pode ser visto na figura B11.

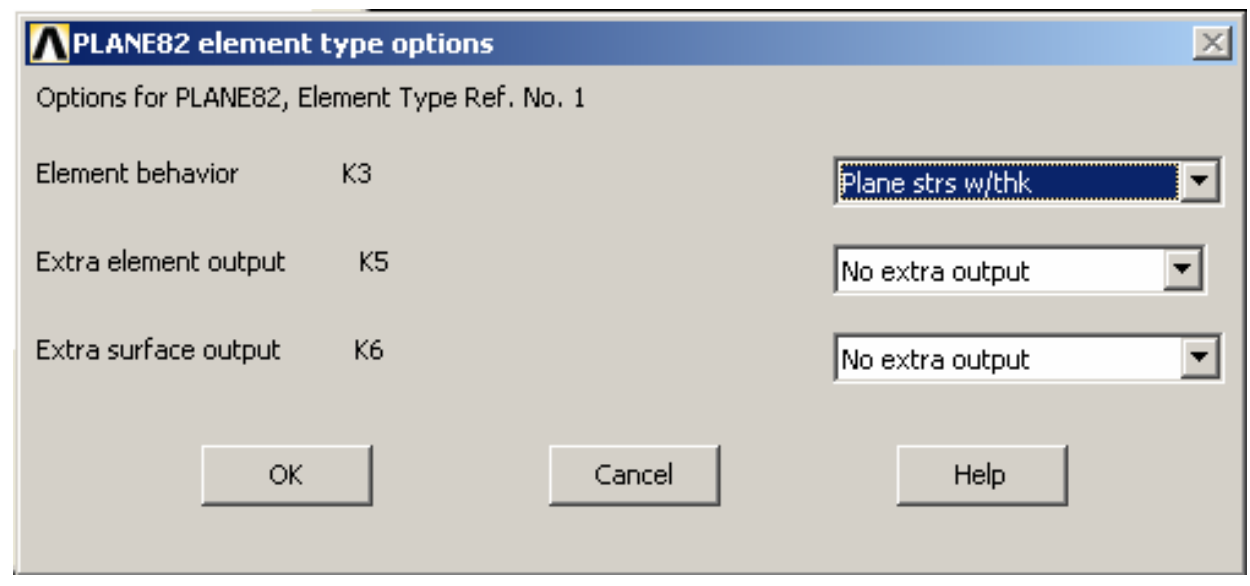

Figura B11 - Janela da opções de tipos de elementos

(o comando alternativo neste caso e ET, 1,Plane82 seguido por Keyopt 1, 3, 3)

4. Definindo Propriedades Geométicas

Assim como nos exemplos anteriores vá em;

Preprocessor Menu > Real Constants > Add/Edit/Delete

Clique no botão $A d d$, em seguida em $O K$ e entre com a espessura do elemento, Thickness, com o valor de 20 como mostra a figura b12 a seguir. (Isso define a espessura da peça em $20 \mathrm{~mm}$ ) 


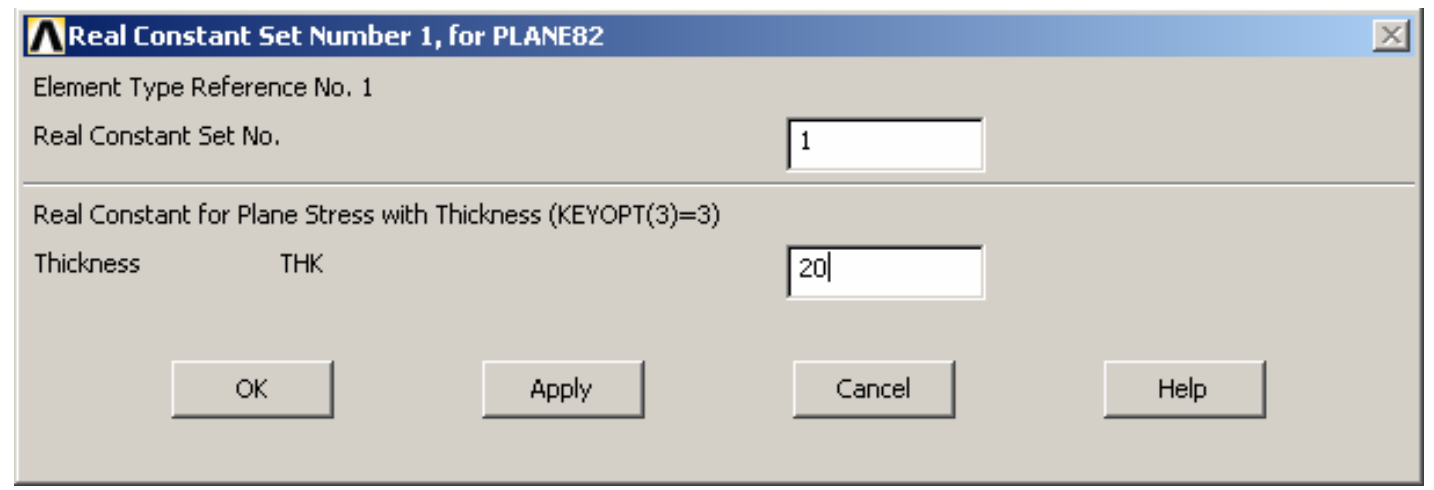

Figura B12 - Janela das constantes reais, definindo espessura do elemento PLANE82 (o comando alternativo neste caso e $\mathbf{R}, \mathbf{1}, \mathbf{2 0}$ )

\section{Propriedades dos Materiais e Elementos}

Antes de começar a definir as propriedades dos materiais envolvidos na simulação, certifica-se das unidades envolvidas de estão coerentes entre si. Esta fase permite especificar através de módulos já conhecidos de literatura ou levantados experimentalmente, capazes de representar o comportamento dos materiais ou meios envolvidos na simulação.

Vá pelos menus, de maneira análoga aos anteriores e selecione,

Preprocessor $>$ Material Props $>$ Material models $>$ Structural $>$ Linear

\section{$>$ Elastic > Isotropic}

Agora serão definidas as propriedades do aço, o material escolhido para a peça a ser simulada, onde o módulo de elasticidade do aço está representado por EX e tem o valor de 200000 Mega Pascal (MPa) e o coeficiente de Poisson , representado por PRXY tem o valor de 0,3.

(A linha de comando para esse passo é MP,EX,1,200000 seguido de MP,PRXY,1,0.3) 
6. Tamanho da malha

Para dizer ao ANSYS qual poder ser o tamanho dos elementos, vá em Preprocessor $>$ Meshing $>$ Size Cntrls $>$ Manual Size $>$ Areas $>$ All Areas

Veja a figura B13.

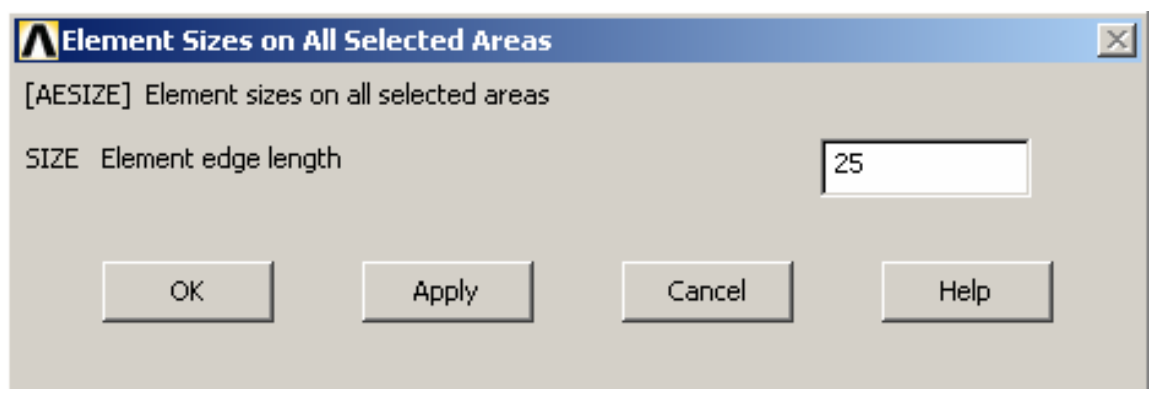

Figura B13 - Janela de definição do tamanho fixo para os elementos da malha a ser criada

Selecione a dimensão da borda do elemento, element edge length, para 25. Mais à frente será necessário retornar para definir se esse é o tamanho adequado do elemento para esse problema.

(Linha de comando alternativa para esse passo, AESIZE,ALL,25N)

7. Malha dos elementos

Neste ponto a malha da peça pode ser criada, meshed.

No menu de Pré-Processamento selecione Meshing $>$ Mesh $>$ Areas $>$ Free e selecione a área mostrada na tela.

(linha de comando alternativa para esse passo é AMESH,ALL)

Deverá aparecer a imagem parecida como a mostrada em B14; 


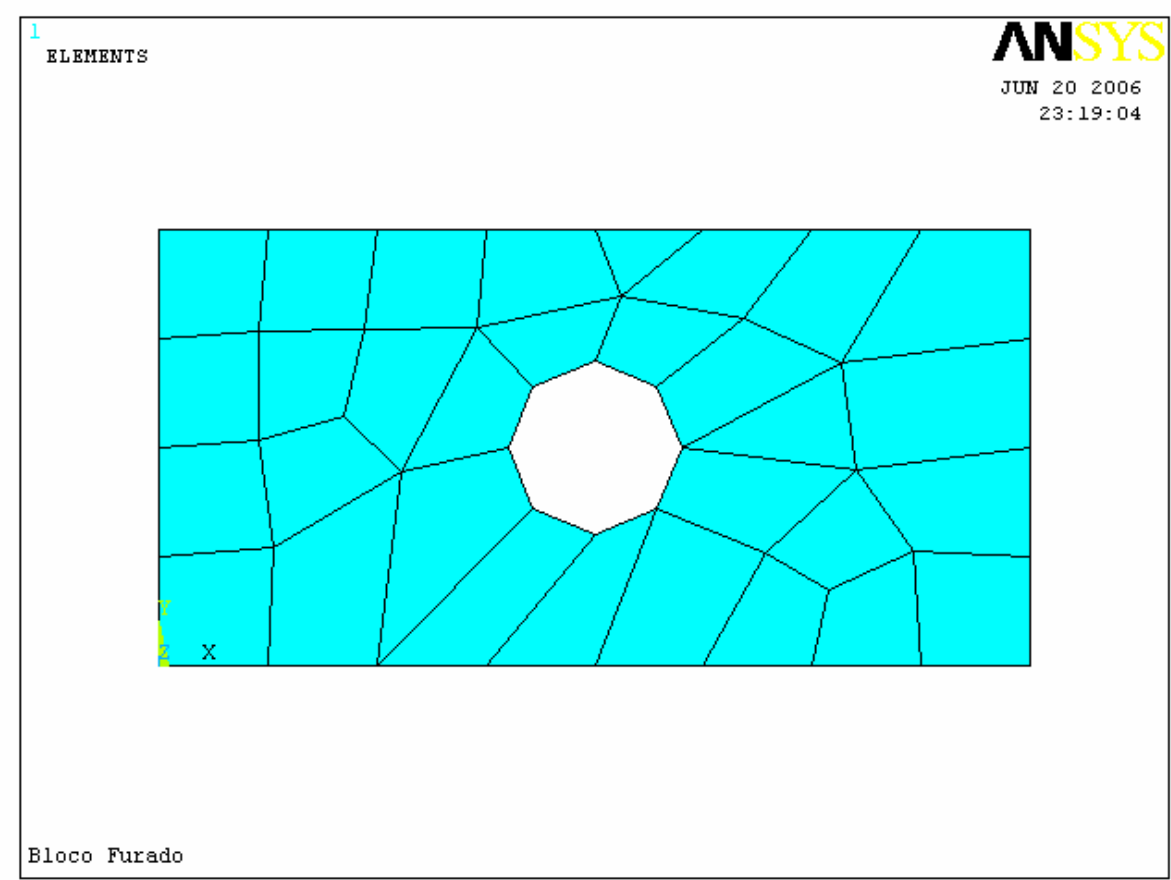

Figura B14 - malha de elementos criada com o elemento PLANE82

Para salvar seu trabalho vá em Utility Menu > File > Save as...

Fase da Solução: Determinando os Carregamentos e Solucionando

modelo está definido, nesta fase deverão ser aplicado os carregamentos e graus de liberdade do modelo, resultando na solução do sistema de equações feitos pelo programa. 
1. Definindo o tipo de análise

Assegure que uma análise estática será feita; Solution > Analysis Type >

\section{New Analysis}

(A linha de comando para esse passo é, ANTYPE,0)

2. Definindo os engastes e deslocamentos

Como mostrado anteriormente, o lado esquerdo da peça é fixo, assim;

Em Solution $>$ Define Loads $>$ Apply $>$ Structural $>$ Displacement $>$ On

\section{Lines}

Selecionando a linha vertical esquerda do modelo, que é a linha de número 4 do mesmo, escolhendo na janela 'Apply U,ROT on Lines' a seguinte opção $A L L$ $D O F$, veja na figura $B 15$;

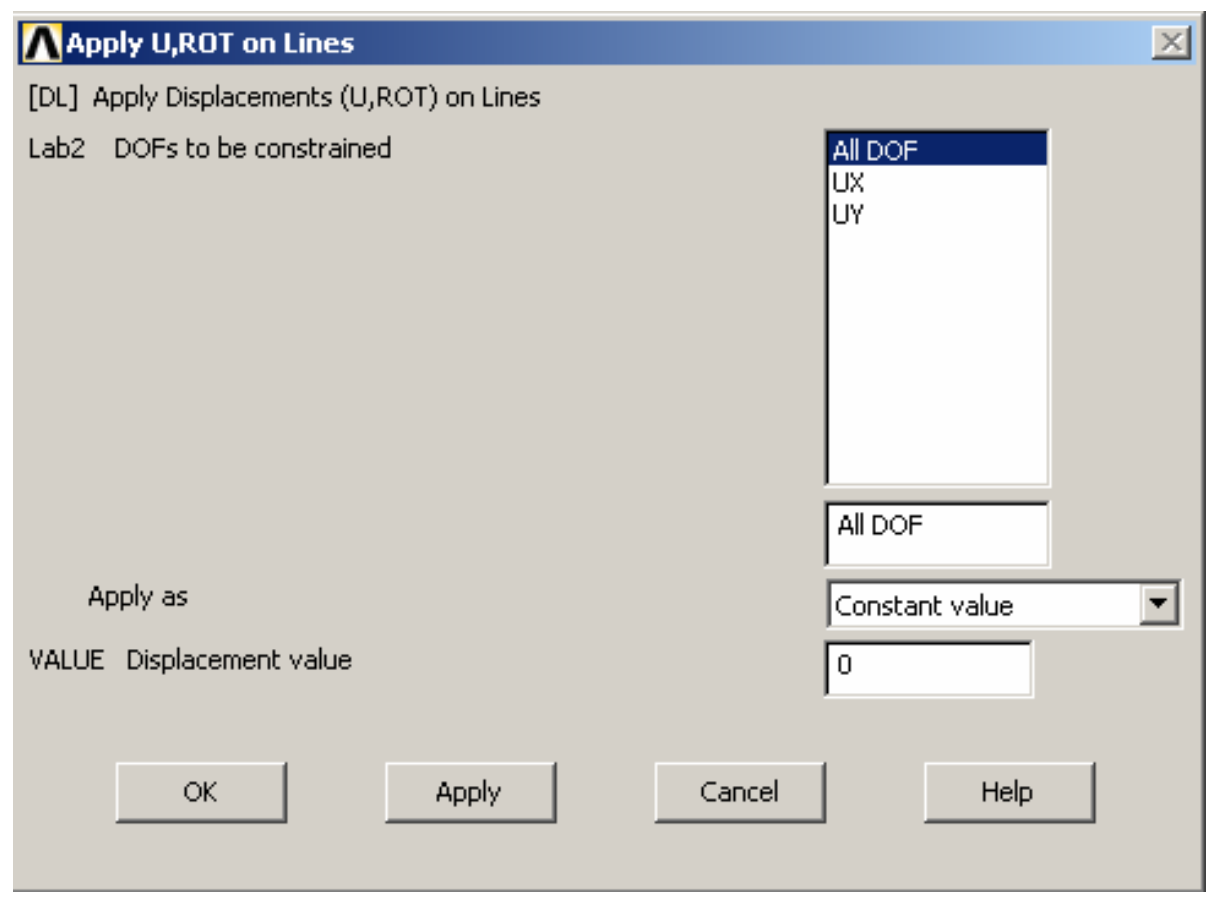

Figura B15 - Janela de definição de Displacements sobre linhas 
A opção escolhida define a linha como fixa para todos os graus de liberdade dessa simulação, ainda na mesma tela defina o valor do deslocamento, Displacement, em zero.

Após confirmar a seleção deverão aparecer na tela triângulos azuis indicando a presença dos engastes definidos.

(Linha de comando, DL,4,,ALL,0)

\section{Aplicando os carregamentos}

Como mostrado anteriormente, existe um carregamento de $20 \mathrm{~N} / \mathrm{mm}$ distribuído em todo o lado direito da peça. Aplicando esse carregamento em; Solution > Define Loads > Apply > Structural > Pressure > On Lines

Após o aparecimento da tela deve-se selecionar a linha vertical da direita do desenho da peça confirmando em OK.

Calcular a pressão na extremidade da placa dividindo a carga distribuída pela espessura da placa e chega-se ao valor de $1 \mathrm{MPa}$.

Preencher na janela Apply PRES on lines com mostrado a seguir na figura B16:

A pressão é uniforme ao longo da superfície da placa, logo o último campo fica em branco.

A ação da pressão está no sentido saindo da peça, assim é definido com valor negativo de pressão. 


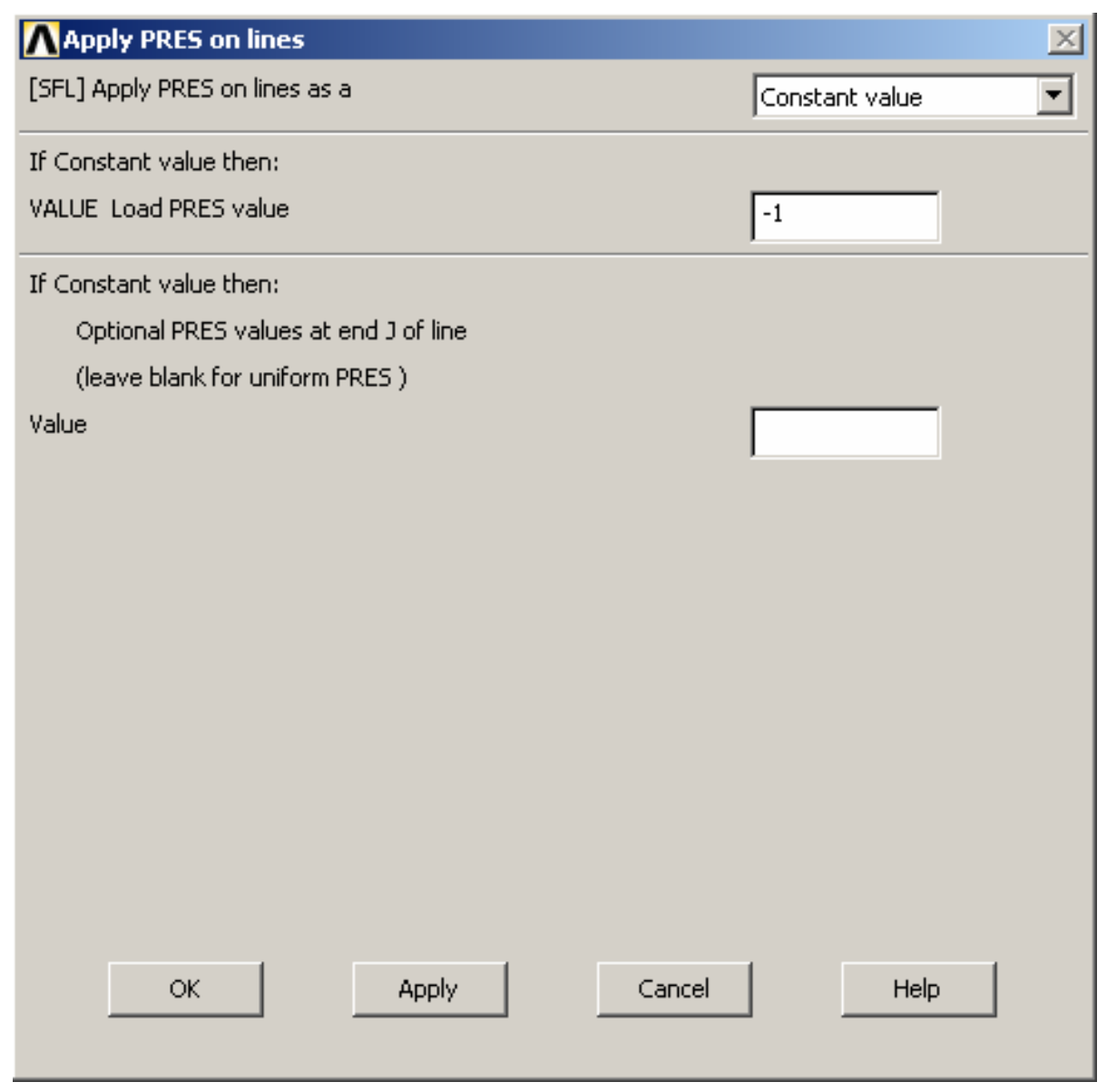

Figura B16 - Janela de parâmetros de aplicação de pressão

A imagem a ser vista deve ser semelhante à mostrada na figura B17. 


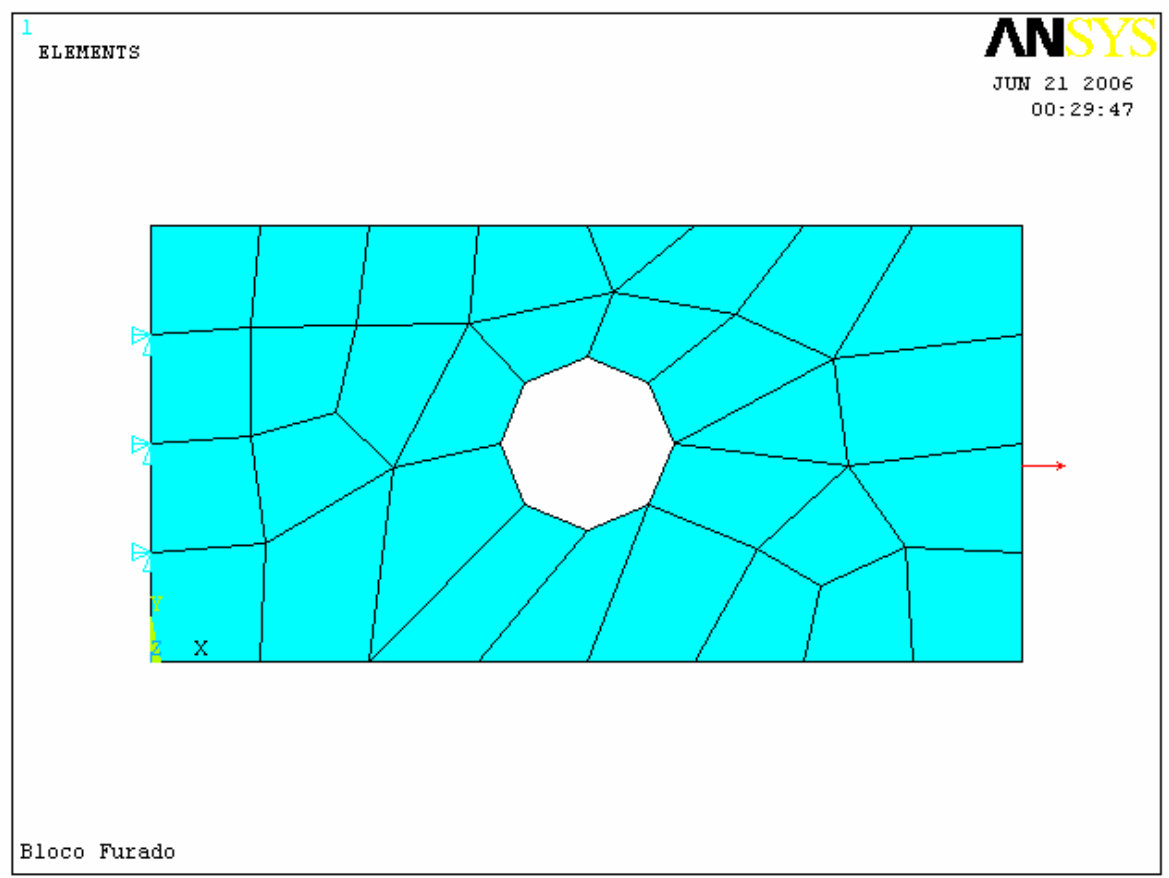

Figura B17 - visualização dos elementos e forças envolvidas na simulação

4. Resolvendo o sistema

Solution > Solve > Current LS

\section{Pós-Processamento: Visualizando os Resultados}

1. Resultado desejado

É importante ter-se noção de onde se deseja chegar quando se está simulando através de elementos finitos, e para isso pode se usar a comparação com resultados analíticos ou resultados experimentais.

Neste caso sabemos que, segundo LAWRENCE (2003), o resultado analítico para este exemplo é:

Deflexão: A máxima deflexão acontece do lado direito da peça e tem o valor calculado em $0,001 \mathrm{~mm}$, desprezando o efeito do orifício na peça 
(apenas a peça fletida). A deflexão esperada é de um valor maior do que este, porém com a mesma ordem de grandeza.

Tensão: O máximo de tensão ocorre no topo e na base do orifício na peça e teve o valor de $3.9 \mathrm{MPa}$.

2. Convergência Usando o ANSYS

Nesse ponto é preciso descobrir se o resultado final converge ou não, avaliando a deflexão e a tensão em nós específicos, enquanto é variado o tamanho da malha dos elementos.

Desde que se tenha um ponto de partida para saber qual é o ponto de tensão máximo, deverá ser avaliado o comportamento deste ponto. Primeiramente é preciso encontrar no modelo da peça qual é o ponto correspondente ao topo ou a base do orifício na peça. Assim plota-se os nós do modelo com seus números.

Utility Menu > Plot $>$ Nodes

Utility Menu > PlotCtrls > Numbering...

A imagem da tela do ANSYSß é igual à mostrada na figura B18, percebe-se que o nó de número 49 está em destaque por estar bem próximo ao topo do orifício da peça: 


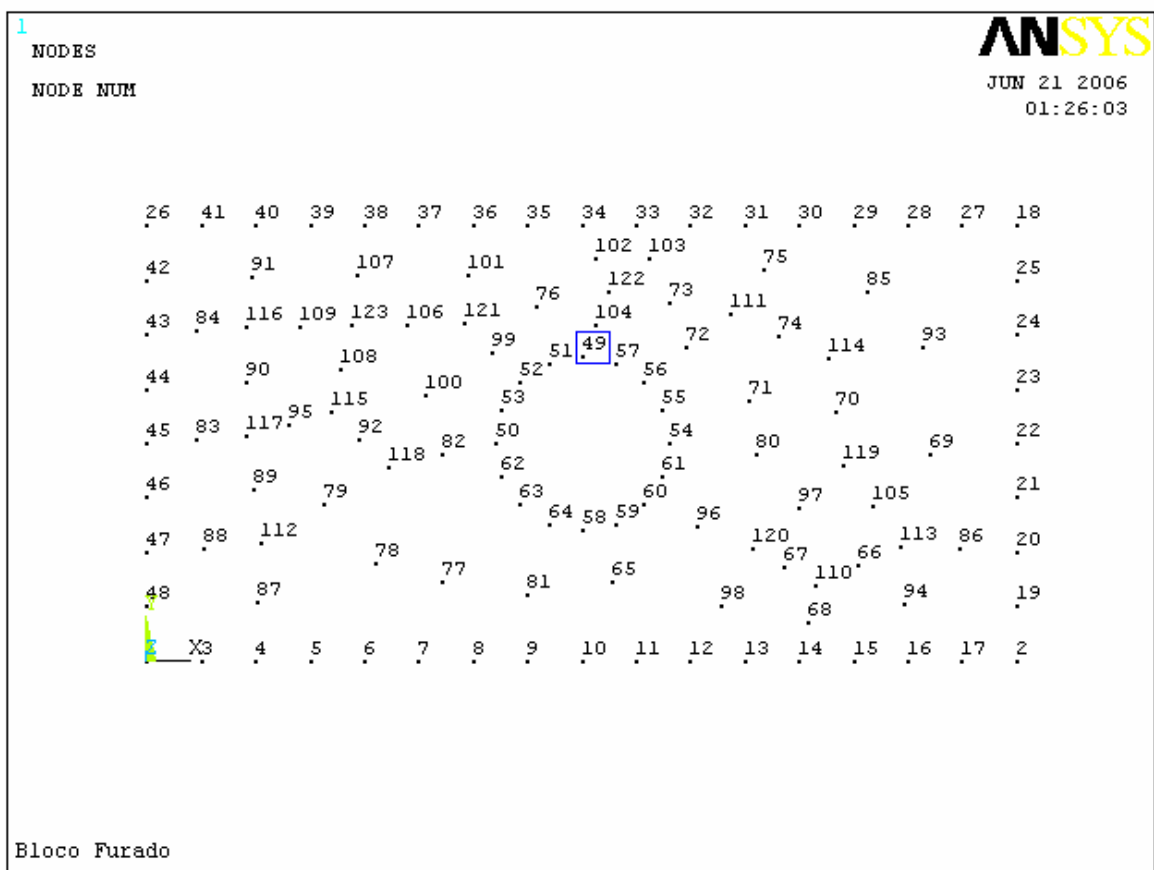

Figura B18 - visualização dos nós dos elementos, com destaque para o nó que apresenta maior tensão

Pare ver a Lista de tensões: General Postproc $>$ List Results > Nodal

\section{Solution > Stress, Principals SPRIN}

Conferindo o valor de SEQV(Tensão equivalente de von Mises) para o nó em questão em destaque na figura B19: 


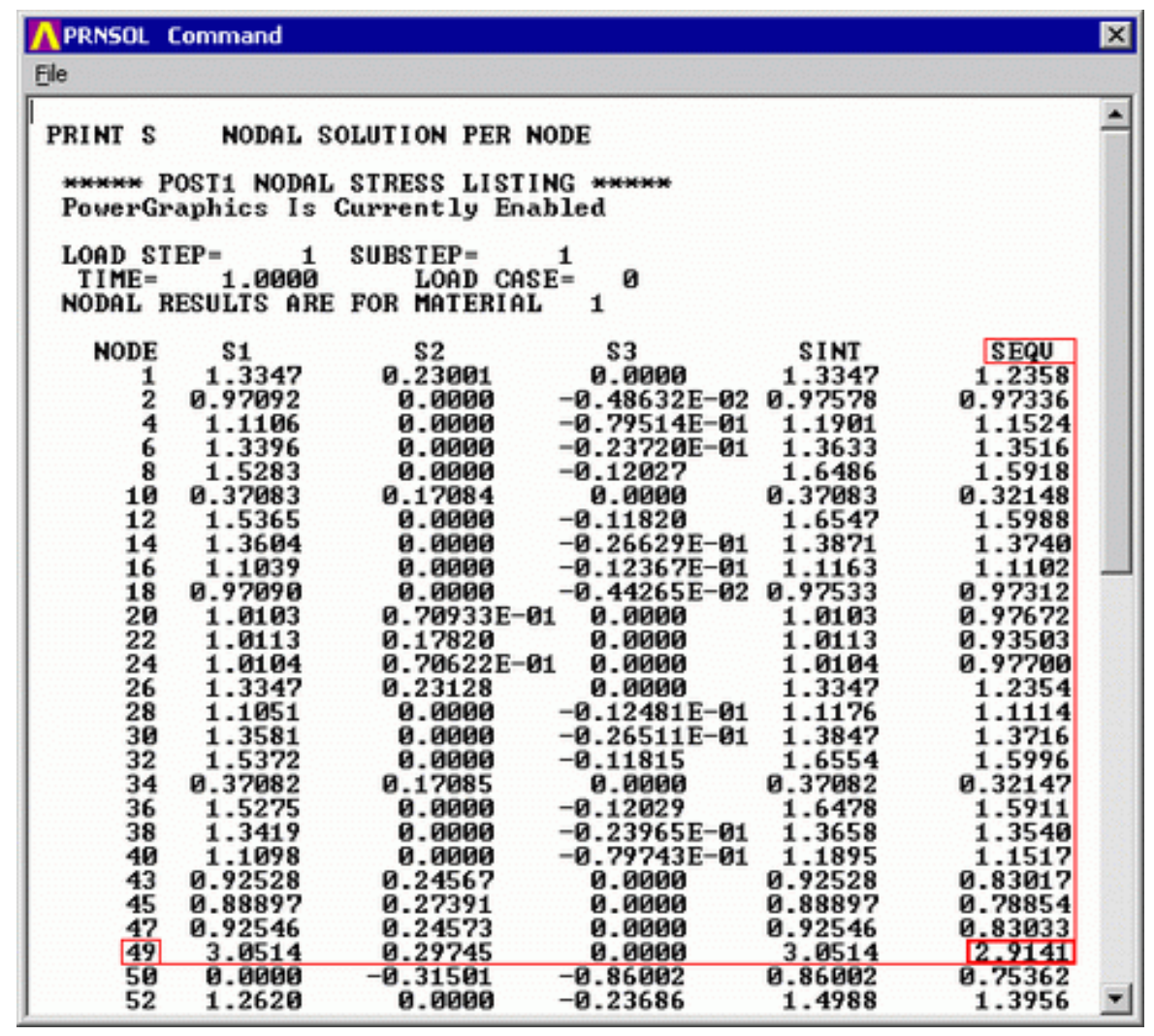

Figura B19 - visualização tabela de tensão nos nós

A tensão equivalente nesse ponto encontrada foi de 2,9141 MPa. $\mathrm{Na}$ busca de resultados mais representativos podem ser usados elementos de menor dimensão.

Para redimensionar os elementos deve-se:

a. Voltar ao menu; Preprocessor > Meshing > Size Cntrls > Manual Size > Areas > All Areas e em seqüência diminuir o valor do comprimento do mesmo, (por exemplo para 20).

b. Gerar novamente a malha de elementos para a peça; Preprocessor > Meshing $>$ Mesh $>$ Areas $>$ Free . Assim que selecionar a peça e confirmado o OK aparece a tela mostrada na figura B20: 


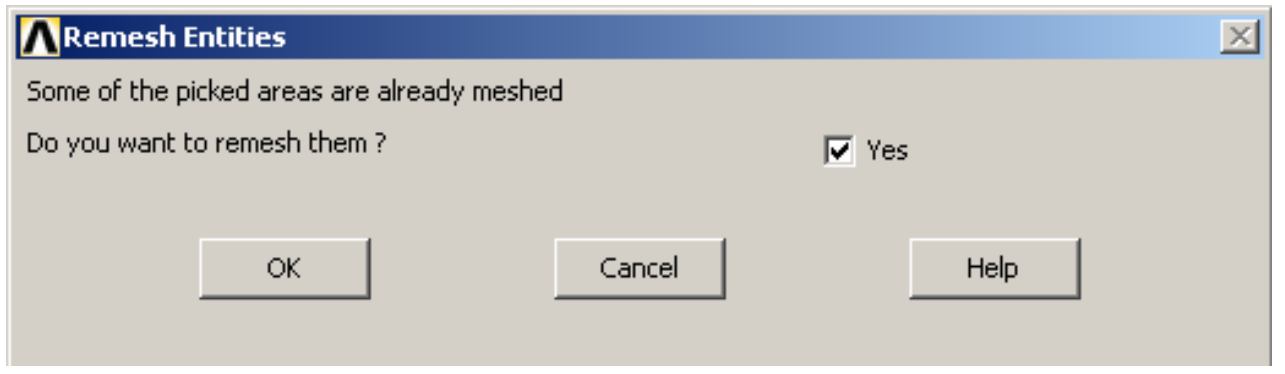

Figura B20 - janela de comando que refaz a malha de elementos

c. A opção é confirmada com o botão $O K$ para a nova malha.

d. Resolve-se o sistema novamente; Solution Menu > Current LS

Repetindo os passos 'a' e 'd' até que o resultado do modelo tenha convergido. Dessa forma a simulação dos nós no ponto crítico do topo do furo da peça avaliando a tensão em relação ao tamanho do elemento confirma-se a convergência. Veja a Figura B21.

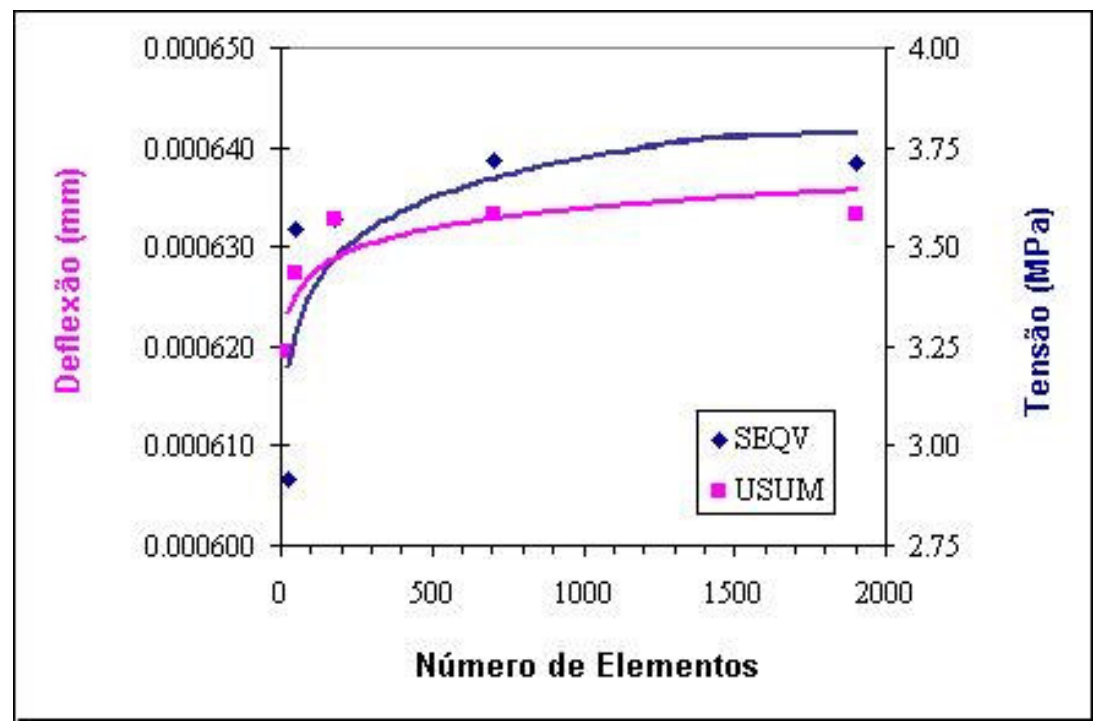

Figura B21 - Gráfico das tendência de Deflexão e Tensão pelo número de Elementos

Percebe-se que tanto o valor da tensão quanto o do deslocamento do ponto escolhido converge com o aumento do número de elementos do modelo. 
A tensão de von Mises no nó escolhido é de aproximadamente 3,8 MPa. Com apenas $2,5 \%$ entre a solução analítica e a solução do ANSYS®

Já a máxima aproximação do deslocamento é de $0,0012 \mathrm{~mm}$, ou seja, $20 \%$ maior que a solução analítica. Lembrando que o resultado da solução analítica não considera a largura do orifício central da peça, onde já se esperava um aumento desse resultado de deflexão.

Dessa forma, os resultados do ANSYS são determinados para ser apropriados na verificação do modelo.

3. Deformação

Vá em General Postproc > Plot Results > Deformed Shape > Def + undeformd para visualizar a peça deformada e não deformada ao mesmo tempo. Figura B22.

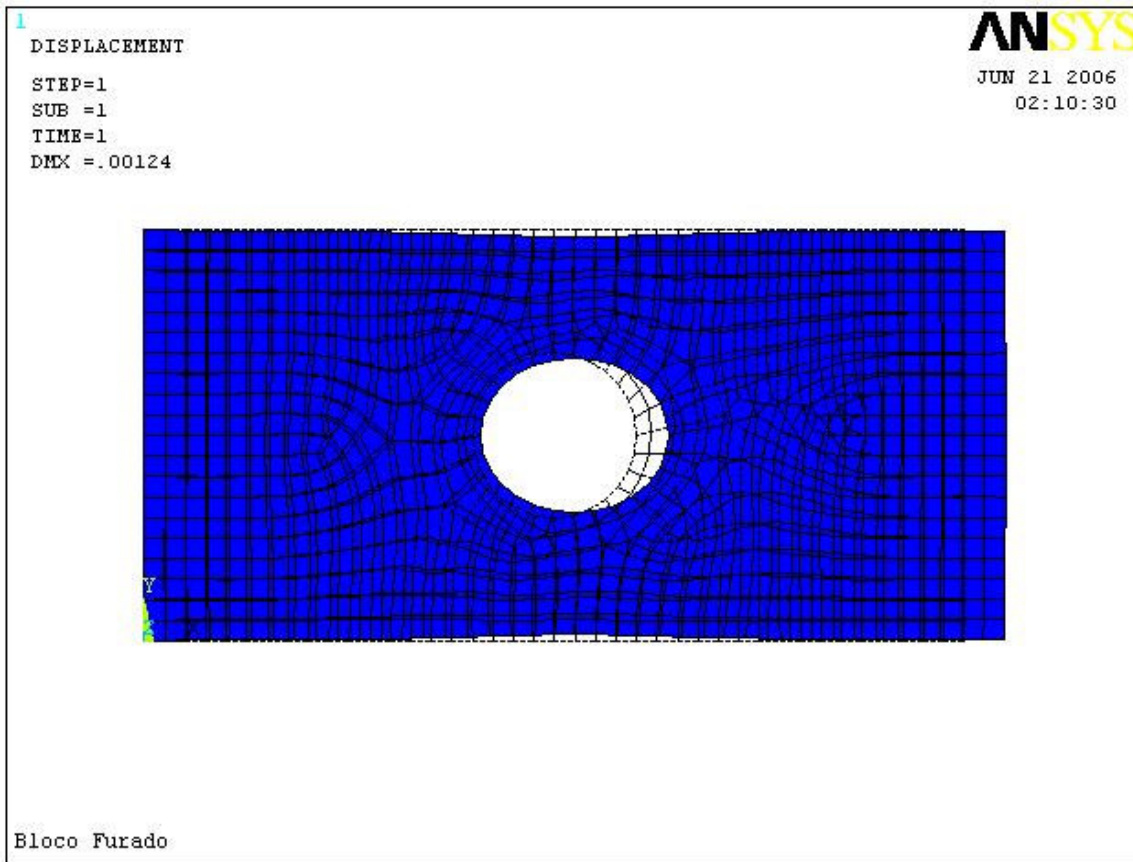

Figura B22 - Imagem da deformação final sobreposta inicial

Observe os locais de deflexão. 
4. Deflexão

Veja em General Postproc > Plot Results > Nodal Solution... depois selecione DOF solution, USUM na janela. Veja na Figura B23

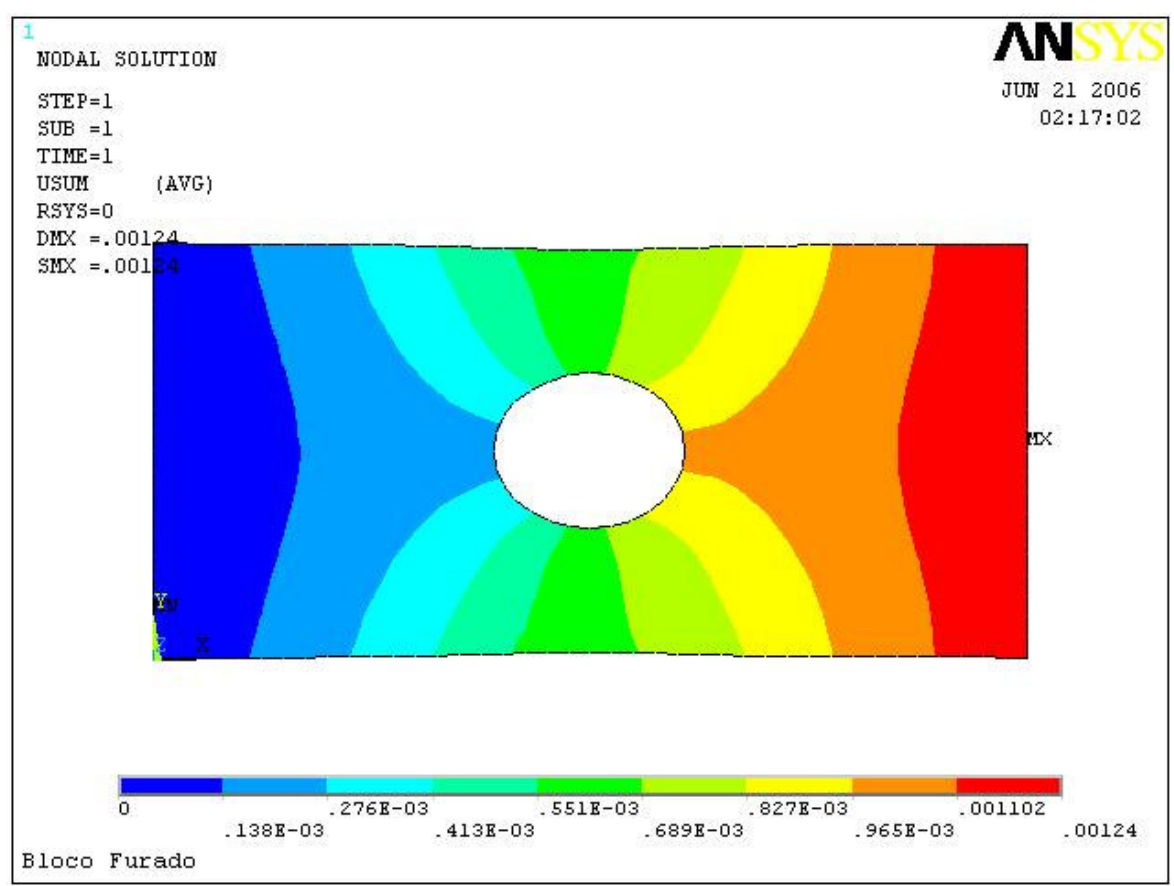

Figura B23 - Imagem da deformação da peça

Percebe-se que os graus de liberdade são fixados em zero no lado esquerdo da peça, conforme foi definido anteriormente.

\section{Tensão}

Veja em General Postproc > Plot Results > Nodal Solution... depois selecionando tensão, Stress, von Mises, na janela, na figura B24. 


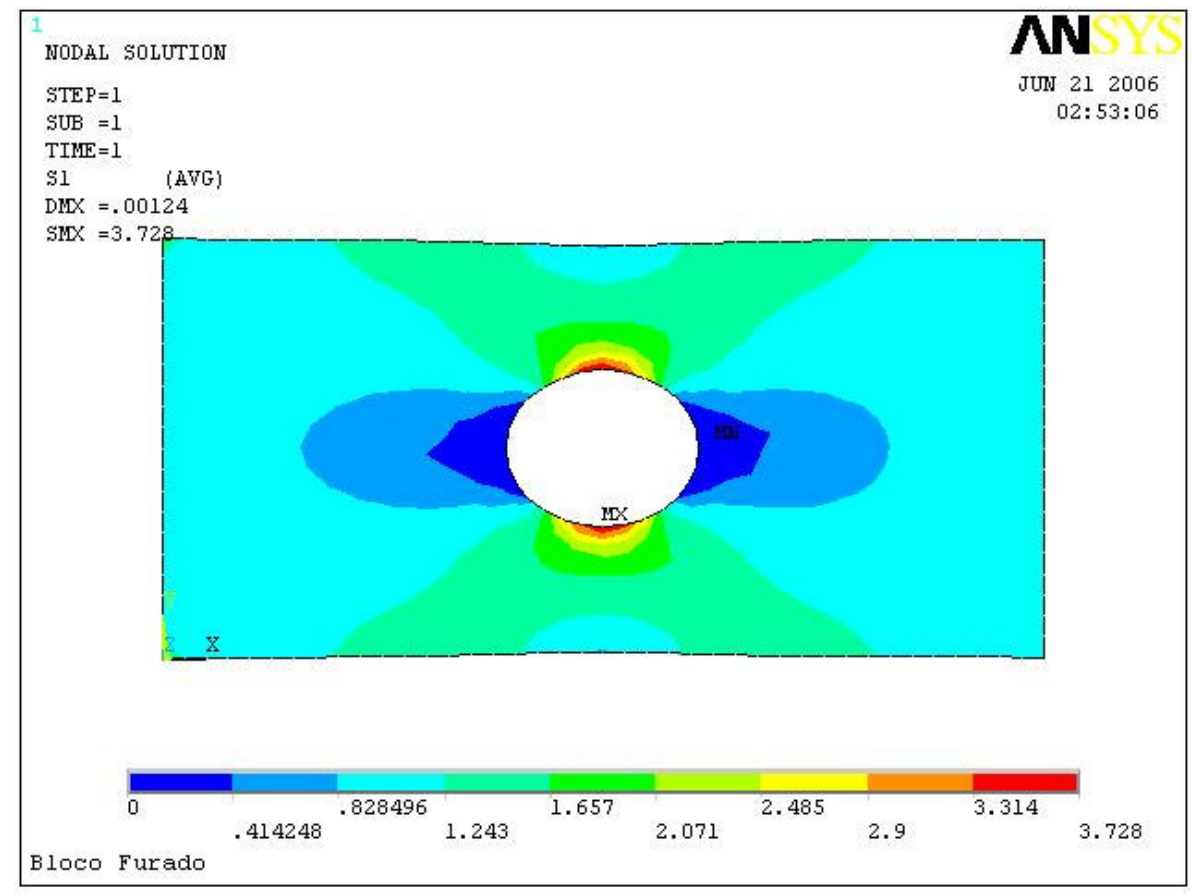

Figura B24 - Imagem da tensões na peça

Também é possível listar as tensões, Stress,de von Mises e verificar os resultados em certos pontos, indo em General Postproc > List Results. selecione Stress, Principals SPRIN.

\section{Listando os Comandos do ANSYS para o problema sob análise}

! Arquivo de Comando no modo 2D de Verificação de tensões em um Plano

/title, Bloco Furado

/ PREP7

$\mathrm{BLC} 4,0,0,200,100$

CYL $4,100,50,20$

ASBA, 1,2

$\mathrm{ET}, 1, \mathrm{PLANE} 42$

KEYOPT , 1, 3, 3

$R, 1,20$

$\mathrm{MP}, \mathrm{EX}, 1,200000$

MP , PRXY, 1, 0.3

AESIZE, ALL, 5

AMESH, ALL

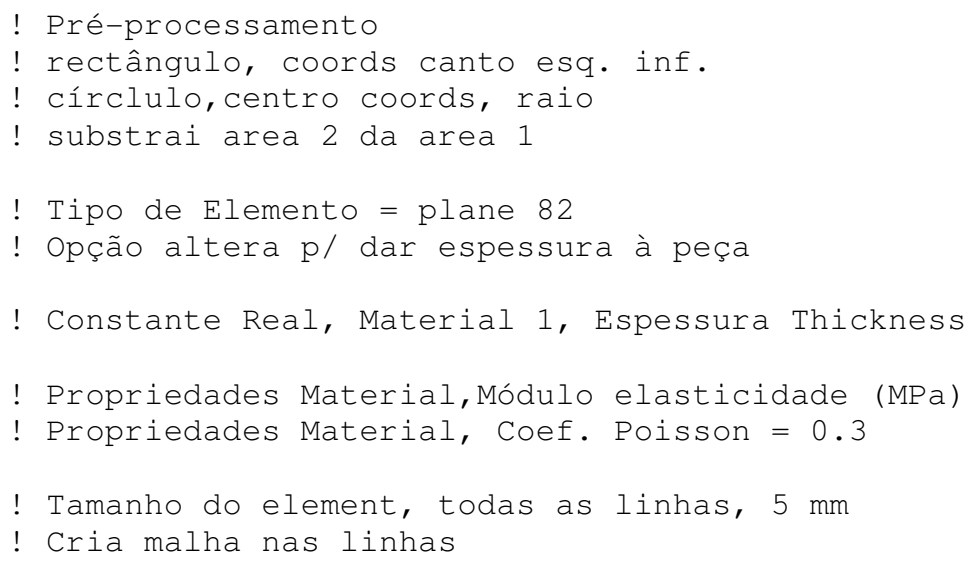




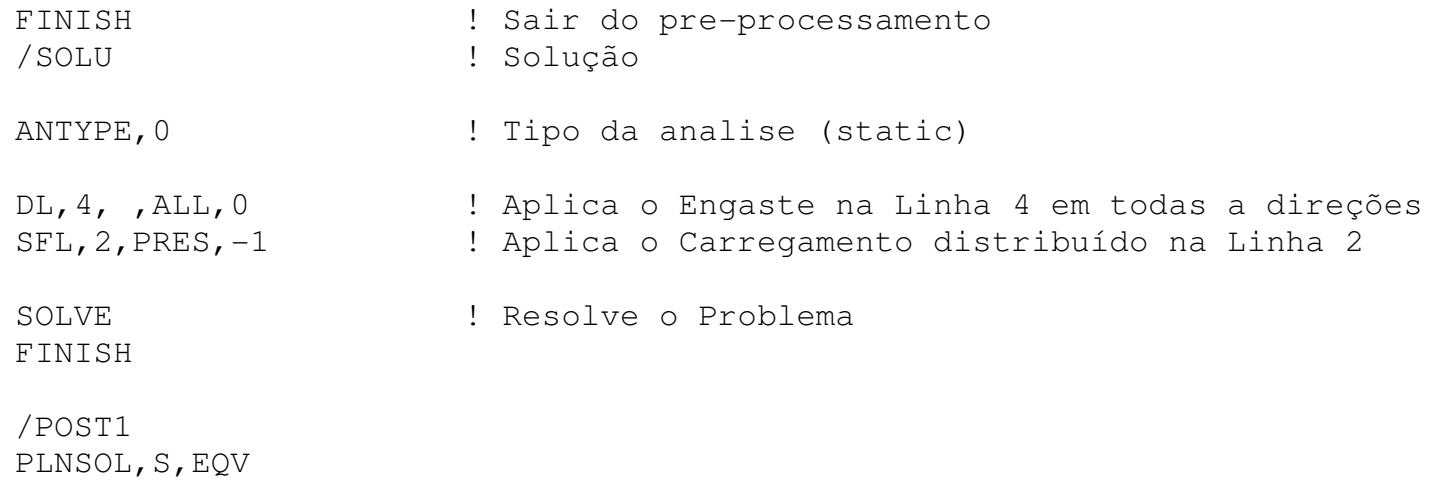

